

\section{DISCLAIMER}

This report was prepared as an account of work sponsored by an agency of the United States Government. Neither the United States Government nor any agency Thereof, nor any of their employees, makes any warranty, express or implied, or assumes any legal liability or responsibility for the accuracy, completeness, or usefulness of any information, apparatus, product, or process disclosed, or represents that its use would not infringe privately owned rights. Reference herein to any specific commercial product, process, or service by trade name, trademark, manufacturer, or otherwise does not necessarily constitute or imply its endorsement, recommendation, or favoring by the United States Government or any agency thereof. The views and opinions of authors expressed herein do not necessarily state or reflect those of the United States Government or any agency thereof. 


\section{DISCLAIMER}

Portions of this document may be illegible in electronic image products. Images are produced from the best available original document. 


\section{LEGAL NOTICE}

This report was prepared as an account of Covernment sponsored work. Neither the United States, nor the Commission, nor any person acting on behalf of the Commission:

A. Makes any warranty or representation, expressed or implied, with respect to the accuracy, completeness, or usefulnes 3 of the information contained in this report, or that the use of any information, apparatus, method, or process disclosed in this report may not instinge privately owned rights; or

B. Assumes any liabilities with respect to the use of, or for daniages resulting from the use of any information, apparatus, method, or process disclosed in this report.

As used in the above, "person acting on behalf of the Commission" includes any employee or contractor of the Commission, or employee of such contractor, to the extent that such employee or contractor of the Commission, or employee of such contractor prepares, disseminates, or provides access to, any information pursuant to his employment or contract with the Commission, or his employment with such contractor.

Printed in the United States of America

Available from

Clearinghouse for Federal Scientific and Technical Information National Bureau of Standards, U.S. Department of Commerce

Springfield, Virginia 22151

Price: Printed Copy $\$ 3.00$; Microfiche $\$ 0.65$ 
WANL-3800-37

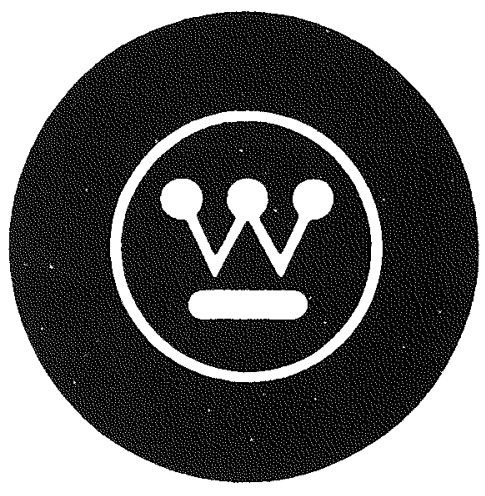

UC-33

WANL-PR-SS-031

Westinghouse Astronuclear Laboratory

PHASE 1

Quarterly Progress Report

June 1, 1969 through August 31, 1969

Prepared for the

U.S.ATOMIC ENERGY COMMISSION

AEC Contract AT 30-1-3800

Prepared September 1969

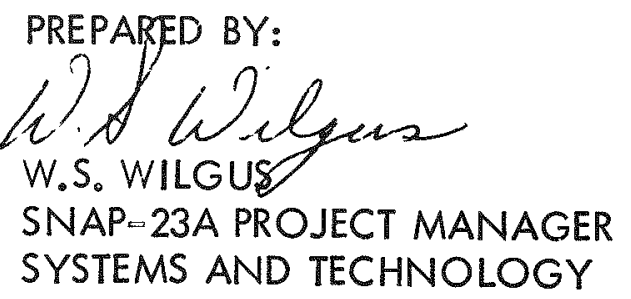

INFORMATION CATEGORY

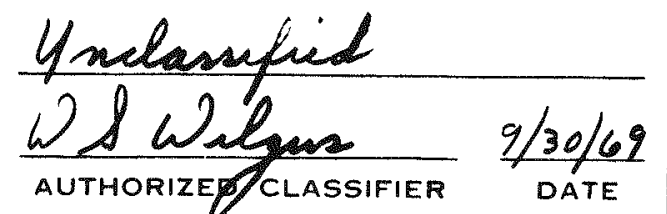




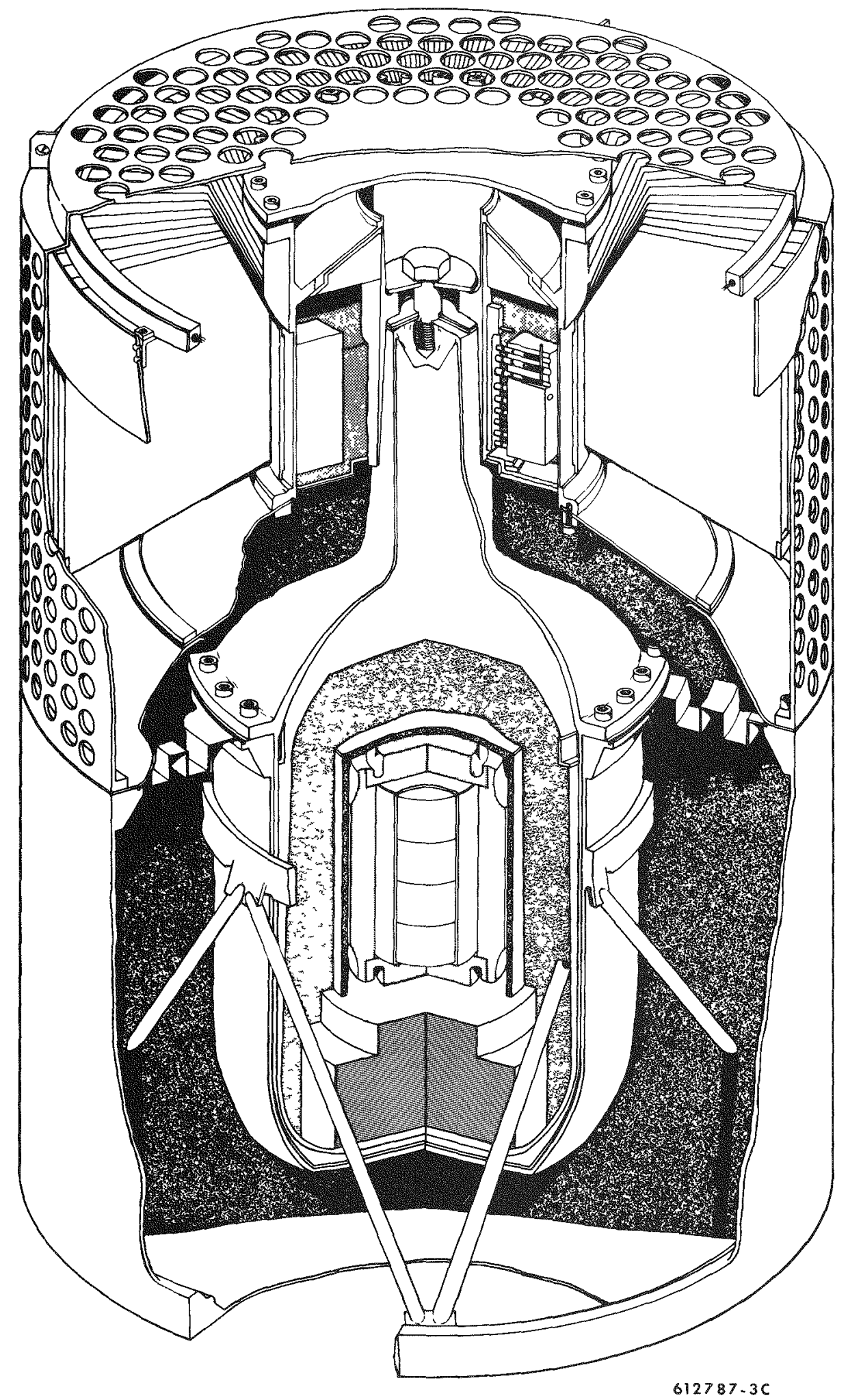


(W) Astronuclear

\section{PREFACE}

This report is the ninth quarterly progress report on the SNAP-23A Project, Advanced Terrestrial Radioisotope Power Systems, under Contract AT(30-1)-3800, authorized by the United States Atomic Energy Commission. Phase I, estimated to cover the period from December 2, 1966 through December 31, 1969, is being conducted by the Astronuclear Laboratory of the Westinghouse Electric Corporation under the direction of the Atomic Energy Commission.

This document reports progress for the period from June 1, 1969 to August 31, 1969. 
BLANK 


\section{TABLE OF CONTENTS}

Section

PROGRAM MANAGEMENT

Subtask 110 - Project Management

Subtask 115 - Program Management

Subtask 140 - Liaison Engineering 3M Company ORNL

2

PRODUCT ASSURANCE

Subtask 210 - Reliability

Subtask 220 - Quality Assurance

SYSTEM DESIGN

Subtask 310 - Systems Engineering

EMS Life Testing

EMS Converter Load Variation Testing Integrated Test Plan

FPMS Preliminary System Design Description (PSDD)

FPMS Design

System Instrumentation

Converter Interface

Subtask 315 - System Analysis

Subtask 320 - Mechanical Design

Base Assembly Hermetic Seal

Heat Source Rain Shield

Radiator Assembly

Insulated Base Assembly
Page

$1-1$

$1-1$

$1-1$

$1-4$

$1-4$

$1-5$

$2-1$

2-1

$2-1$

3-1

$3-1$

3-1

3-1

3-9

3-9

3-9

3-9

$3-11$

$3-11$

$3-13$

3-13

3-18

3-18 
TABLE OF CONTENTS (Continued)

Section

Subtask 330 - Stress Analysis

Page

Radiator Fin

Heat Source Support Truss

Subtask 340 - Thermal Analysis

EMS Life Tests

FPMS Performance

Converter - Heat Source Assembly Operations Spherical Insulation Life Tests

Subtask 350 - Thermoelectric Analysis

PMC-IA Operation on EMS Life Test - Design Load

Off-Design Load Testing of PMC-IA Converter

PMC-2 Performance at Off-Design Conditions

Subtask 390 - Capsule Design \& Development

Subtask 410 - Materials Engineering and Testing

Min-K 2002

4-1

Min-K 2000

4-2

Thermal Grease Testing

Room Temperature Test Results

4-2

$140^{\circ} \mathrm{F}$ Test Results

4-5

U-8Mo Impact Test Results

4-10

Fusible Insulation Testing

Galvanic Corrosion Evaluation - Electrical Conductivity of Moist Salt Cake

Galvanic Corrosion Evaluation 


\section{TABLE OF CONTENTS (Continued)}

Section

5

6

SYSTEM DEVELOPMENT

Subtask 510 - System Testing

SAFETY ANALYSIS

Subtask 610 - Safety Analysis

Fire Analysis

Air Transport Investigation

Ground Level Airborne Fuel Release

Subtask 630 - Preliminary Safety Analysis Report

Subtask 640 - Safety Review

FPMS Licensing

Converter Fire Test

Miscellaneous
Page

5-1

5-1

$6-1$

$6-1$

6-1

$6-1$

$6-8$

6-9

6-9

$6-9$

$6-10$

$6-10$ 
BLANK 


\section{LIST OF ILLUSTRATIONS}

Figure

3-1

$3-2$

$3-3$

3-4

3-5

3-6

3-7

3-8

3-9

3-10

3-11

$3-12$

$3-13$

3-14

$3-15$

$3-16$

3-17

$3-18$

$3-19$

$3-20$

3-21

$3-22$
Converter Output Characteristics for Constant Hot and Cold

Temperatures

Converter Output Characteristics for Constant System Thermal

Output and Thermal Equilibrium for Load Variation (System

$Q_{\text {in }}=1414$ to 1423 Watts)

$3-4$

SNAP-23A Converter Output Versus Resistance Ratio

$3-10$

EMS and FPMS Hermetic Seal Configurations

3-14

FPMS Heat Source Rain Shield

$3-15$

Comparison of FPMS and EMS Rain Shield Configurations

$3-17$

Radiator Fin Cutouts for Converter Gland and Power Lead Cable

$3-19$

Insulated Base Assembly Design

$3-20$

Test Case Model

$3-23$

Standard Fin Model

$3-24$

Heat Loss Versus Truss Height

$3-26$

EMS System Performance on Life Test

$3-29$

EMS System Performance on Life Test

$3-30$

FPMS System Performance

$3-32$

FPMS Heat Flow

$3-33$

FPMS System Temperatures

$3-36$

Temperature Measurements Versus Time for Min-K 2000

(Krypton Backfilled) During Life Test

3-38

3-39

(Krypton Backfilled) During Life Test

$3-43$

EMS/PMC-IA Converter Performance at Off-Load Conditions

$3-44$

PMC-2 Converter Thermoelectric Performance in FPMS

PMC-2 Converter Thermal Performance in FPMS
$3-46$

$3-48$ 


\section{LIST OF ILLUSTRATIONS (Continued)}

Figure

4-1

$4-2$

4-3

4-4

4-5

4-6

4-7

$4-8$

4-9

4- 10

4-11

4- 12

4-13

4- 14

4- 15

4-16

4-17

$4-18$

Samples of Aluminum 6061 and Inconel 625 Coated With GE 641 Silicone Thermal Conducting Grease After Exposure in Fresh and Synthetic Sea Water for 1119 Hours. Samples 1, 2, 3 , and 4 are Inconel 625; Samples 21, 22, 23, and 24 are 6061-T6 Aluminum.

$4-3$

Effect of Exposure on the Surface of the 6061 Aluminum (Samples 21 Through 24) and the Inconel 625 (Samples 1 through 4) as a Result of the 1119 Hour Exposure to Room Temperature Fresh and Synthetic Sea Water.

Metal Samples With Grease Removed Showing Effect of 920 Hour Exposure at $140^{\circ} \mathrm{F}$. Aluminum Samples (25 through 28). Inconel 625 Samples (5 through 8).

"Bleeding" of Thermal Grease When Applied to an Inconel 625 and 6061 Aluminum Surface.

Charpy-Impact Test Results on U-8Mo

Original Size of As-Received Insulation Required to Attain an Insulation Density of $7 \mathrm{lb} / \mathrm{ft}^{3}$ Within the Volume of the Stainless Steel Box.

Effect of Time and Temperature on the Volume of a Constant Weight of E-Fiber Borosilicate Insulation.

Sample No. 1, $1200^{\circ} \mathrm{F}$ for 168 Hours.

Sample No. 7, 67 Hours at $1250^{\circ} \mathrm{F}$

Sample No. 7, 235 Hours at $1250^{\circ} \mathrm{F}$

Sample No. 5, 1 Hour at $1350^{\circ} \mathrm{F}$

Sample No. 5, $1350^{\circ} \mathrm{F}$ for 6 Hours

Sample No. $5,1350^{\circ} \mathrm{F}$ for 22 Hours

Sample No. 5,85 Hours at $1350^{\circ} \mathrm{F}$

Sample No. 3, 30 Minutes at $1600^{\circ} \mathrm{F}$

Configuration of Moist Salt Cake Test

Surface of 6061-T6 Aluminum Exposed to Moist Salt Cake for Approximately 2 Hours at $150^{\circ} \mathrm{F}$ (Unanodized).

Voids in Anodized Coating of Salt Cake Test Specimen as Revealed by Dye Penetrant Tests 


\section{LIST OF ILLUSTRATIONS (Continued)}

Figure

4-19

4-20

$4-21$

$4-22$

$4-23$

4-24

4-25

$4-26$

$4-27$

$4-28$

$4-29$

$6-1$

$6-2$

6-3

$6-4$

6-5
Galvanic Corrosion Apparatus

Electrochemical Corrosion Rate Measurements of Galvanically Coupled SNAP-23 Materials in Synthetic Sea Water at Elevated Temperatures

Side One of Galvanic Corrosion Couples 1 Through 4 Showing the Effect of Corrosion on the Aluminum Electrode

Side Two of Galvanic Corrosion Couples 1 Through 4 Showing the Effect of Corrosion on the Aluminum Electrode

Side One of Galvanic Corrosion Couples 5 Through 8 Showing the Effect of Corrosion on the Aluminum Electrode

Side Two of Galvanic Corrosion Couples 5 Through 8 Showing the Effect of Corrosion on the Aluminum Electrode

Effect of Edge Treatment on Corrosion Current

Effect of Edge Treatment on Corrosion Current

U-Mo/Copper Interface Showing Reaction Zone at $1400^{\circ} \mathrm{F}$ and $1200^{\circ} \mathrm{F}$

4-44

Lack of Reaction Zone Between Copper and Inconel 718. A Diffusion Bond Has Been Formed

Lack of Reaction Showing the Effectiveness of Tantalum and Tungsten as a Diffusion Barrier Between U-10Mo and Hastelloy-C

Calculated Response of SNAP-23A Converter Components During $1850^{\circ}$ Half-Hour Fire

Calculated Response of SNAP-23A Converter Components During $1475^{\circ} \mathrm{F}$ Half-Hour Fire

SNAP-23A Aircraft Accident Network

6-4

Requirements for Various Impact Velocities

6-6

Terminal Velocity of SNAP-23A System in an Aluminum Cubic Container 


\section{LIST OF TABLES}

Table

SNAP-23A EMS System Performance Summary

Page

$3-2$

EMS Equilibrium Load Test Data

EMS Load Test Thermal Summary

$3-6$

$3-4$

FPMS Instrumentation

3-8

3-5

SNAP-23A EMS Thermal Test Point Summary Life Test

FPMS Predicted Performance

PMC-IA Converter Performance

PMC-IA Converter Performance at Off-Load Conditions

Strain Gage Data for SNAP-23A Capsule 23-4

Results of Room Temperature Thermal Grease Solubility Evaluation

Sintering Evaluation Experimental Conditions and Results

Galvanic Couples Evaluated During the Electrochemical Corrosion Test Program

Results of Electrochemical Corrosion Program

(Constant Submersed Area)

Results of Electrochemical Corrosion Program (Variable Submersed Area)

4-9 Comparison of Calculated and Actual Diffusion Zone Thickness Between Copper and the Uranium-Moly Alloy 
(W) Astronuclear Laboratory

\section{PROGRAM MANAGEMENT}

Subtask $110-$ Project Management

EMS life testing has continued through the reporting period. As of August 31, 1969, the EMS unit has accumulated a total of 8300 hours of operation, including approximately 6100 hours on life test. Analysis of test data has shown no significant change in unit performance; the thermal and electrical performance of the EMS system has continued to be stable. Preparations for and testing of the EMS system at off-load conditions has been completed. Detailed discussions of this test are found in Subtasks 310 and 350.

WANL submitted and received approval for Revision 4 of the SNAP-23A Phase I Project Plan. In addition, AEC approval of the FPMS design and material selection, as presented in the FPMS Preliminary System Design Description (PSDD) draft, was received. At a meeting held on July 9, 1969, RDT established that a revision and expansion of the Preliminary Safety Analysis Report (PSAR) was required to satisfy the programmatic objective of the report and that the preliminary system shipping container design effort, scheduled to be completed in Phase II, would now have to be completed in Phase I. The PSAR revision is required for submittal to RDT by the end of Phase I. WANL is currently reviewing the RDT Standard, RDT-F- 2-2T, Quality Assurance Program Requirements, forwarded by the AEC.

WANL/3M Interface Meetings were held on June 13, 1969 and July 30, 1969. During this quarter, agreement was reached on the power cable and stuffing gland based on tests

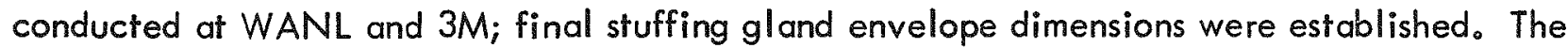
FPMS/PMC-2 Interface Control Drawing was reviewed and issued in final form. At the July meeting, WANL established that stiffening of the base assembly struts to the degree required to limit the lateral shock and vibration magnification factor to a value of 2 would impose a significant thermal penalty on the FPMS system. Thermal analyses indicate that an additional heat loss of as high as 23 watts BOL ( 18 watts EOL) could result. The axial magnification factor of 2 , which is the most critical from the point of view of the converter structure, can be met without additional heat loss. In response to a WANL request, 3M reviewed the PMC-2 shock and vibration analysis and concluded that the converter structure could withstand an 
increase in the lateral magnification factor from 2 to 3 . It should be noted that PMC-1A was successfully subjected to loading conditions during EMS mechanical testing corresponding to a lateral factor of 3. WANL has recommended that the FPMS be designed with a lateral magnification factor of 3. FPMS/PMC-2 assembly requirements were reviewed, and it was established that assembly of the converter/radiator assembly to the hot end source stud could be accomplished by limiting the rate of temperature rise of the converter hot frame and the $\Delta T$ at the time of mating. Development of the final assembly procedure is being coordinated with $3 M$. Review of the $3 M$ draft Converter Fire Safety Evaluation Test Plan has been completed by WANL and HAI and comments forwarded to $3 \mathrm{M}$. A design review meeting has been scheduled for the September Interface Meeting.

Preparation of the heat source transportation license documentation was completed and was reviewed with RDT prior to formal submittal of the license application to the AEC and DOT. Minor review comments were received from the AEC and resolution is in process. No problems are expected in receiving the transportation license for the heat source prior to the required shipping date. With regard to facility licensing, appropriate documentation was submitted to and approved by the WANL Radiation Safety Committee. The Westinghouse License Administrator is processing the formal WANL License Amendment and, similarly, submittal to AEC is expected on schedule.

Advance material procurement activities were completed and FPMS fabrication is in process in a number of areas. Purchase orders and/or work orders have been placed for all major FPMS components, including the heat source shipping container. As a result of the failure of the selected honeycomb fabricator to honor his quotation due to a bidding error, it has been necessary to renegotiate with the remaining suppliers. This development has placed honeycomb delivery on the critical path in terms of meeting the Phase I schedule. At present, the full schedule impact is not known; however, attempts are being made to expedite delivery of this material and subsequent series operations to minimize impact on the overall schedule.

Design and analysis of FPMS is continuing. Manufacturing drawings have been released for all major components and subassemblies including: heat source, base assembly, radiator, and heat source shipping container. Preparation of miscellaneous drawings is 
continuing; review and release of these drawings is expected during September. Preparation of assembly route cards has been initiated.

ORNL has completed hydrostatic testing of two fuel capsules. Strain gage and dimensional measurements are being reviewed prior to initiating testing of the final capsule. Post-pressure-test ultransonic inspection of the capsules has shown no changes in the closure welds. A coordination meeting was held at ORNL to review detailed procedures for handling and welding of the FPMS heat source and preparations for shipment of the fueled assembly from ORNL to WANL. At this meeting it was agreed that leak testing of the heat source welds can be accomplished by standard helium leak test procedures, in lieu of krypton-85 spiked helium, without reduction in weld integrity.

Life testing of Min-K 2000 was terminated in mid-August. This test has exceeded the original projected test time and there has been no observable degradation in properties. Over an 8-month period, the measured temperature differential varied by 2 percent from the initial value with no discernible trend indicated. Testing of Min-K 2002 is continuing. Testing of the fusible insulation has been initiated. Sintering tests have shown that the material will fuse at high temperature as expected. Additional tests, which result in exposure of the fusible insulation to temperatures approximating the normal operating point, are in process. Design of the mockup of the rain shield area for the full-scale fusible insulation test has been completed. Elevated temperature thermal grease testing has been initiated, and evaluation of electrical conductivity of moist salt cake at the aluminum/Inconel 625 interface has been completed. Impact testing of U-8Mo at elevated temperature has been completed and data evaluation is in process.

During the reporting period, the following docunents were prepared and submitted to the AEC:

1) WANL-3800-32, "April Progress Report," June 1969.

2) Corrected pages - WANL-3800-28, "Quarterly Progress Report," December 1968 through February 1969 March 1969. 
3) Corrected pages - WANL-3800-30, "SNAP-23A Advanced Terrestrial Radioisotope Power Systems, Project Plan (Rev. 4)," March 1969.

4) WANL-3800-33, "Quarterly Progress Report, March 1969 through May 1969," July 1969.

5) WANL-3800-34, "Engineering Analysis for Shipment of SNAP-23A Heat Source," July 1969.

6) WANL-3800-35, "June Progress Report," July 1969.

Subtask 115 - Program Management

The key work items accomplished during this reporting period include normal technical and management activities and liaison efforts. Liaison efforts with WANL and ORNL hove continued. Programmatic planning discussions were continued and several proposed additional work items were submitted to WANL as requested.

Subtask 140 - Liaison Engineering

\section{$3 M$ Company}

Definition of the WANL/3M interface for the FPMS was completed and documented as Revision $A$ to the interface control drawing, 914E462. Copies of the approved drawing are being prepared for formal issue to the $A E C$.

Problems relating to the power lead cable and stuffing gland were resolved by the acceptance of an available neoprene-coated cable that has exceptionally good resistance to axial water leakage (see Subtask 310) and passing it through a stuffing gland with dimensions similar to an approved Navy gland. The use of a standard Navy gland with a nylon body was considered, but nylon creep data indicate that relaxation of the gland seal could occur under FPMS design operating conditions. Therefore, it was recommended that the gland body be fabricated from Inconel 625.

The converter instrumentation as defined on the interface drawing is essentially the same as that used on PMC-IA. The internal instrumentation includes all the measurements made on PMC-IA, except for the two cold frame thermocouples which did not yield useful 
data. Externally, the bottom cover thermocouples were eliminated and the outer case thermocouples reduced from six to four. The upper hot frame and support cone thermocouples that were clipped off prior to PMC-1A shipment are retained on PMC-2A since removal would have required replacement of the top insulation.

A tentative procedure was established to permit mating the converter to the hot stud of the heat source assembly. Such a procedure was unnecessary for the EMS since both mating parts were cold at assembly. WANL and $3 M$ are proceeding on the development of a final procedure for this operation. The present intent is to bring the two components together slowly so that the converter heatup rate is limited to a permissible value.

WANL has recommended a change in the converter shock and vibration design criterion from $10 \mathrm{~g}^{\prime} \mathrm{s}$ to $15 \mathrm{~g}$ 's in the lateral direction, while retaining the $10 \mathrm{~g}$ requirement parallel to the converter axis. This change was occasioned by WANL analyses (Subtask 340) which showed that significant additional heat losses would result if the truss support design were changed to reduce the lateral magnification factor from 3 to 2. Calculations made by $3 M$ indicate that the lateral stiffness of the converter is sufficient to withstand the increased loading; however, there is no experimental verification of this except for the inadvertant loading applied to EMC-IA during WANL testing of the EMS.

Coordination of the converter fire test (Subtask 640) is continuing. Revised predictions for the heating and cooling phases of the $1475^{\circ} \mathrm{F}$ and $1850^{\circ} \mathrm{F}$ fires were obtained from Hittman Associates. The test plan and the test hardware design concepts were reviewed.

\section{ORNL}

Two test capsules were subjected to hydrostatic pressures of 9200 psi or greater without any obvious damage. There are apparent anomalies in the strain gage data (Subtask 390), but pre and post-test dimensional measurements show that very little permanent deformation occurred. Post-test ultrasonic inspection of the capsule welds was delayed because of a failure in the test equipment. Some of the replacement components have been received by ORNL and the inspection is expected to be completed early in the next reporting period. 
Detailed fueling procedures for the FPMS heat source assembly were reviewed in a meeting at ORNL on July 24. Discussions were held on weld qualification requirements, heat source assembly handling and evacuation procedures, and preparations for shipment of the fueled assembly. WANL agreed to supply machined sections of heat-treated Inconel 718 plate to ORNL for weld qualification.

WANL supplied a set of drawings and procedures applicable to the fueling and shipment of the assembly. ORNL will prepare detailed procedures and will coordinate the procedures with WANL. WANL will supply observers during the fueling operations; however, ORNL will have the prime responsibility for all operations conducted at ORNL.

A brief review was held to discuss the current status and plans for future ORNL evaluation of strontium fuel processing, properties, and compatibility with containment materials.

Subsequent to the July meeting since the final FPMS heat source assembly geometry retained the purge tube, WANL recommended all leak testing of the heat source welds be accomplished by standard helium leak test procedures instead of using krypton-85. Since the heat source assembly will be backfilled with helium, leaks can be detected without any reduction in sensitivity by evacuating a volume around the weld zones and checking for helium. This applies to both the jacket closure weld and the degassing tube closure weld. 


\section{PRODUCT ASSURANCE}

Subtask 210-Reliability

Reliability effort this quarter was limited to the following:

The design for holding the Heat Source Shipping Container on the truck-bed for transport was reviewed and found satisfactory.

The FPMS Base Assembly design was reviewed and found satisfactory.

A cross-check of the Failure Mode Analysis File against the Preliminary System Design Description was begun and a failure mode analysis was initiated.

Subtask 220 - Quality Assurance

During this period the following significant activities occurred:

1) Drawings were reviewed and approved for the radiator, heat source assembly, base assembly, hermetic seal, and other parts. The manufacturing sequences for the radiator and hermetic seal differ from those used on EMS. Specifically, the radiator parts will be fabricated at WANL, the brazing will be subcontracted, the final bore machining will be done at WANL, and the anodizing will be subcontracted in that order. For the hermetic seal, the fabrication of the parts will be subcontracted and the assembly welding will be done at WANL. On EMS both parts were completely subcontracted.

2) Quality Engineering participated in discussions with suppliers to resolve questions relating to bid requests on the heat source parts. The prime areas of concern were the techniques to be used in measuring these parts. This is recognized as a difficult area due to the basic part configurations, the limitations on functional checks due to parts interference (by design), and correlation of measurements to a common reference.

3) Orders have been reviewed and quality requirements incorporated for heat source parts, heat source shipping container, and other parts. A converter hot frame discrepancy has been reported by $3 M_{0}$. This discrepancy was discovered at the piece-part stage and is in the bore section of the part. This discrepancy is being evaluated: recommendations will be 
forwarded to the Project Manager. This could conceivably result in changing the part that mates with the converter jacket in the hot frame area.

4) Quality Engineering has begun preparation of inspection instructions for source and internal inspection operations. Some of the prime concerns in source inspection are:

(I) to discover potential or existing problems at the earliest feasible point in time, and (2) to eliminate the need for special gaging at WANL. Complete supplier submittals ( AR format) are required by Quality Engineering to assure that inspection plans, including gaging, are adequate to evaluate the product. In all inspections, source or internal, the prime concern is to provide maximum assurance for the lowest cost.

5) The AEC RDT Standard, RDT F 2-2T, is presently being evaluated to determine the impact on the SNAP-23A program at WANL. 


\section{SYSTEM DESIGN}

Subtask 310 - Systems Engineering

EMS Life Testing

The EMS has continued on test during this reporting period without significant longterm performance changes for the system. A summary of the system's mean performance over the life test is given in Table 3-1, where values shown represent arithmetic means of the life test data presented in Table 3-5. Graphic displays of some of these data are shown in Figures 3-12 and 3-13. Long-term performance trends have not been apparent from the test data accumulated to date. During most of the life test, the average hot cap temperature has been in the range of $980^{\circ} \mathrm{F}$ to $1000^{\circ} \mathrm{F}$, which is below the temperatures at which converter deterioration occurs. The maximum heat source temperatures have remained within the range of $1300^{\circ} \mathrm{F}$ to $1330^{\circ} \mathrm{F}$ while the heat input was maintained in a $1430-1450$ watt range. The maintenance of an inert atmosphere within the heat source assembly apparently prevents the buildup of significant interface resistance as a result of oxidation, and there has been no measurable change in interface thermal resistances from other causes, i.e., other metallurgical reactions or mechanical separation at the interfaces.

As of August 31, the life test was underway for about 6100 hours and total system operating time at that date was about 8300 hours. The helium leakage rate has continued unchanged and the electrical leakage from the heater circuits remains at a fairly constant level of about $0.2 \mathrm{ma}$.

\section{EMS Converter Load Variation Testing}

Testing of the SNAP-23A EMS was performed at converter external loads different from the normal load imposed by the system power conditioner and load resistor according to EMSN-3C life test procedure. System equilibrium operating conditions were obtained for the various converter load conditions. Instantaneous characteristics of the converter were obtained for electrical loads selected as short circuit (minimum converter load resistance), a nominal one-third the normal load resistance, a nominal three times the normal load resistance, and the normal load resistance at the equilibrium conditions of the test. The data 
Net Conditioned Power watts (e)

65.3

Gross Converter Output, watts (e)

79.6

Net System Thermal Power watts $(t)$

1255

Total Heater Power, watts (e)

1440

Conditioned Voltage, VDC

24.0

TE Converter Voltage, VDC

24.9

Converter Current, amperes

3.2

Current Through Load, amperes

Converter Internal Resistance, ohms

Key System Temperatures, ${ }^{\circ} \mathrm{F}$

$\begin{array}{ll}\text { Heat Source Surface } & 1207\end{array}$

Mean Stud

1088

Mean Hot Cap

992

Mean Cold Cap

185

Mean Radiator Base

140

Ambient 
taken at each of the equilibrium load operating points is summarized in Table 3-2. A baseline for reference during the entire load test was the heater input power which was maintained near the 1420 watt start-of-test level. Heater power varied between 1414 and 1424 watts during the load tests.

Figure $3-1$ is a plot of the converter output characteristics for the constant hot and cold cap temperatures achieved at equilibrium conditions for the various load resistances. As expected, the voltage-current characteristic is a straight line and the power-current characteristic is a parabola. At the constant hot and cold cap temperatures, the thermoelectric parameters for the thermoelectric materials (Seebeck coefficient, resistivity, and thermal conductivity) are all constant. The equivalent electrical circuit of the converter for constant cap temperatures is an emf equivalent to the instantaneous open-circuit voltage, in series with a resistor equivalent to the internal resistance of the converter. For this circuit, the maximum power occurs at a load current equal to one-half the short circuit current and a voltage equal to one-half the open-circuit voltage.

The range of conditions shown on these curves demonstrates that the data are consistent and that they follow expected patterns. However, only one point on each curve corresponds to an achievable operating condition. Figure 3-2 shows the measured converter output characteristics for constant system power input when operating at thermal equilibrium for the various load resistances. As can be seen, the voltage-current characteristic is no longer a linear relationship and the output power-current relationship is no longer parabolic. The distortion of these curves from those obtained while under the constant temperature conditions results from: 1) Changes of hot and cold cap temperatures due to the change of converter current, and 2) Change of thermal input to the converter due to the changes of the system thermal losses at the different equilibrium system temperatures. 
TABLE 3-2

EMS EQUILIBRIUM LOAD TEST DATA

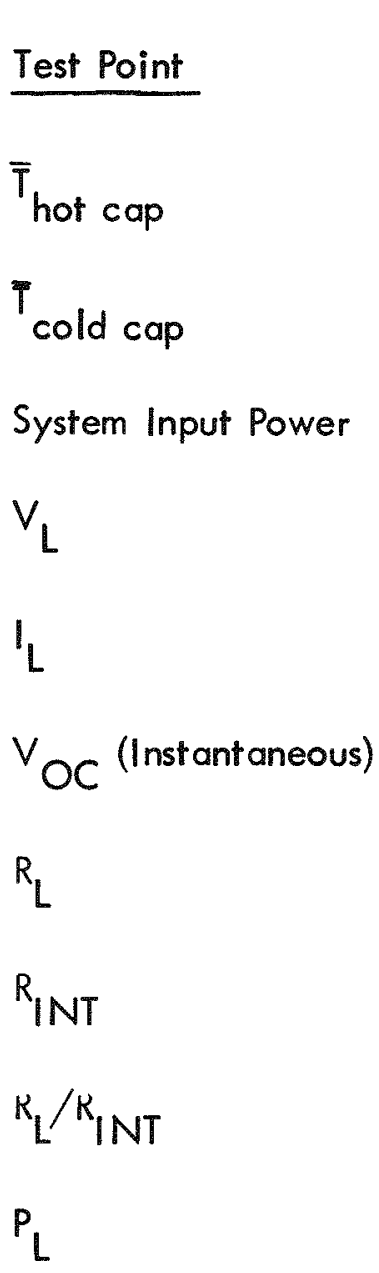

Normal Load (With Power Condition)

$1013^{\circ} \mathrm{F}$

$192^{\circ} \mathrm{F}$

$1424 \mathrm{w}$

$24.96 v$

$3.269 a$

$48.17 v$

$7.635 \Omega$

$7.10 \Omega$

1.075

$81.59 w$
Nominal

Short Circuit

923.2

202.6

1423

1.584

5.924

42.160

0.267

6.85

0.039

9.38

193.7

1422

15.05

4.326

44.65

3.479

6.84

0.508

65.106
Nominal $3 \times$ Normal Load

1078

189

1414

41.60

1.505

52.72

27.7

7.378

3.75

62.61 


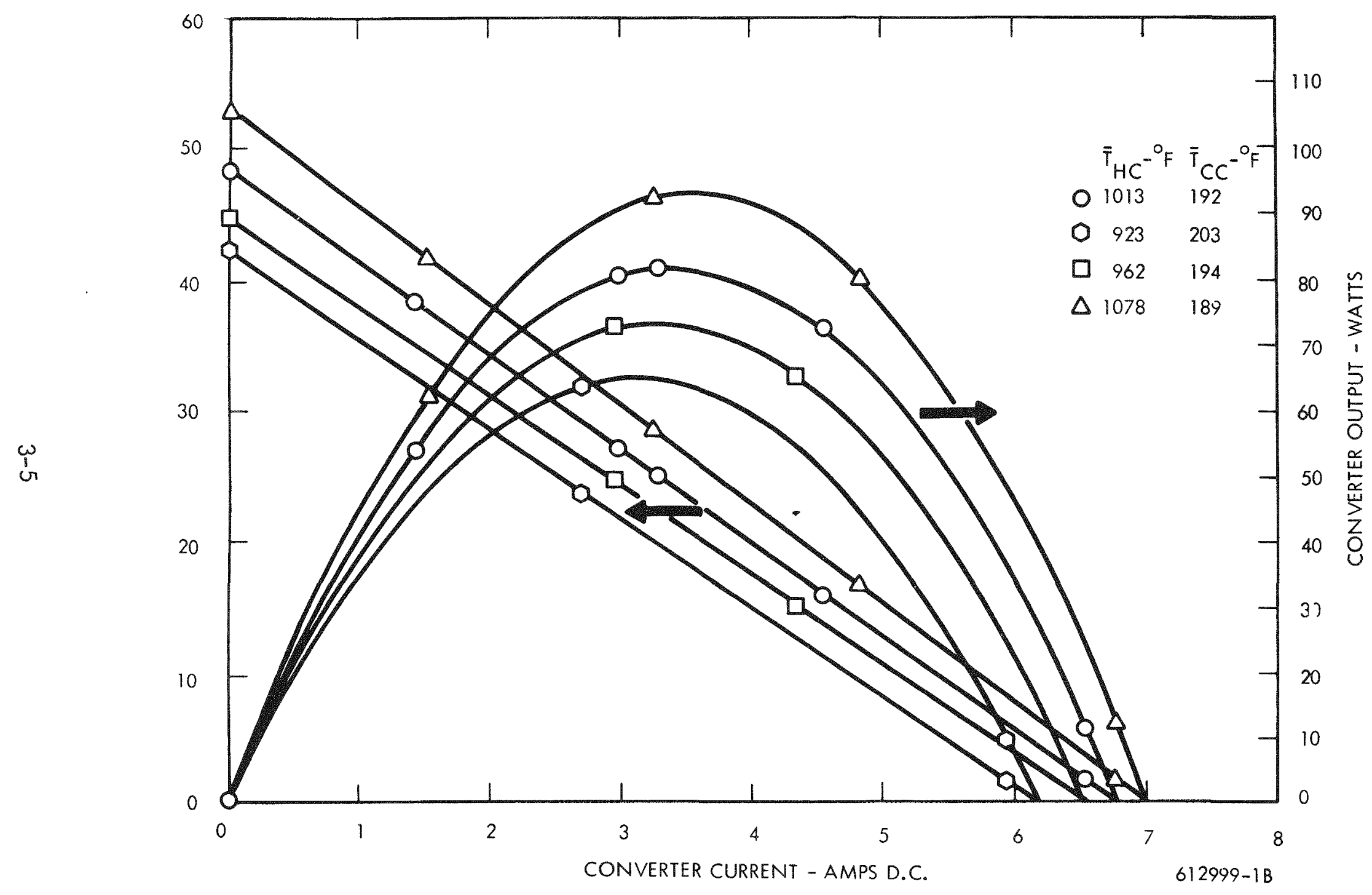

Figure 3-1. Converter Output Characteristics for Constant Hot and Cold Temperatures 


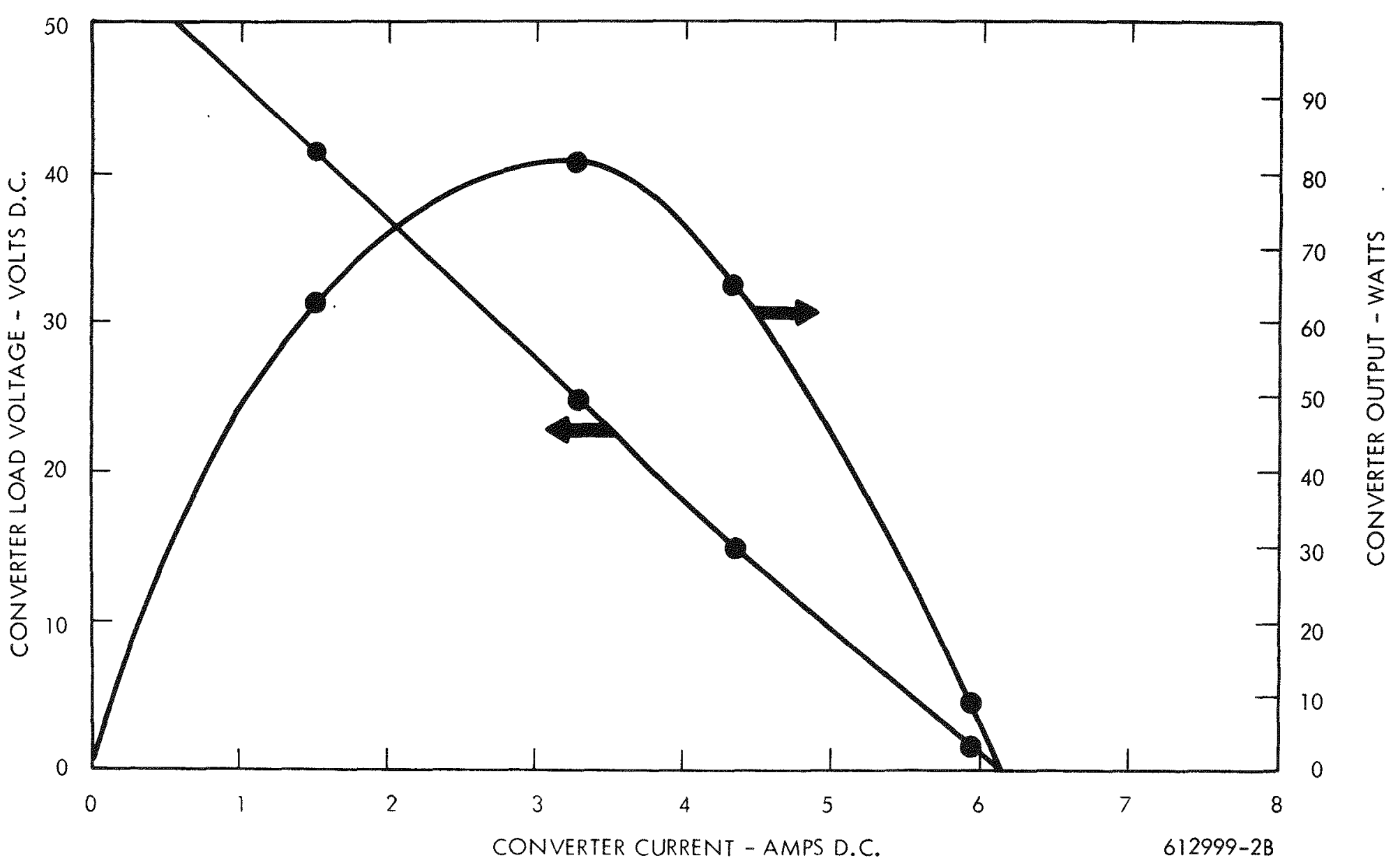

Figure 3-2. Converter Output Characteristics for Constant System Thermal Output and Thermal Equilibrium for Load Variation (System $Q_{\text {in }}=1414$ to 1423 Watts) 
As the converter current increases (load resistance decreases), more of the available heat is transported from the converter thermoelectric hot junctions to the cold junctions by the Peltier effect. The heat transported across the converter due to conduction is decreased, which means that the effective temperature differential across the converter is reduced. Since the cold junction temperature is maintained constant by the radiator, the overall temperature level of the heat source is reduced, making the heat source insulation system more effective. Therefore, more heat is available to the converter than under normal load conditions so that the current increases above that expected for a constant heat input.

Conversely, as the load current decreases (load resistance increases), the conducted heat increases, which in turn increases the effective temperature differential across the converter. The temperature level of the heat source is thus increased and the system losses increase. Less heat is available to the converter than under normal load conditions. The current is reduced from that expected for a constant heat input.

A discussion of the system and converter thermal changes, as anticipated from the load variation test data, follows. Using the average hot cap and cold cap temperatures and the converter load voltage conditions, an estimate of the heat input to the converter can be obtained from the computer code used to predict the performance of the converter. Since the gross system thermal input is known from the test data, an estimate of the total system losses and the change of heat delivered to the converter can be made for the different temperature operating conditions. Table 3-3 illustrates the thermal effects of the various system operating conditions. Further analyses performed on the data taken from this test are described in Subtask 350 .

Because of the variation of thermal input to the converter, the power-current characteristic is noticeably distorted from being parabolic. Maximum power output from the 
TABLE 3-3

EMS LOAD TEST THERMAL SUMMARY

\begin{tabular}{|c|c|c|c|c|c|c|c|}
\hline \multirow{5}{*}{$\underset{\infty}{w}$} & Test Condition & Hot Cap Temp & Cold Cap Temp & ${ }^{Q}$ Converter & ${ }^{Q}$ Converter & $\begin{array}{c}\text { Gross } \\
\Delta Q_{\text {System }}\end{array}$ & $\begin{array}{c}\text { Total } \\
\text { System Losses }\end{array}$ \\
\hline & Short Circuit & $923.2^{\circ} \mathrm{F}$ & $202.6^{\circ} \mathrm{F}$ & $1023.5 w$ & $-45 w$ & $1423 w$ & $400 w$ \\
\hline & I/3 Normal $R_{L}$ & 962.5 & 193.7 & 988.7 & -12 & 1422 & 433 \\
\hline & Normal $R_{L}$ & 1013 & 192 & 979 & 0 & 1424 & 445 \\
\hline & $3 \times$ Normal $R_{L}$ & 1077.8 & 188.6 & 923.3 & +36 & 1414 & 491 \\
\hline
\end{tabular}


converter is expected at a load resistance slightly greater than the converter internal resistance due to a change of equilibrium conditions. Figure $3-3$, a plot of the converter power output versus the ratio of load resistance to converter internal resistance, illustrates that the maximum power output occurs at a load resistance value greater than the internal resistance. For comparison, the calculated curve for normal operation (81.50 watts at 7.10 ohms) is also shown to illustrate the displacement of the measured peak power value from the expected load resistance. The value of the load resistance at which peak power occurs must be determined experimentally. An analytical determination would be extremely complex due to the non-linearity of the converter thermoelectric characteristics and the other system components, especially the insulation system.

\section{Integrated Test Plan}

Revision 2 of the Integrated Test Plan will be submitted to the AEC for review during the next reporting period. Revision 2 includes new sections on the FPMS performance test, shipping container pre-assembly tests, fire safery evaluation, fusible insulation tests, and sand conductivity tests.

\section{FPMS Preliminary System Design Description (PSDD)}

AEC comments on the draft PSDD, after internal review and revision, were received and incorporated into the final draft, along with internal WANL comments. The PSDD has been submitted for final typing. Issue is scheduled during the next reporting period.

\section{FPMS Design}

System Instrumentation - Instrumentation requirements have been coordinated with the 3M Company and WANL design and analysis personnel. The total number of thermocouples has been reduced from 189 for the EMS to 85 for the FPMS. Major reductions occurred in the radiator and base assembly external thermocouples were needed only for component tests. All internal heat source assembly instrumentation has been eliminated to assure the integrity of 
(2) Astronuclear

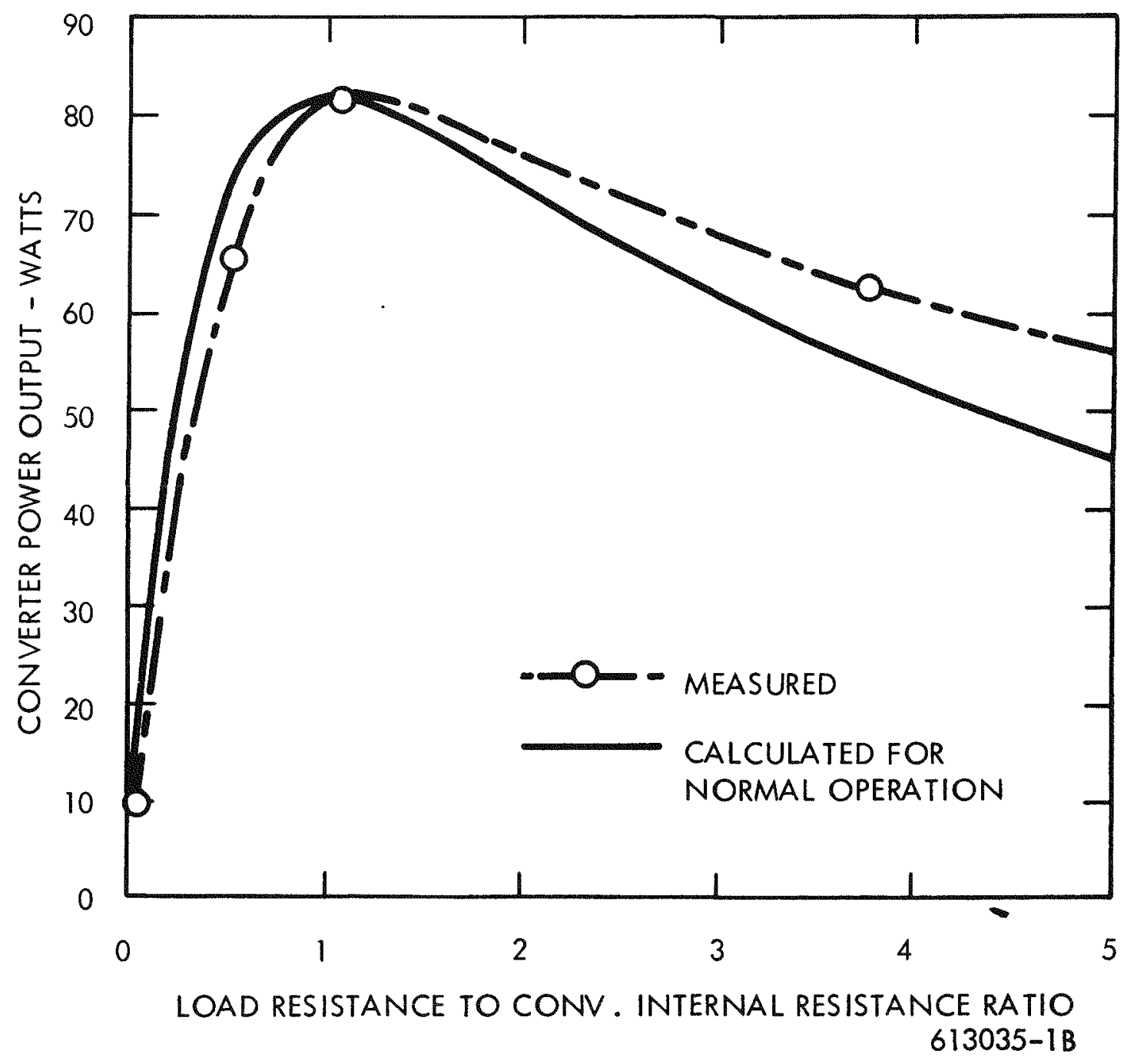

Figure 3-3. SNAP-23A Converter Output Versus Resistance Ratio 
the fueled assembly. Table 3-4 summarizes the FPMS instrumentation.

Converter Interface - Agreements were concluded with $3 \mathrm{M}$ concerning the various aspects of the converter power lead interface. Rather than placing a special order with a cable manufacturer for a silicone-insulated cable, inquiries by $3 \mathrm{M}$ disclosed the current availability from one supplier of a limited length of a neoprene cable which met the critical WANL requirements. This cable was subsequently evaluated as acceptable for FPMS use.

The cable being used for FPMS is designated as type DSS-2 under MIL-C-915A. The wire insulation, the filler around the insulated wires, and the binder around the filler are all made of butyl rubber covered by a tinned copper braid and sheathed with polychlorprene (neoprene). This particular cable has a greater resistance to axial leakage than any other cable previously examined. WANL tests of this cable included helium leak checks for axial flow. An unsealed sample showed a relatively low helium leakage. After sealing the cable with RTV-88 (the potting compound used to seal terminals on the power conditioner), no defectable helium leakage was found.

It has not been demonstrated that neoprene fully meets the 10-year lifetime required for the specific SNAP-23A conditions, but sufficient data are available to indicate that it is one of the prime candidates for such an application. Therefore, it was concluded that this cable is definitely acceptable for use on the FPMS and should be capable of meeting the full environmental requirements for SNAP-23A.

Subtask 315 - System Analysis

Hittman Associates assisted WANL during this reporting period by providing technical and programmatic support. Review of the FPMS design activities has continued. Subtask 320 - Mechanical Design

During this reporting period, the defail design of the radiator, insulated base assembly, heat source rain shield assembly, and base assembly hermetic seal were established and detail manufacturing drawings for these components were released. 
TABLE 3-4

FPMS INSTRUMENTATION

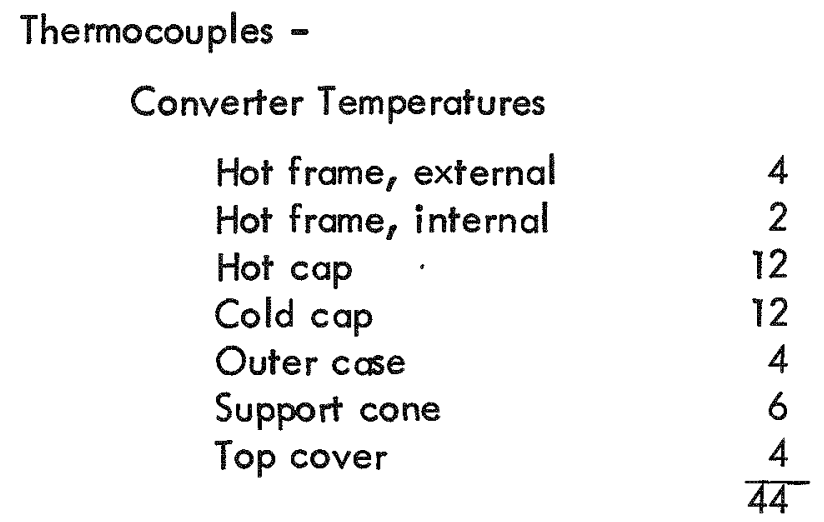

Heat Source

Stud jacket

5

Jacket shoulder

Base Assembly

Internal

Inner ring of hermetic seal 3

Inner ring of strut support 4

Base of inner container

4 (Within insulation 1)

External

$\frac{9}{21}$

Radiator

Hub

Shroud

Air inlet

Air outlet

Ambient $3 \mathrm{ft}$. from radiator

Power Conditioner

Power transistor

Total $\frac{2}{85}$

Electrical Measuring Instruments -

Converter voltage

Converter current

Power conditioner voltage

Load current

1
1
1
1
$-\frac{1}{4}$




\section{Base Assembly Hermetic Seal}

A design study was performed to arrive at a new hermetic seal configuration for the FPMS which would have a longer heat path and a resultant lower heat loss than the EMS seal. Configurations with both more and deeper convolutions were investigated. However, since increasing the number of convolutions increased the welding required to fabricate the seal, it was decided to obtain all the heat path length change by increasing the depth of the convolutions. The hermetic seal configuration established for the FPMS is compared with the EMS seal in Figure 3-4. The convolutions for the FPMS configuration are about 2.5 times as deep as those of the EMS and should result in a heat loss reduction of about 4 watts.

\section{Heat Source Rain Shield}

Heat source rain shield designs were developed that will permit either Min-K 2002 or fusible micro-fiber insulation to be used above the base assembly hermetic seal (see Figure 3-5). If safety studies indicate that a heat shunt around the converter is required to avoid excessive heat source temperatures under credible accident conditions, fusible insulation will be proposed for use in this area. When very high heat source temperatures are attained, this insulation should fuze and permit sufficient loss of heat from the heat source between the converter and base assembly so that the heat source components will not be heated to the extent that shielding effectiveness or fuel containment will be lost. The actual response of this material is currently being investigated by WANL, Subtask 410 , to verify and expand upon vendor supplied data.

It is presently planned to use the insulation arrangement shown in configuration (A) of Figure 3-5 in the FPMS. This arrangement is similar in some respects to that of the EMS, but the principal insulation material is Min-K 2002 instead of Min-K 2000, and the sheet material from which the insulation disks are cut is 2 inches instead of 1 inch thick. Also, since the FPMS heat source does not have internal instrumentation or an electrical heater, the passages provided in the EMS insulation for routing the heat source instrumentation and power lead protective tubulations were eliminated. Min-K 2002 was selected for the FPMS because it does not have a binder, which must be baked out to avoid outgassing during system 
(20) Astronuclear

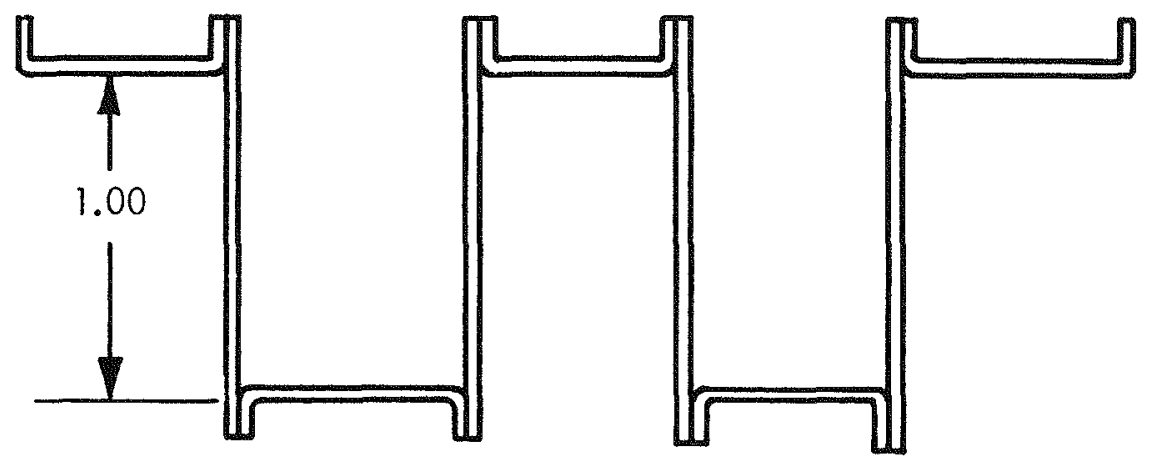

EMS CONFIGURATION

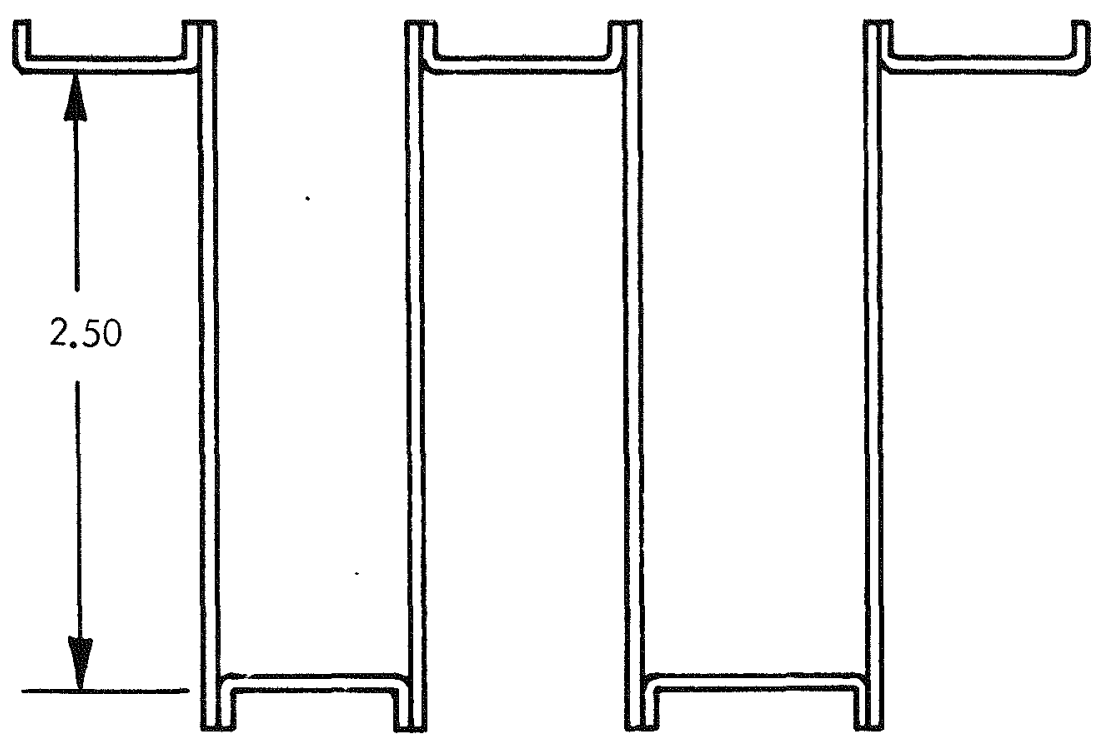

FPMS CONFIGURATION

Figure 3-4. EMS and FPMS Hermetic Seal Configurations 


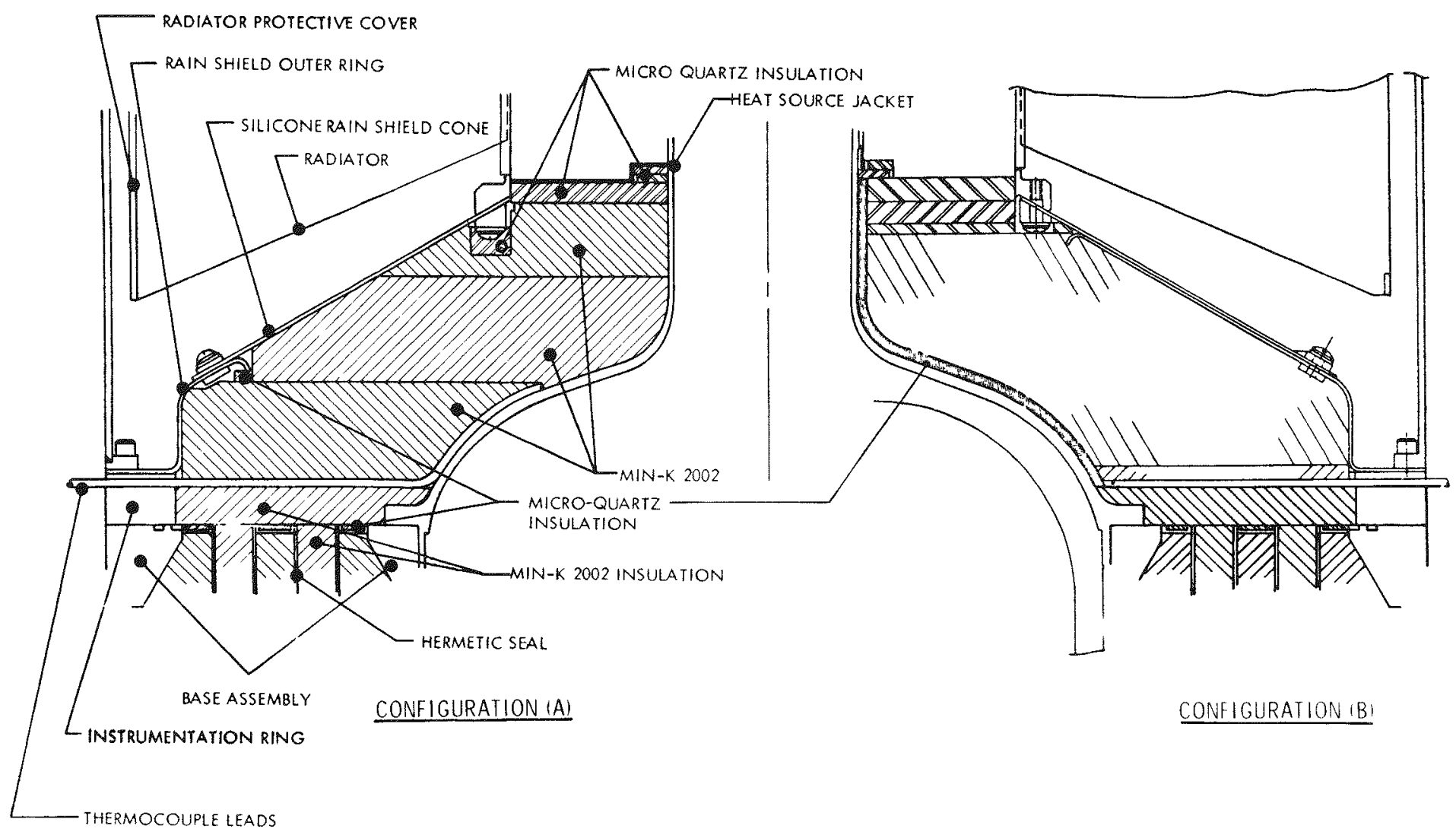

Figure 3-5. FPMS Heat Source Rain Shield 
operation as is the case for Min-K 2000. The 2-inch sheet thickness was selected to minimize the number of interfaces and more nearly approach the heat loss that would be obtained if the insulation were molded in place. Two-inch thick Min-K 2000 material could not be used in the EMS because excessive delamination of this material occurs when it is pressed into a sheet of that thickness.

If fusible insulation is required and the WANL test program verifies the expected material properties, configuration (B) in Figure 3-5 will be used. The principal insulation material is Johns-Manville micro-fiber insulation in bulk and felt form. Since the temperature of the heat source jacket adjacent to the fusible insulation can be as high as $1300^{\circ} \mathrm{F}$ during normal operation and the vendor-recommended maximum long-life operating temperature of the fusible insulation is $1200^{\circ} \mathrm{F}$, a thin high-temperature insulation blanket was provided around the neck and shoulder of the heat source to prevent overheating of the fusible irsulation during normal operation. The material originally considered for the insulation blanket was flexible Min-K, but it was later decided to use micro-quartz because this material has the same thermal conductivity as flexible Min-K at normal operating temperature and a higher conductivity under accident conditions where increased conductivity through the insulation blanket is desired. The bulk fusible insulation will be installed after the rain shield outer ring is attached to the base assembly so that the fusible insulation can be confined by the ring while the converterradiator assembly with silicone cone attached is mounted on the heat source stud.

The insulation arrangement shown in configuration (B) of Figure 3-5 can provide a large enough heat shunt around the converter under accident conditions to prevent melting of the copper accumulator and formation of a copper-uranium eutectic, which can cause breeching of the heat source jacket. However, the heat loss with this arrangement will be about 35 watts higher than the loss with configuration (A).

The heat source rain shield geometry for the FPMS differs from that of the EMS (see Figure $3-6$ ) as follows: 


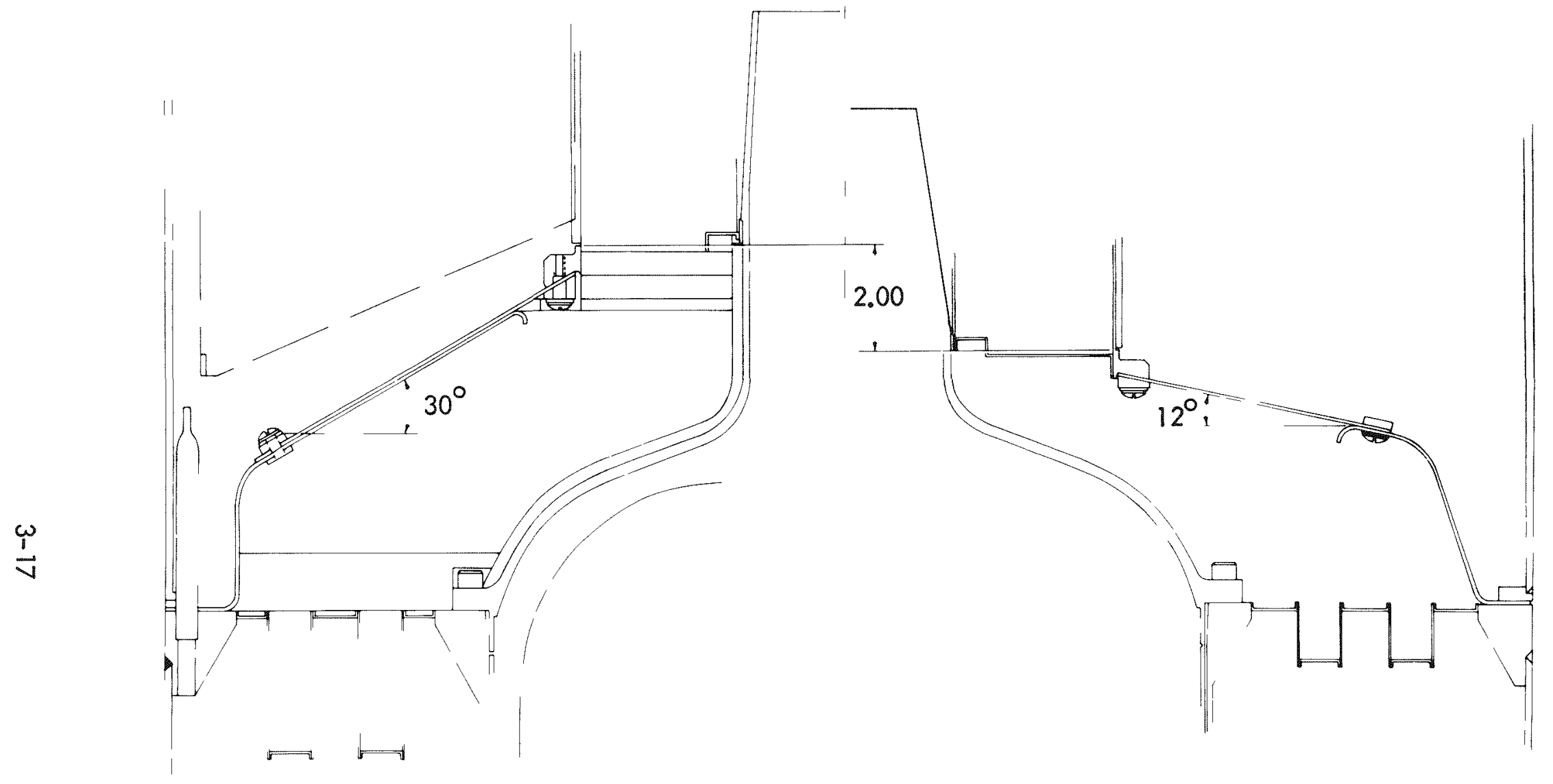

FPMS HEAT SOURCE RAIN SHIELD

EMS HEAT SOURCE RAIN SHIELD

Figure 3-6. Comparison of FPMS and EMS Rain Shield Configurations 
I) The vertical thickness of insulation adjacent to the neck was lengthened 2 inches. This change is expected to reduce the heat loss by approximately 31 watts. A change in the angle of the rain shield conical surface with the horizontal axis from about 12 to 30 degrees resulted from the change in insulation thickness.

2) The geometry of the rain shield outer ring was changed to provide space within the radiator and insulated base assembly envelope for the base assembly purge fubes.

Radiator Assembly

The radiator assembly manufacturing drawing was completed. The fin cutouts required to provide adequate clearance for the converter power lead cable and stuffing gland are shown in Figure 3-7. A cutout about 1.5 inches high and 1.5 inches long was required at the top inner edge of seven fins to clear the stuffing gland, and an additional strip about 1.0 inch high and 2.0 inches long was removed from the top of three of the seven fins to provide clearance for the power lead cable and potting.

Insulated Base Assembly

The FPMS base assembly manufacturing drawing was completed. The FPMS design differs from the EMS design as follows (see Figure 3-8).

1) The height of the base assembly was increased $1-1 / 2$ inches to permit the thickness of insulation beneath the heat source to be increased from $1-5 / 8$ to $3-1 / 8$ inches. This change is expected to yield a reduction in heat loss of 13 watts.

2) The heat source support truss and truss support rings were designed to have the same stiffness as the EMS support structure. With this stiffness, the heat source horizontal and vertical natural frequencies and magnification factors will be reproduced. Although the separation distance between the heat source and bottom of the base assembly was increased from $1-5 / 8$ to $3-1 / 8$ inches, the truss height was reduced from 9.81 to 9.35 inches so that the truss heat loss could be minimized as indicated by the results of the stress analysis reported under Subtask 330. This analysis shows that for a given truss stiffness, a truss height of about 9 inches would yield the minimum heat loss. Also, the distance from the bottom of the truss 

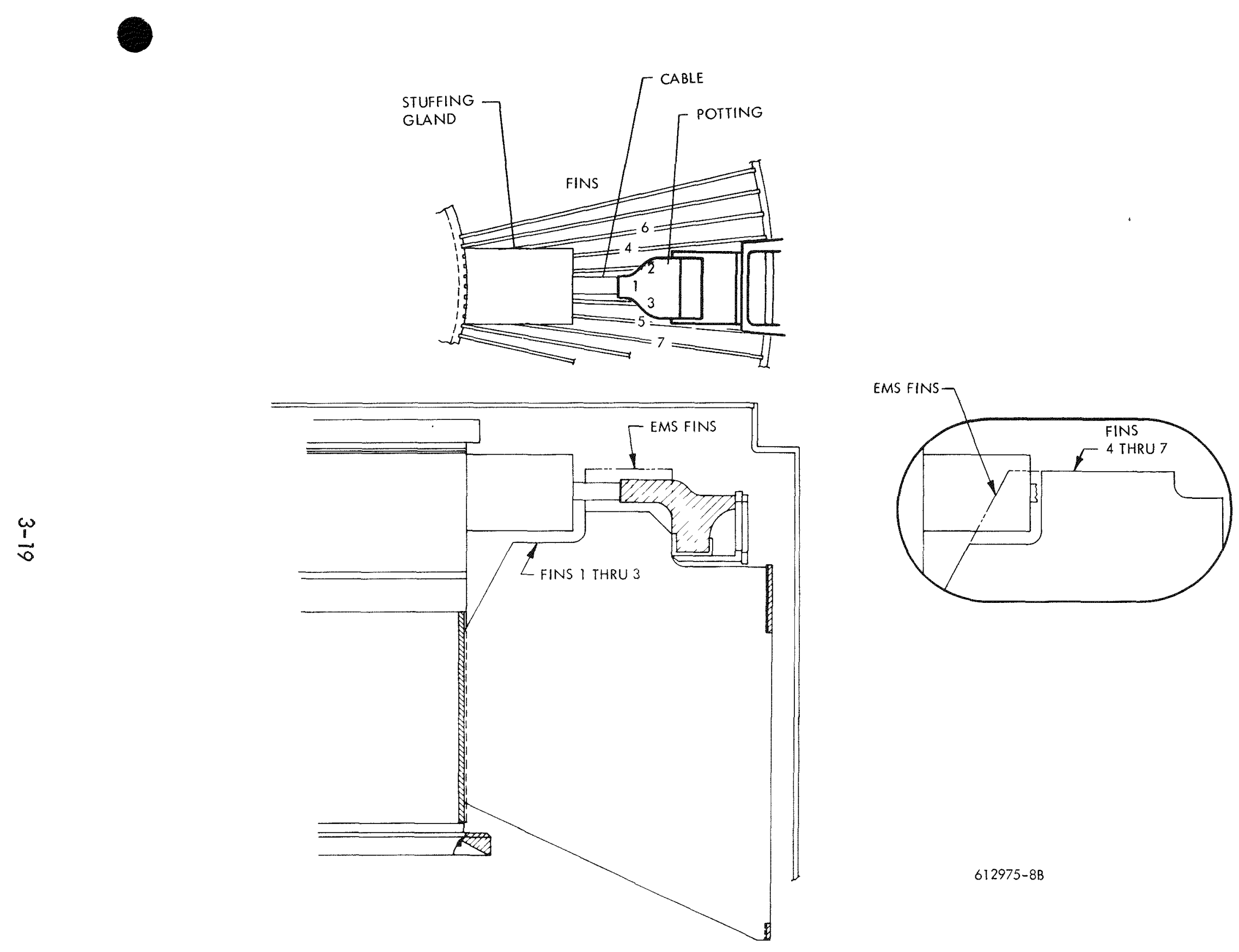

Figure 3-7. Radiator Fin Cutouts for Converter Gland and Power Lead Globe 


\section{(w) Astronuclear \\ Laboratory}

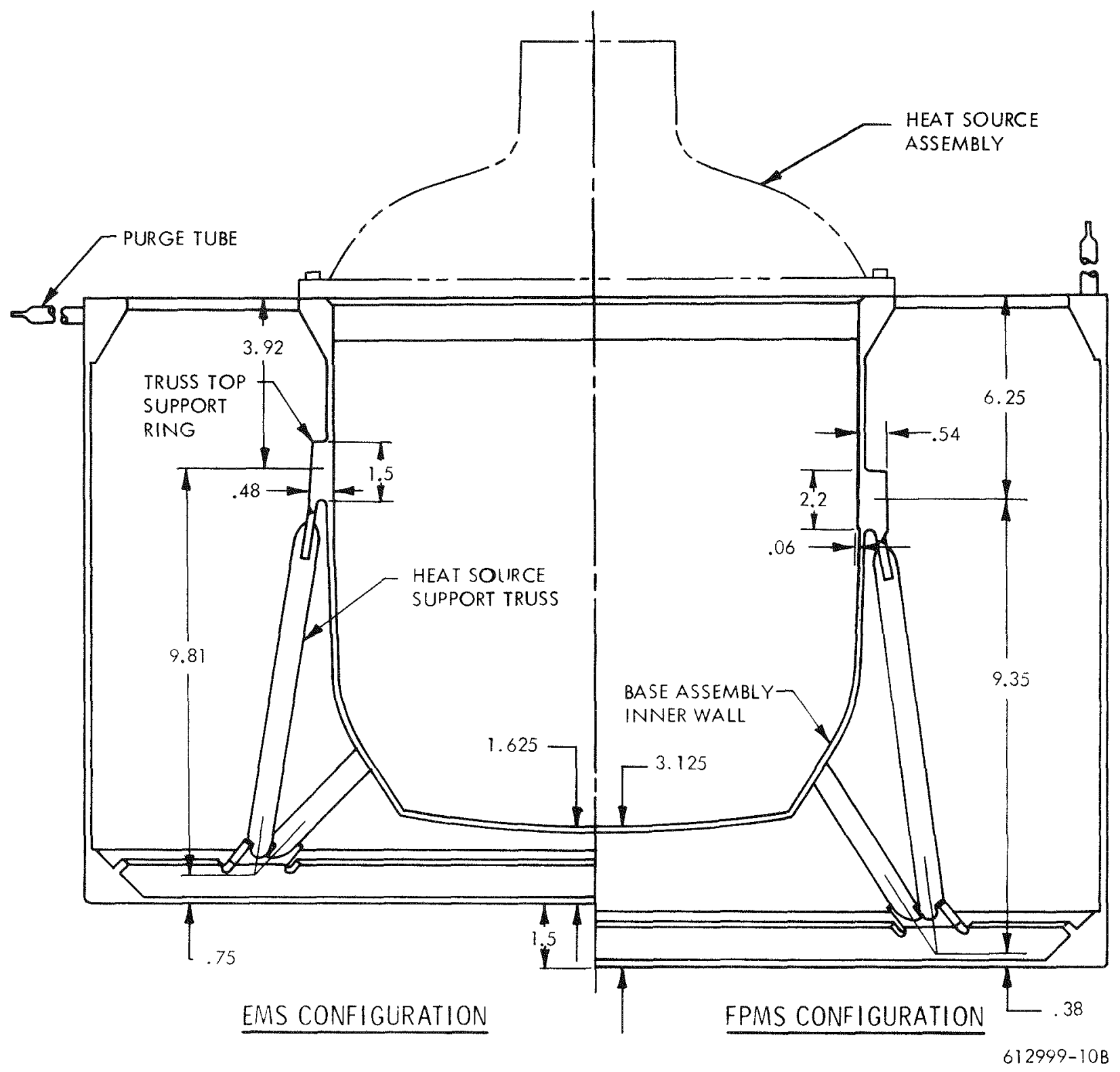

Figure 3-8. Insulated Base Assembly Design 
to the bottom of the base assembly was reduced from $3 / 4$ to $3 / 8$ inch to minimize bending of the bottom truss support ring due to eccentric strut loading. The changes in truss height and location were accomplished by increasing the depth of the forged ring that forms the top inner wall of the base assembly. However, because the forging for this ring was ordered before the advantage of a short truss was identified, it will not be possible to machine a ring deep enough to obtain the minimum heat loss truss height indicated by the analysis. Nevertheless, almost all of the heat loss reduction that can be achieved by reducing the truss height will be realized with the truss height selected.

3) The size of the top and bottom truss support rings was increased to provide the required stiffness for the heat source support structure. The ring cross-section dimensions were changed as shown in Figure 3-8.

4) The purge tubes required for evacuating and backfilling the base assembly with krypton emerged radially from the side of the EMS base assembly. In order to preserve the system envelope dimensions dictated by the base assembly proper, the purge tubes for the FPMS system are welded to the top surface of the top outer ring of the base assembly and aligned along the longitudinal axis of the system.

5) The clearance between the heat source and sheet metal bucket that forms the lower portion of the base assembly inner wall was increased so that relatively wide dimensional tolerances for the bucket would be acceptable. Also, a relief was machined at the lower end of the inner surface of the truss top support ring so that the weld shrinkage which occurs when the bucket is welded to the support ring cannot cause interference between the heat source and base assembly wall.

Subtask 330 - Stress Analysis

During this reporting period, stress analyses of the radiator fins and heat source support system were conducted to support the design of these components.

Radiator Fin

The FPMS radiator fin size was increased over that of the EMS unit by taking advantage of 
the increased heat source neck length. The fin height at the outside edge was increased from 8.25 inches to 10.25 inches. The outer support ring spacing also was increased by 2 inches. The fin size was sufficiently increased over that of the proven EMS fin to the extent that it was considered necessary to check the fin natural frequency.

A new plate element was added to the element library of the STASYS general purpose computer program (Structural Analysis System) to permit the use of this program in the stress analysis of the radiator fins. This program will handle static, elastic, and plastic problems, transient thermal problems, dynamic elastic, forced harmonic, and transient response problems. The program also has a library of ten different elements (i.e., bars, beams, plates, etc.). It was decided that a check case should first be analyzed to determine how the results of the coarse grid finite element program would compare with those from available literature before analyzing the radiator fins. The check case model, as shown in Figure 3-9, is an eightelement square plate clamped along one edge and simply supported along the other edges. Harris and Crede in "Shock and Vibration Handbook" give results for this case. For a 0.062inch thickness and aluminum density, they indicate the first mode natural frequency should be 388 cps. STASYS gives 20 frequencies for the model of Figure $3-9$, i.e., 381, 840, 948, 1369, 1587 and $1769 \mathrm{cps}$ and fourteen higher values. The excellent agreement of the first mode value with literature results indicates that this finite element model is entirely satisfactory.

Figure 3-10 is the model selected for the standard fin. It was assumed to be built-in at the hub and simply supported at each band. The calculated notural frequencies are 144, 156, $302339,470,554 \mathrm{cps}$, and higher values. This frequency level is well above the specification level of forced vibration (50 cps maximum) and no resonance problems should be encountered.

\section{Heat Source Support Truss}

The truss heat loss (conducted along the legs) is a function of strut area and length, assuming constant thermal conductivity and end temperatures as weil as adiabatic surfaces. A larger strut cross section area increases the heat loss while longer strut length decreases 


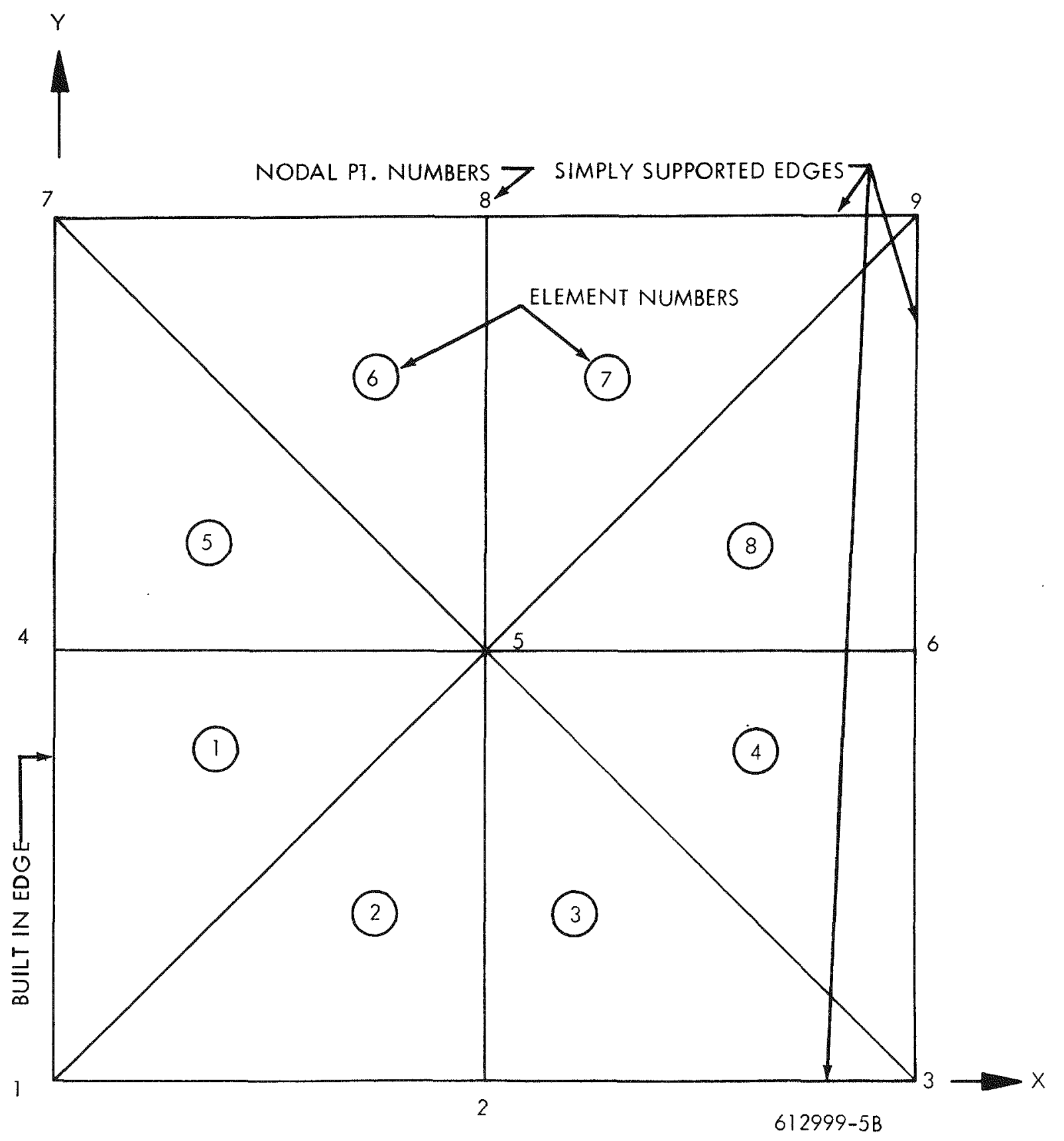

Figure 3-9. Test Case Model 


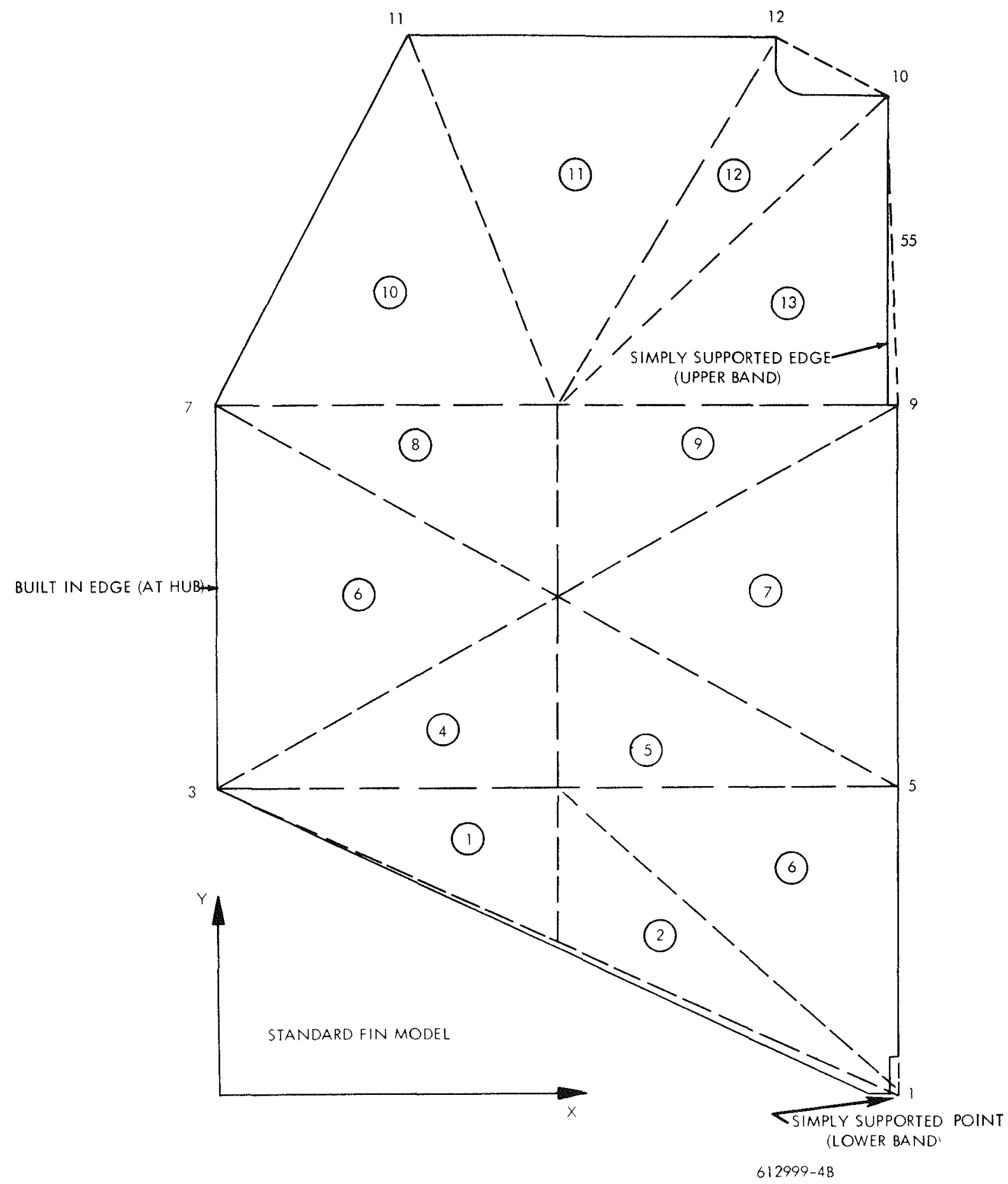

Figure 3-10. Standard Fin Model 
heat loss. The lateral stiffness of the truss, for a constant heat source weight and center of gravity (cg) location, is a function of strut area, length, and angle for given support ring diameters and strut elastic moduli. A larger strut cross-section area increases the stiffness directly, while the length and angle are related and influence the stiffness in a more complicated fashion.

It was found possible to vary the truss height while keeping the lateral natural frequency constant and examine the heat loss. Figure 3-11 shows the results of the study. The logical truss height (to the $\mathrm{cg}$ plane) is not optimum primarily because of the shallow leg angle. A very short truss is not optimum either, although the strut area decreases to a very small value. A truss having a height of about 9 inches appears to be optimum.

Subtask 340 - Thermal Analysis

During this quarter EMS life testing was continued, and data obtained for normal operation indicated a stable condition. Data were also obtained for the system operating at off-load conditions. The thermal and thermoelectric performance of FPMS was predicted for a range of system heat inputs encompassing the $\mathrm{BOL}$ and EOL design objectives. Spherical insulation life testing data show no significant changes in performance. The test on Min-K 2000 was terminated on August 15, 1969, after approximately 5800 hours of the life test. Supporting efforts were provided in the design of the FPMS base assembly and rain shield and to establish assembly procedures.

\section{EMS Life Tests}

Two data points were taken with the EMS on life test under normal load conditions. Table 3-5 summarizes these data along with previous life test data. Figures 3-12 and 3-13 show the system input power, converter power output, converter hot cap temperature, and system efficiency over the life test period. The slight increase in power output and converter hot cap temperature for the last data point was attributed primarily to the increased heat 
(2) Astronuclear

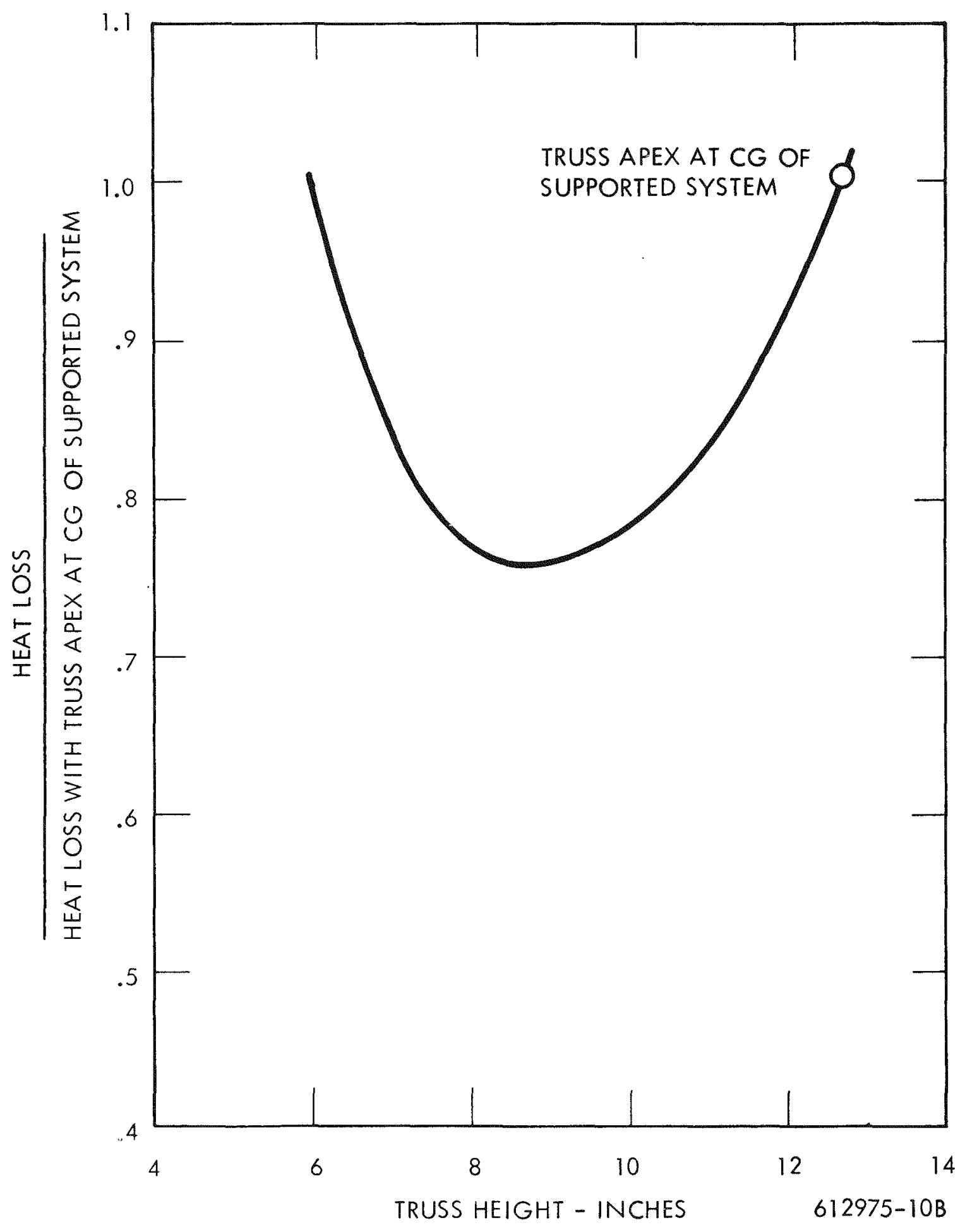

Figure 3-11. Heat Loss Versus Truss Height 
input which was at the upper limit of the allowable band in power supply variation. This anomaly was, therefore, considered within data scatter for the life test period. As more data are obtained, further examinations will be made to determine whether the slight deviation of these data points from the line representing earlier data is a definite trend. No significant changes in the temperature drops from the stud to the converter hot cap and converter outer case to radiator base have been noted during the life test period, indicating no changes in interface conditions. The converter temperature drop has remained stable, indicating no significant changes in thermal resistance in the converter. As indicated in Subtask 350, the converter thermoelectric performance also remained stable.

\section{FPMS Performance}

Updated performance estimates were made on the FPMS and compared to design objectives and EMS measured performance for inclusion in the final version of PSDD.

Thermal/mechanical analyses identified that stiffening of the FPMS Base Assembly struts to the degree required to limit the lateral magnification factor to a value of 2 would impose a significant thermal penalty on the FPMS. This thermal penalty is a direct result of changing the ratio of cross-sectional area to the length of the struts. A comparison of heat losses for strut dimensions which limit the lateral magnification factors to 2 and 3 is as follows:

$\begin{array}{lcc}\text { Lateral Magnification Factor } & 2 & 3 \\ \text { Area to Length Ratio } & 0.180 & 0.090 \\ Q_{\text {Loss }}(E O L) \text {, watts } & 35 & 17 \\ Q_{\text {Loss }}(B O L) \text {, watts } & 45 & 22\end{array}$

The predicted increase in heat loss, based on EOL conditions, would therefore be 18 watts. A further thermal improvement has been made in the detail design of the FPMS base assembly, specifically, by redefining the geomerry of the hermetic seal. The depth of convolutions of the hermetic seal has been increased from a nominal 1 -inch (EMS) to $2-1 / 2$ inches (FPMS). This change is predicted to reduce EOL heat losses by 4 watts. 
TABLE 3-5

SNAP-23A EMS THERMAL TEST POINT SUMMARY LIFE TEST

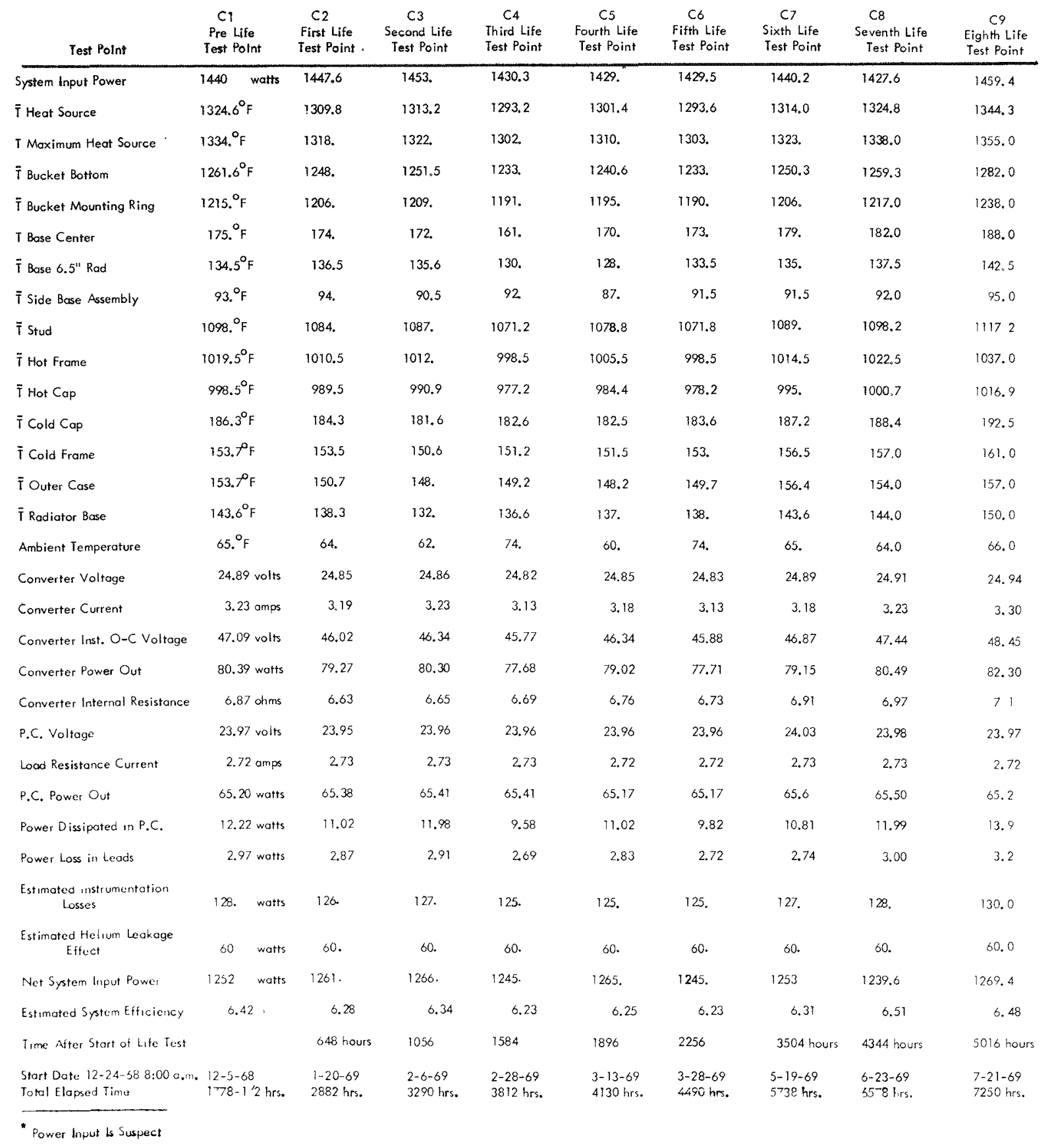




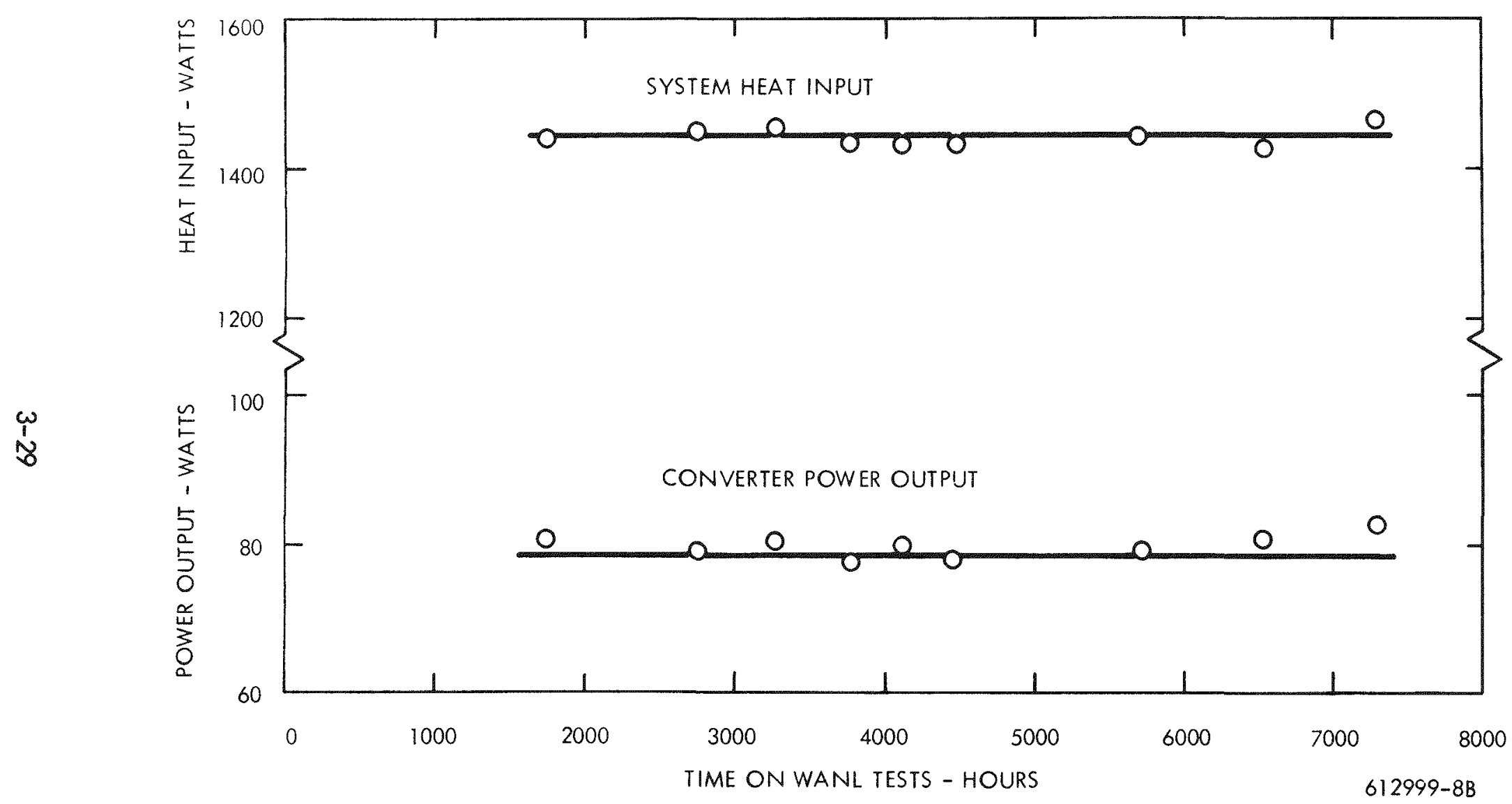

Figure 3-12. EMS System Performance on Life Test 

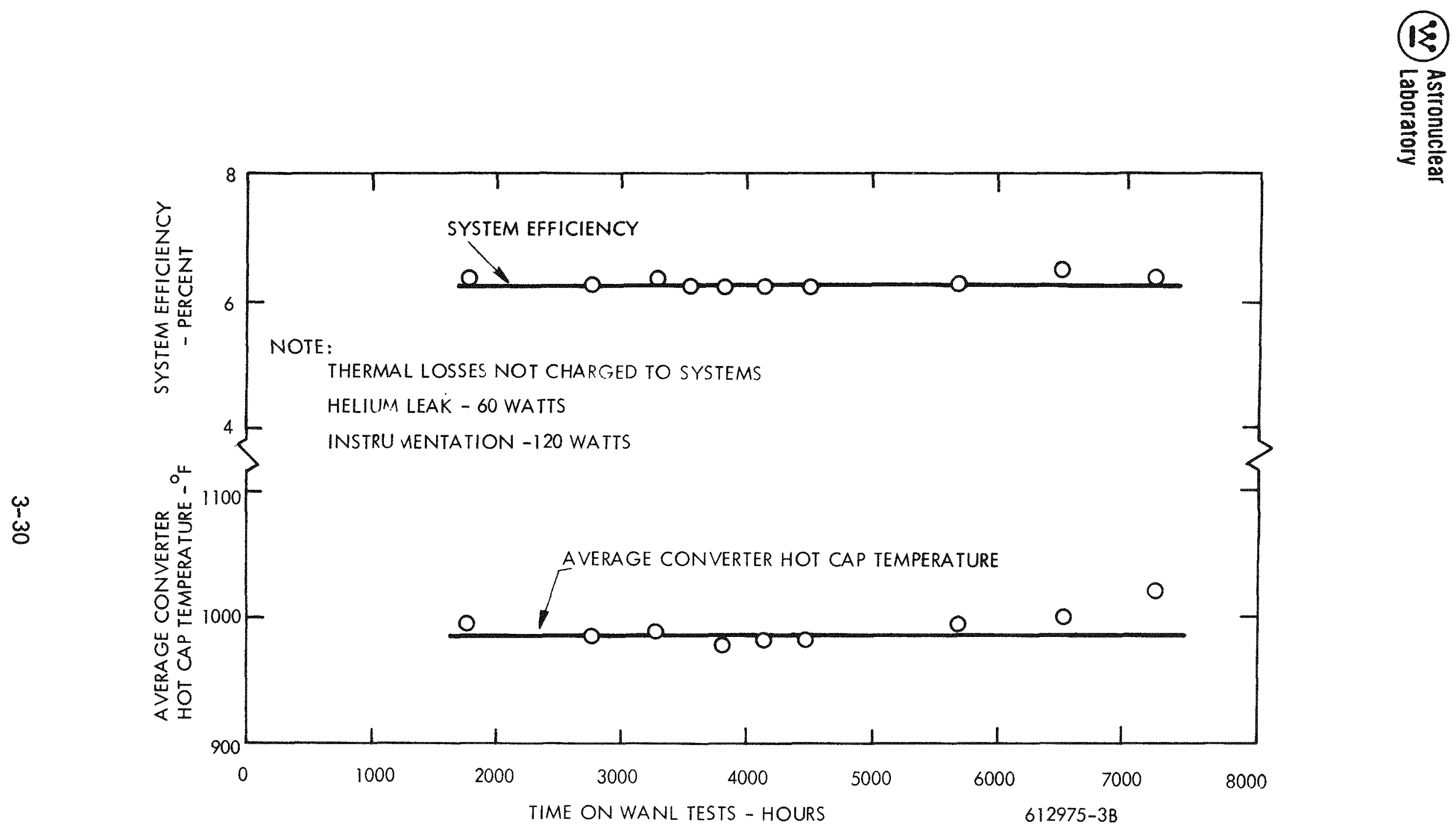

Figure 3-13. EMS System Performance on Life Test 
Using the converter performance data presented in Subtask-350, based on predicted nominal converter performance and using system heat loss data as defined from TØSS analyses of the system, performance estimates of the system were defined over a range of converter hot cap temperatures. Fgiures 3-14 and 3-15 present the predicted system performance. The heat losses presented in these figures are based upon the system with the design finalized for the heat source subassembly, base assembly, rain shield, converter, and insulation above the converter. Struts providing a lateral magnification factor of 3 are represented. The heat source thermal efficiency as shown in Figure 3-14 decreases slightly with increasing hot cap temperature. This trend results from the fact that heat losses increase more rapidly with increasing temperature (due primarily to the insulation conductivity) than does the heat input to the converter. The overall system efficiency peaks at around $950^{\circ} \mathrm{F}$ primarily due to the fact that the converter efficiency peaks near this temperature level. Using these figures and Figure 3-15, the performance of FPMS at initiation of testing was predicted along with the performance at design EOL conditions upon which the converter design was based. Table 3-6 compares the FPMS BOL and EOL predictions with the design objectives and with the measured performance of EMS. Based on an FPMS test date of 12/1/69, the fuel loading will be approximately 1100 watts. The predicted performance for FPMS at initiation of testing is shown in Table 3-6 consistent with this fuel loading. A power output of 74 watts at a load voltage of $24+1$ volts with a system efficiency of 6.8 percent is predicted.

The converter was designed to produce 61 electrical watts output at $24+1$ volts under "worst case conditions" at EOL. Nominally, the converter will produce 62.7 watts at a converter efficiency of 7.7 percent. With a heat source thermal efficiency of 86 percent, the system efficiency would be 6.6 percent. Because the converter is nominally producing more than 61 watts at EOL and because heat losses are calculated to be slightly in excess of design goals, the predicted EOL and BOL system thermal requirements are greater than design objectives. These differences, however, are within calculational accuracy of the converter and heat source thermal performance. 
W. Astronuclear

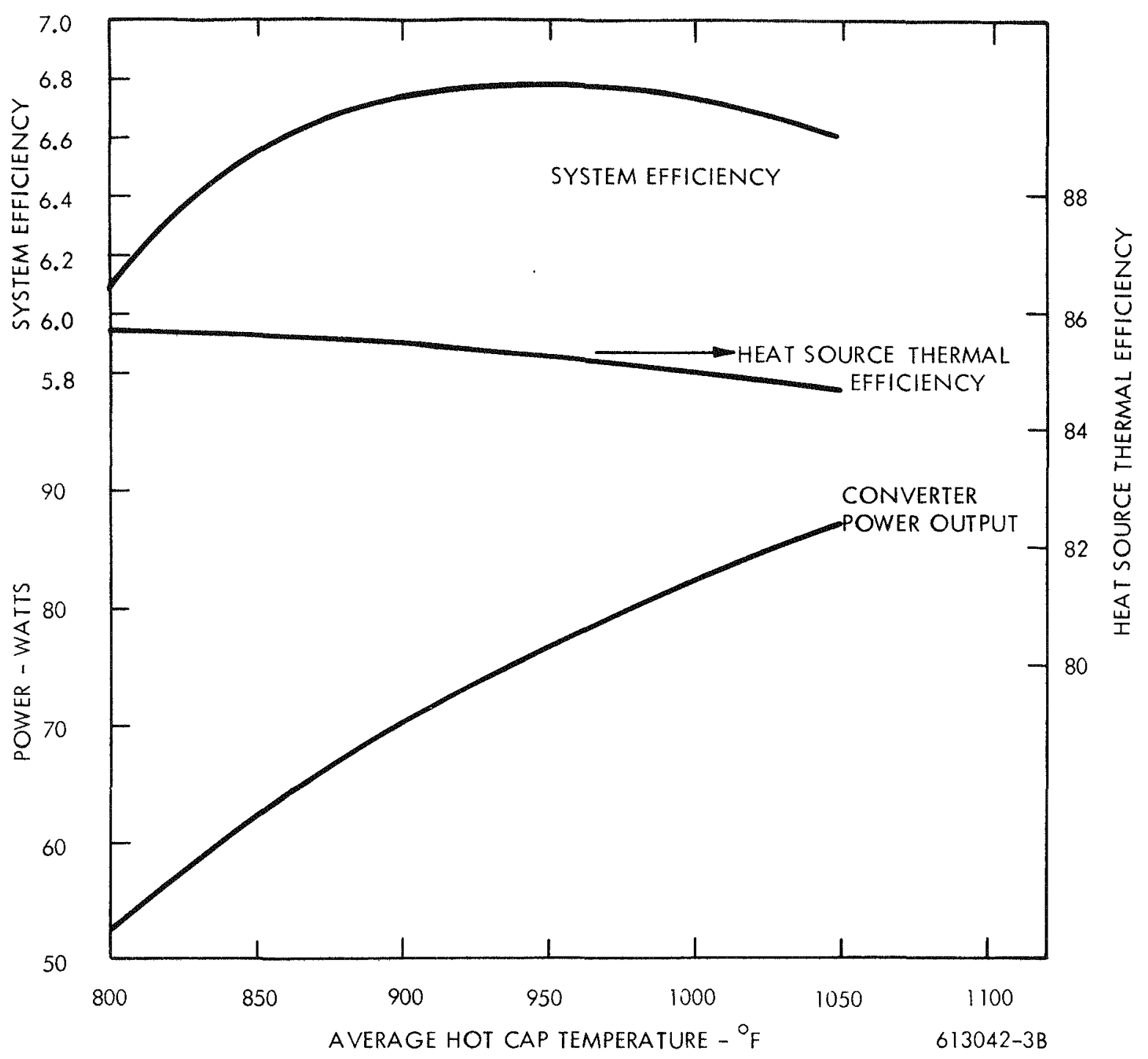

Figure 3-14. FPMS System Performance 

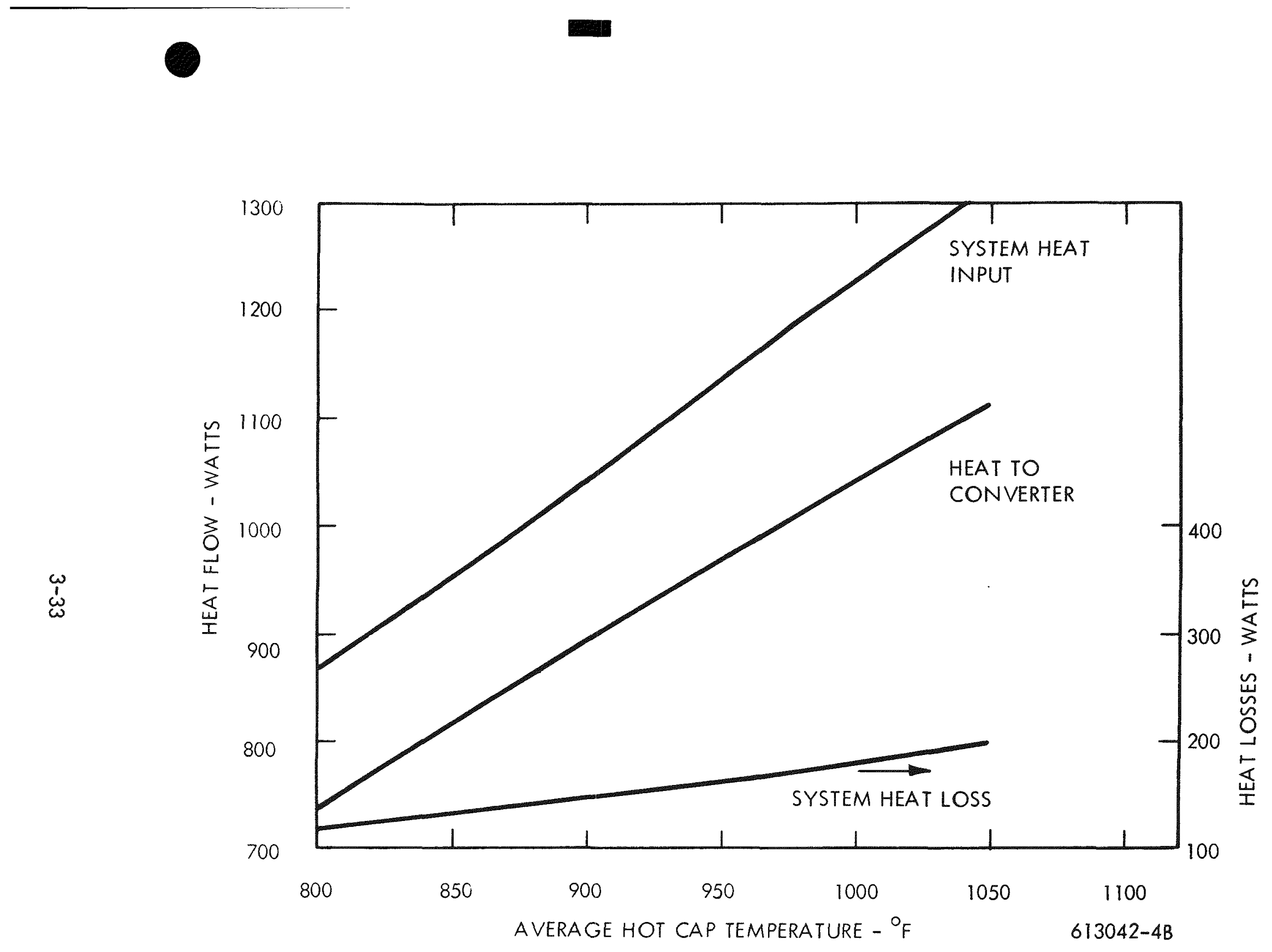

Figure 3-15. FPMS Heat Flow 
For comparative purposes, the EMS measured performance at design EOL is shown in Table 3-6. The converter, which was designed to produce 60 watts at 7.7 percent efficiency under worst case conditions, produced 64.8 watts at an efficiency of 7.9 percent. The heat source thermal efficiency was 82 percent for an overall efficiency of 6.5 percent.

Figure 3-16 presents representative temperatures predicted for the system at the initiation of FPMS testing and at EOL.

\section{Converter - Heat Source Assembly Operations}

For EMS a maximum heat source stud temperature of $600^{\circ} \mathrm{F}$ was established for the converter-heat source mating operation. Since EMS is electrically heated, the assembly operation was accomplished with the heat source stud at room temperature. Since the isotopically fueled FPMS heat source will be at an elevated temperature at the time of assembly, thermal analyses were completed to help define procedure and time constraints. Steady-state heat source stud temperatures, with the heat source installed in the base assembly, were estimated as follows:

1) No insulation around the shoulder of the heat source $T_{\text {stud }}=720^{\circ} \mathrm{F}$

2) $3-1 / 2$ inches of rain shield insulation $T_{\text {stud }}=1070^{\circ} \mathrm{F}$

3) Complete rain shield insulation $T_{\text {stud }}, 1500^{\circ} \mathrm{F}\left(\mathrm{T}_{\text {capsule }}=1900^{\circ} \mathrm{F}\right)$

If the heat source is allowed to reach steady-state temperature in the base assembly prior to installation of the rain shield insulation, it will take approximately 10 hours for a new steady-state temperature to be reached with $3-1 / 2$ inches of rain shield insulation and another 10 hours for reaching steady-state temperature with full rain shield insulation.

These temperature and time estimates indicate the need to minimize the installation time for the rain shield insulation during assembly and to redefine the FPMS stud temperature limit criteria. The $3 M$ Company has identified that a $\Delta T$ criterion is acceptable (converter hot frame to heat source stud) to control the actual mating and that the converter hot frame may be heated by the stud provided that the rate of temperature change of the hot frame is 
TABLE 3-6.

FPMS PREDICTED PERFORMANCE

\begin{tabular}{|c|c|c|c|c|c|}
\hline & \multicolumn{2}{|c|}{$\begin{array}{l}\text { SNAP-23A Program } \\
\text { Design Objectives }\end{array}$} & \multicolumn{2}{|c|}{$\begin{array}{l}\text { FPMS Predicted } \\
\text { Performance } \\
\end{array}$} & \multirow[t]{2}{*}{$\begin{array}{l}\text { EMS Measured } \\
\text { Performance }\end{array}$} \\
\hline & $\begin{array}{l}\text { For Original } \\
\text { EOL Condition }\end{array}$ & $\begin{array}{l}\text { For Redefined } \\
\text { EOL Condition }\end{array}$ & $\begin{array}{l}\text { At System } \\
\text { Startup* } \\
\end{array}$ & $\begin{array}{l}\text { At EOL } \\
\text { Conditions** }\end{array}$ & \\
\hline $\begin{array}{l}\text { Required System BOL Heat input } \\
\text { for 10-year life }\end{array}$ & 1167 & 1181 & & 1226 & 1285 \\
\hline $\begin{array}{l}\text { Maximum Steady-State Hot Cap } \\
\text { Temperature at } B O L\end{array}$ & 1100 & 1040 & 946 & 1022 & 1078 \\
\hline \multicolumn{6}{|l|}{ EOL Parameters: } \\
\hline Gross System Input Power, watts & 909 & 921 & 1097 & 956 & 1002 \\
\hline Average Hot Cap Temperature, ${ }^{\circ} \mathrm{F}$ & 904 & 852 & 928 & 852 & 904 \\
\hline System Heat Losses, watts & 130 & 129 & 160 & 138 & 181 \\
\hline Heat Flow to Converter, watts & 779 & 792 & 937 & 818 & 821 \\
\hline Converter Output Power, watts & 60 & 61 & 74.2 & 62.7 & 64.8 \\
\hline Conditioned Power Output, watts & & 60 & 73.2 & 61.7 & 62.2 \\
\hline Converter Efficiency, percent & 7.7 & 7.7 & 7.9 & 7.7 & 7.9 \\
\hline Heat Source Efficiency, percent & 86 & 86 & 85 & 86 & 82 \\
\hline + Overall System Efficiency, percent & 6.6 & 6.6 & 6.8 & 6.6 & 6.5 \\
\hline
\end{tabular}

* Based on nominal converter performance and a capsule heat output calculated for 12/1/69 based on 11/1/68 ORNL measurements

* Occurs 4.6 years after FPMS startup based on the nominal PMC-2 performance predictions.

+ Overall system efficiency defined by product of converter efficiency and heat source thermal efficiency. 


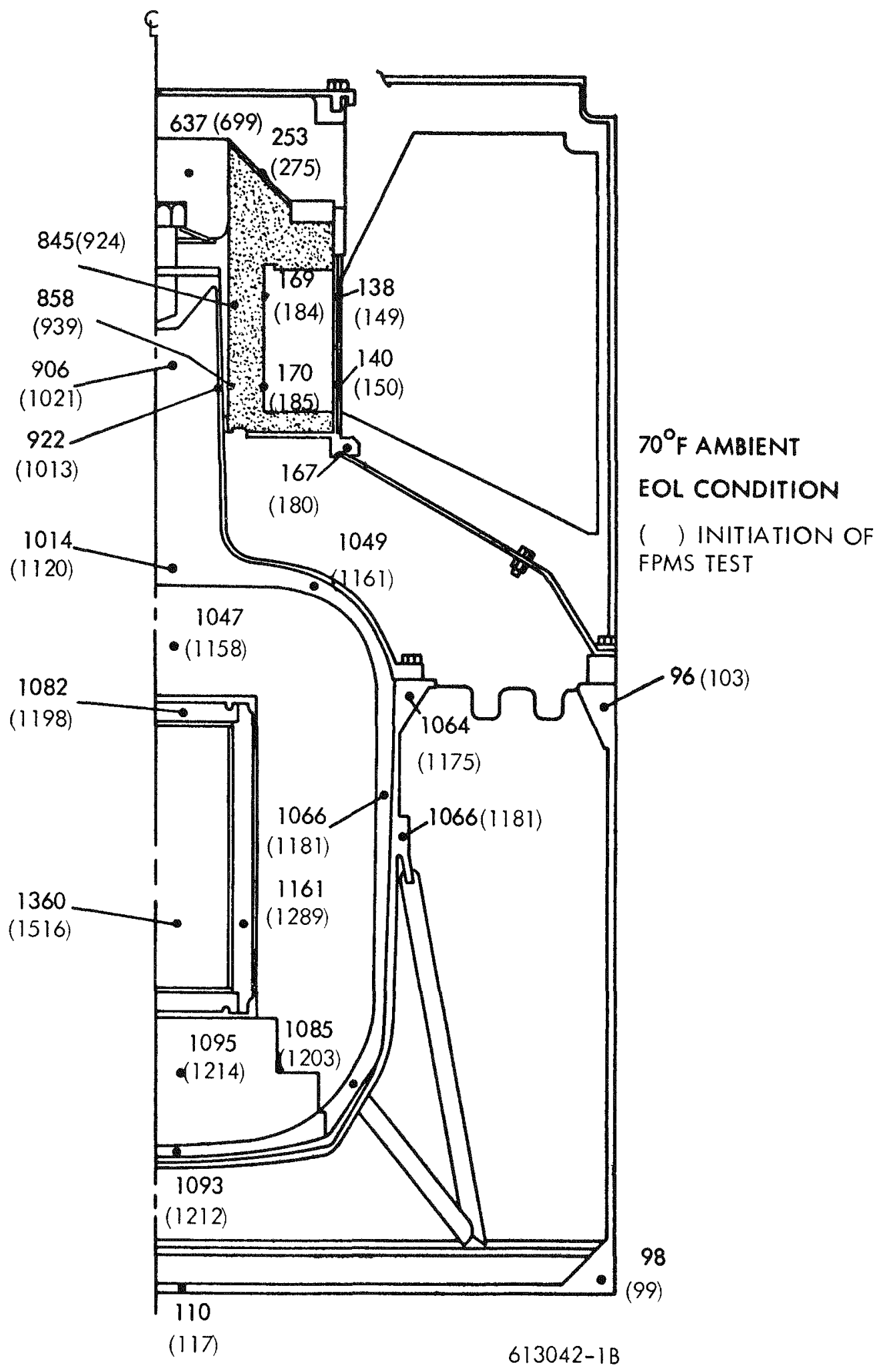

Figure 3-16. FPMS System Temperatures 
limited. The $3 M$ Company will define this maximum rate of converter hot frame temperature change.

\section{Spherical Insulation Life Tests}

The observed performance of Min-K 2000 material from the spherical insulation tests is shown in Figure 3-17. The temperature differential between hot and cold surfaces has been essentially unchanged in the last 66 days. During approximately 5800 hours of life test, the measured temperature differential varied by 2 percent of the value representing the first data point. Similar trends are observed from the measurements of Min-K 2002 material, as shown in Figure 3-18. During approximately 4300 hours of the life test the measured temperature differential varied by $I$ percent of the value representing the first data point. Thus, no significant change in performance has been observed. In view of this observation and the fact that the spherical insulation test on Min-K 2000 exceeded the original projected test time, this test was terminated August 15, 1969. The testing of Min-K 2002 is continuing.

Subtask 350 - Thermoelectric Analysis

\section{PMC-IA Operation on EMS Life Test - Design Load}

The PMC-I A converter performance on EMS life test at design load condition was examined by comparing the measured thermoelectric performance with the predicted values based on previously reported Seebeck and resistance ratios as recommended by $3 \mathrm{M}$ Company (WANL 3800-28). These ratios were defermined from life test data up to the second life test

dat a point (3290 hours). Using these values and the measured converter hot and cold cap temperatures and load voltage in the last thermal data point, converter performance was calculated as shown in Table 3-7. Good agreement was obtained between calculated and measured thermoelectric performance data. 

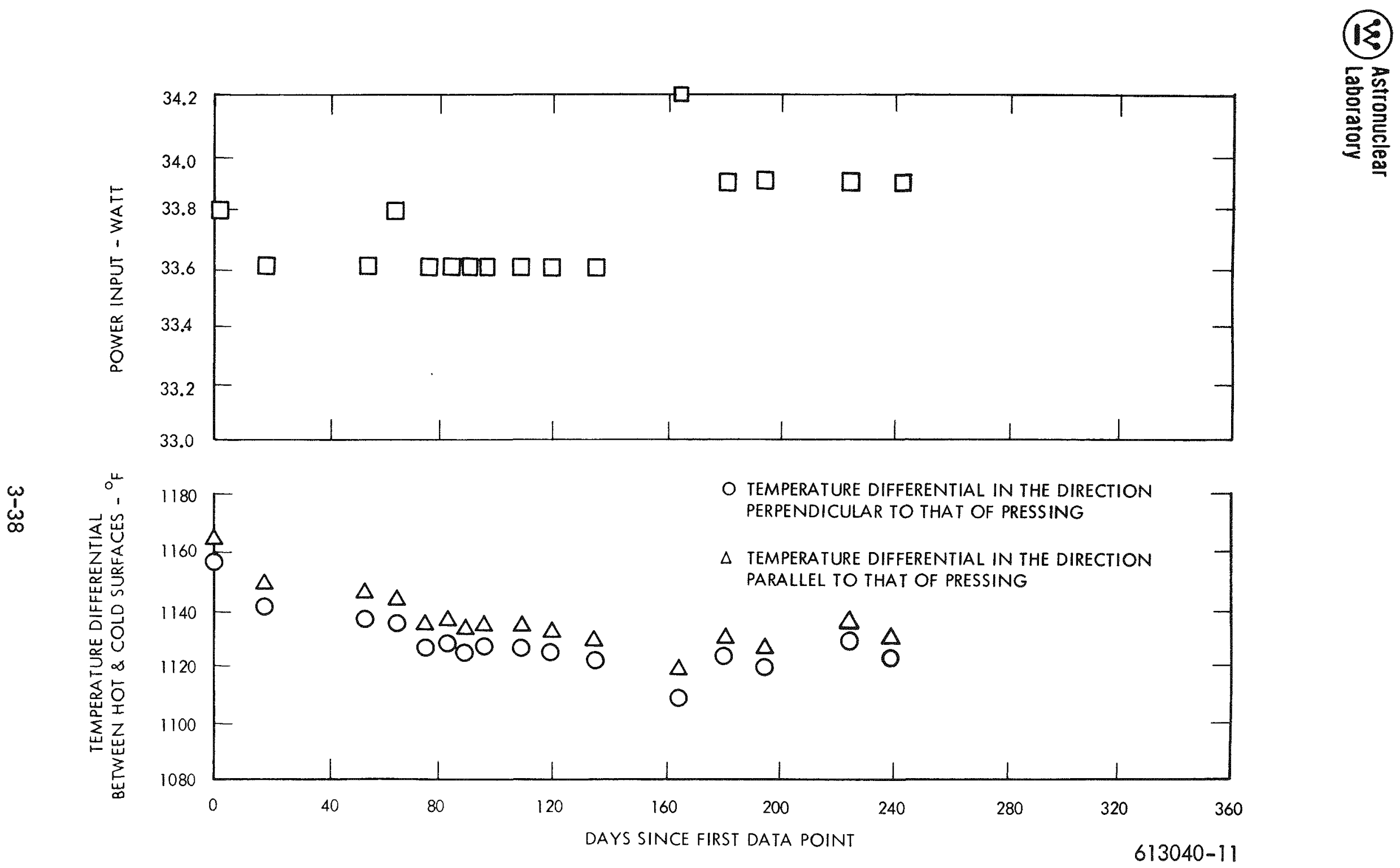

Figure 3-17. Temperature Measurements Versus Time for Min-K 2000 (Krypton Backfilled) During Life Test 

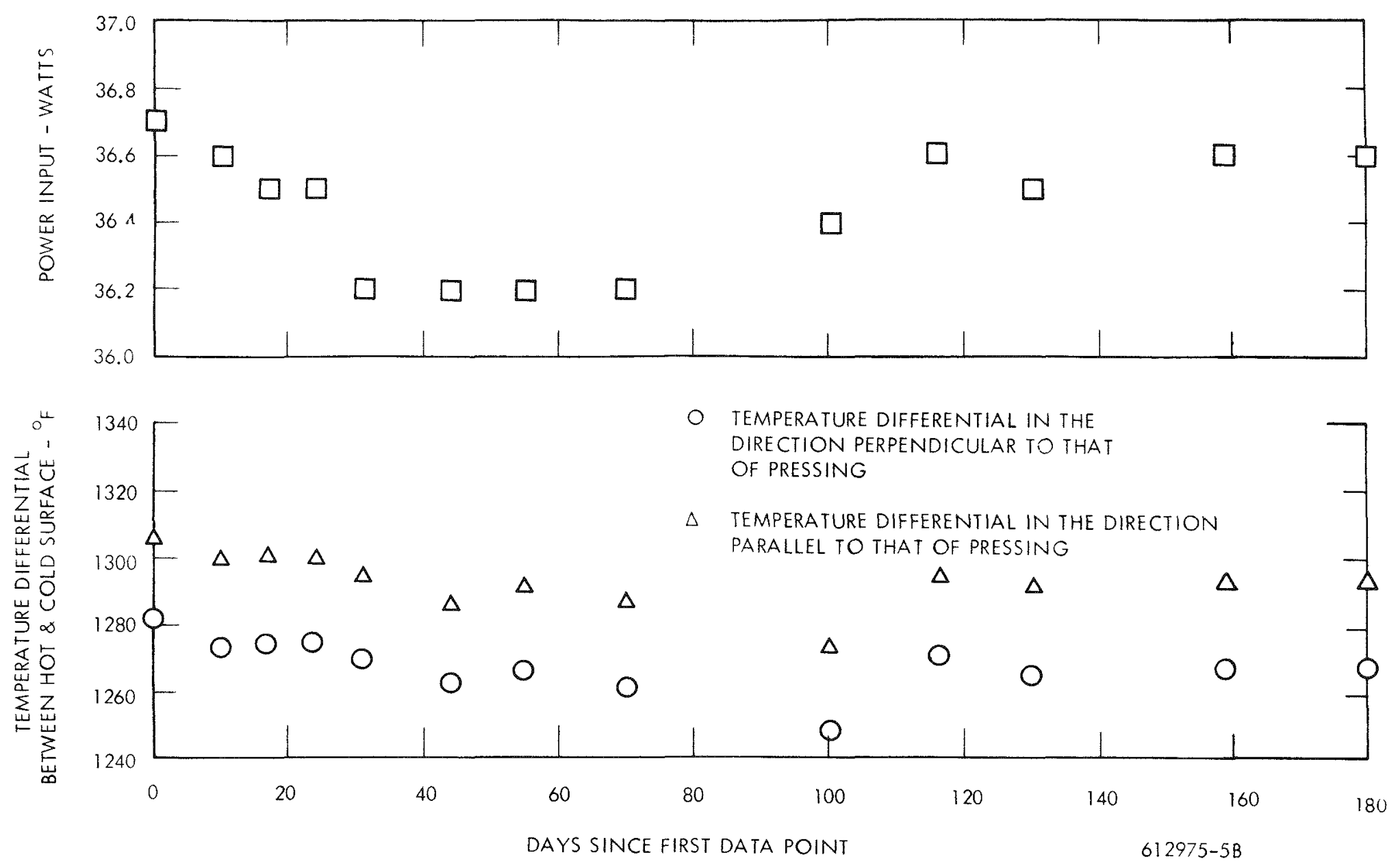

Figure 3-18. Temperature Measurements Versus Time for Min-K 2002 (Krypton Backfilled) During Life Test 
(2) Astronuclear

Laboratory

TABLE 3-7

\section{PMC-IA CONVERTER PERFORMANCE}

\begin{tabular}{|c|c|c|c|}
\hline & Predicted & $\begin{array}{l}\text { Measured } \\
\text { (7250 Hours) } \\
\end{array}$ & $\%$ Deviation \\
\hline Average Hot Cap Temperature, ${ }^{\circ} \mathrm{F}$ & $1016.9 *$ & 1016.9 & \\
\hline Average Cold Cap Temperature, ${ }^{\circ} \mathrm{F}$ & $192.5^{*}$ & 192.5 & \\
\hline Load Voltage, volts & $24.94^{*}$ & 24.94 & \\
\hline Converter Power Output, watts & 81.6 & 82.3 & +0.86 \\
\hline Converter Internal Resistance, ohms & 6.98 & 7.1 & +1.72 \\
\hline Converter Current, amperes & 3.29 & 3.3 & +0.30 \\
\hline $\begin{array}{l}\text { Converter Instantaneous Open } \\
\text { Circuit Voltage, volts }\end{array}$ & 47.9 & 48.35 & +1.12 \\
\hline
\end{tabular}

* Input values for the prediction. 


\section{Off-Design Load Testing of PMC-IA Converter}

Off-design load testing of the PMC-IA converter while on EMS life test was conducted (Subtask 310). Instantaneous and steady-state performance data were obtained at nominal load resistances of $R_{L}$ (design), $3 R_{L^{\prime}} 1 / 3 R_{L^{\prime}}$ and short circuit. Table 3-8 presents a summary of the steady-state thermal and thermoelectric performance at off-load conditions. Using the abovementioned Seebeck and resistance ratios obtained for converter operation at design load, and the measured values of converter hot and cold cap temperatures and load voltage, converter performance at off-load conditions was calculated. Table 3-8 compares the calculated results to the measured performance data. Figures 3-19 and 3-20 compare the measured and calculared performance data as a function of converter current. The calculated open circuit voltage was within 2 percent of the measured values over the full range of converter current. Since open circuit voltage is a function of the Seebeck coefficient and converter temperature drop, this suggests that the Seebeck ratios predicted at design loads remained uniform for the limited range of converter temperatures experienced in the off-load tests.

The measured values of converter internal resistance and converter current, on the other hand, deviate from calculated values significantly at currents approaching short circuit conditions (for example, the percent deviation in internal resistance varies from 2 percent at design load to 10 percent at short circuit). This trend suggests that possibly the converter performance code, which has Seebeck, resistance, power output, and heat input correction factors to match performance at design conditions with load voltages near 24 volts, is not an accurate tool for characterizing the converter performance over a broad range of operating temperatures and load voltages.

\section{PMC-2 Performance at Off-Design Conditions}

The thermal and thermoelectric performance of the PMC-2 converter has been estimated for a range of operating temperatures encompassing the design EOL and $B O L$ points. This prediction is based upon the converter as an integral part of the FPMS design. In a system such as FPMS where constraints are imposed on the converter, such as the heat dissipation capability of the radiator and a fixed system heat input, the converter may not 
TABLE 3-8

PMC-IA CONVERTER PERFORMANCE AT OFF-LOAD CONDITIONS

\begin{tabular}{|c|c|c|c|c|c|c|c|c|c|c|c|c|}
\hline & $\begin{array}{r}\text { Sho } \\
\text { Calc. } \\
\end{array}$ & $\begin{array}{l}\text { rt Circui } \\
\text { Meas. }\end{array}$ & $\%$ Dev & $\begin{array}{l}1 / 31 \\
\text { Calc. } \\
\end{array}$ & $\mathrm{L}_{\text {Meas. }}$ & $\%$ Dev & Calc. & $\begin{array}{l}R_{L} \\
\text { Meas. }\end{array}$ & $\%$ Dev & $\begin{array}{l}3 R_{L} \\
\text { Calc. } \\
\end{array}$ & Meas. & $\%$ Dev \\
\hline $\begin{array}{l}\text { Average Hot Cap } \\
\text { Temperature, }{ }^{\circ} \mathrm{F}\end{array}$ & 923.2 & 923.2 & & 962.5 & 962.5 & & 1013. & 1013. & & 1077.8 & 1077.8 & \\
\hline $\begin{array}{c}\text { Average Cold Cap } \\
\text { Temperature, }{ }^{\circ} \mathrm{F}\end{array}$ & 202.6 & 202.6 & & 193.7 & 193.7 & & 192. & 192. & & 188.6 & 188.6 & \\
\hline Load Voltage, volts & 1.58 & 1.58 & & 15.05 & 15.05 & & 24.96 & 24.96 & & 41.6 & 41.6 & \\
\hline $\begin{array}{l}\text { Converter Power } \\
\text { Output, watts }\end{array}$ & 9.49 & 9.35 & -1.5 & 66.44 & 65.2 & -1.9 & 81.13 & 81.6 & & 59.3 & 62.4 & +5.2 \\
\hline $\begin{array}{l}\text { Converter Internal } \\
\text { Resistance, ohms }\end{array}$ & 6.23 & 6.85 & +9.9 & 6.49 & 6.83 & +5.2 & 6.94 & 7.1 & +2.3 & 7.54 & 7.41 & -1.7 \\
\hline $\begin{array}{l}\text { Converter Current, } \\
\text { Amperes }\end{array}$ & 6.28 & 5.92 & -5.7 & 4.44 & 4.33 & -2.5 & 3.27 & 3.27 & +0.0 & 1.44 & 1.5 & +4.2 \\
\hline $\begin{array}{l}\text { Converter Instantan- } \\
\text { eous Circuit } \\
\text { Voltage, volts }\end{array}$ & 40.74 & 42.16 & +3.5 & 43.92 & 44.64 & +1.6 & 47.64 & 48.17 & +1.1 & 52.43 & 52.72 & +0.55 \\
\hline
\end{tabular}




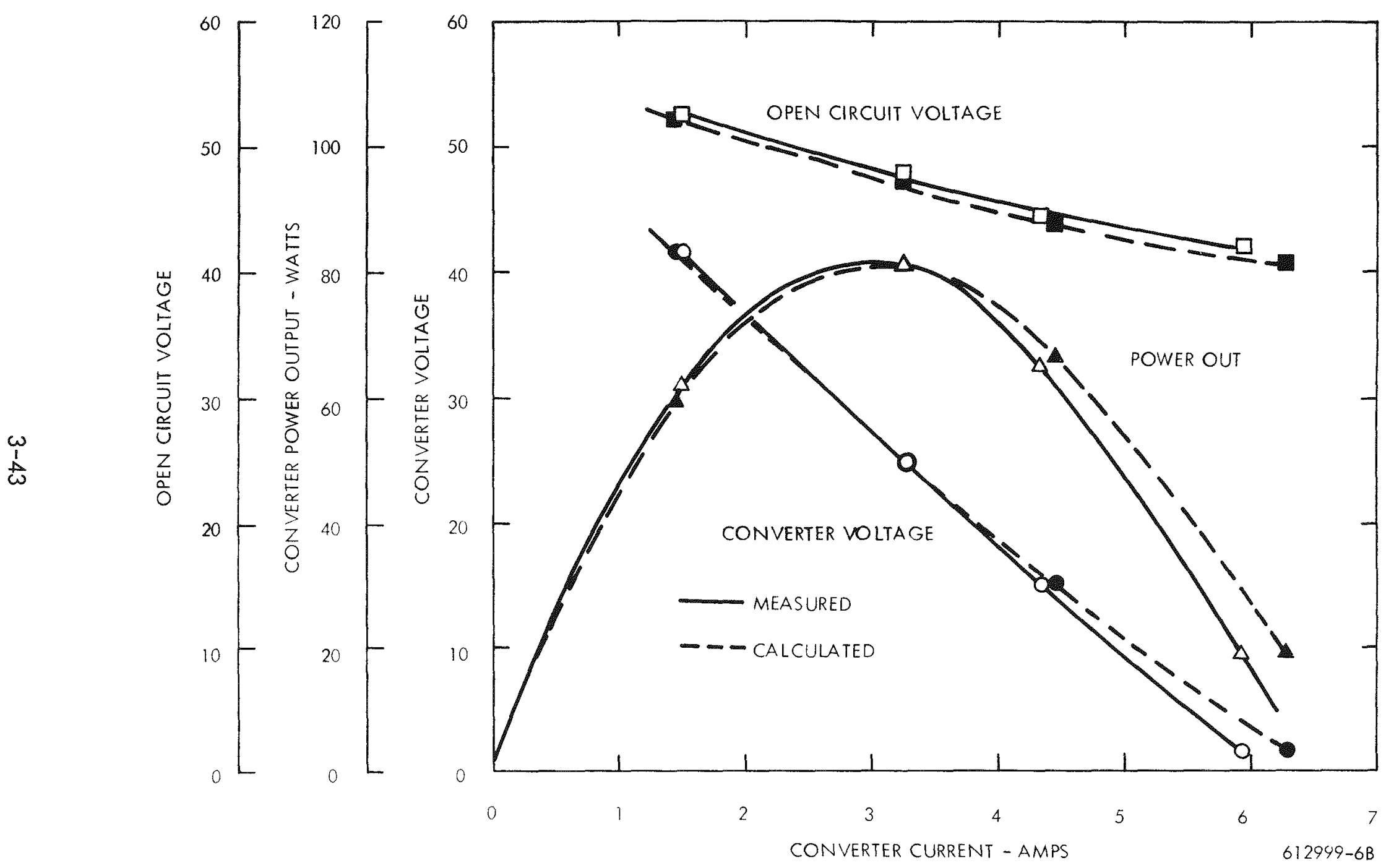

Figure 3-19. EMS/PMC-IA Converter Performance at Off-Load Conditions 


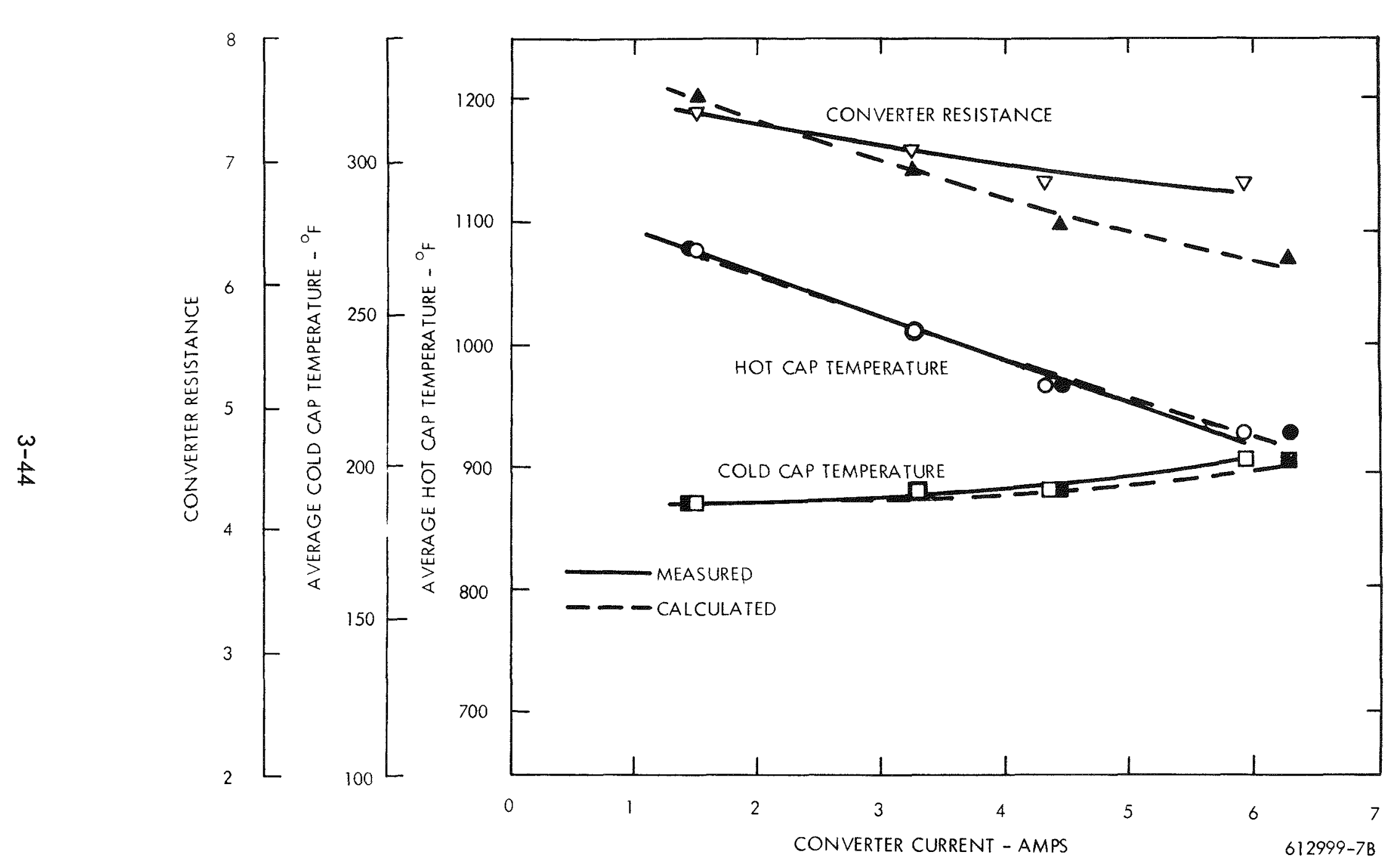

Figure 3-20. EMS/PMC-IA Converter Performance at Off-Load Conditions 
perform as predicted on a component basis predicated on design or nominal adjustment factors.

The analysis was based on $3 M$ Company performance predictions presented in the April 1969 Quarterly (MMM-3824-0034) with the following assumptions:

1) Load voltage $=24$ volts

2) Ambient temperature $=70^{\circ} \mathrm{F}$

3) Nominal adjustment factors

4) Nominal heat source performance

Under these conditions, $3 M$ Company predicted converter performance at design $\mathrm{BOL}$ and EOL as follows:

\begin{tabular}{lcc} 
& $\mathrm{BOL}$ & $\frac{\mathrm{EOL}}{852}$ \\
\cline { 2 - 3 } & 1004 & 852 \\
Average cold cap temperature, ${ }^{\circ} \mathrm{F}$ & 187 & 169 \\
Power output, watts & 82.7 & 62.7 \\
Resistance, ohms & 8.42 & 6.65 \\
Open circuit voltage, volts & 53.0 & 41.4 \\
Heat input, watts & 1048 & 818 \\
Efficiency, \% & 7.88 & 7.66
\end{tabular}

The above calculations were obtained by use of 3M's PRAM-03 computer program. A correction of +20 watts in the heat input was incorporated by $3 M$ Company in the above performance based on previous performance data for other converters. An additional correction of +4 watts was included in the heat input based upon analysis of the redesigned converter upper support core.

Based upon the above analysis by $3 M$ Company and projected performance for the FPMS radiator, the converter performance was calculated over a range of hot cap temperatures encompassing the EOL and $\mathrm{BOL}$ points, using the WANL CONV computer program (which performs the same calculations as $3 M^{\prime}$ 's PRAM code) that calculates the converter thermal and thermoelectric performance. Figure 3-21 presents the results of this 
(W) Astronuclear
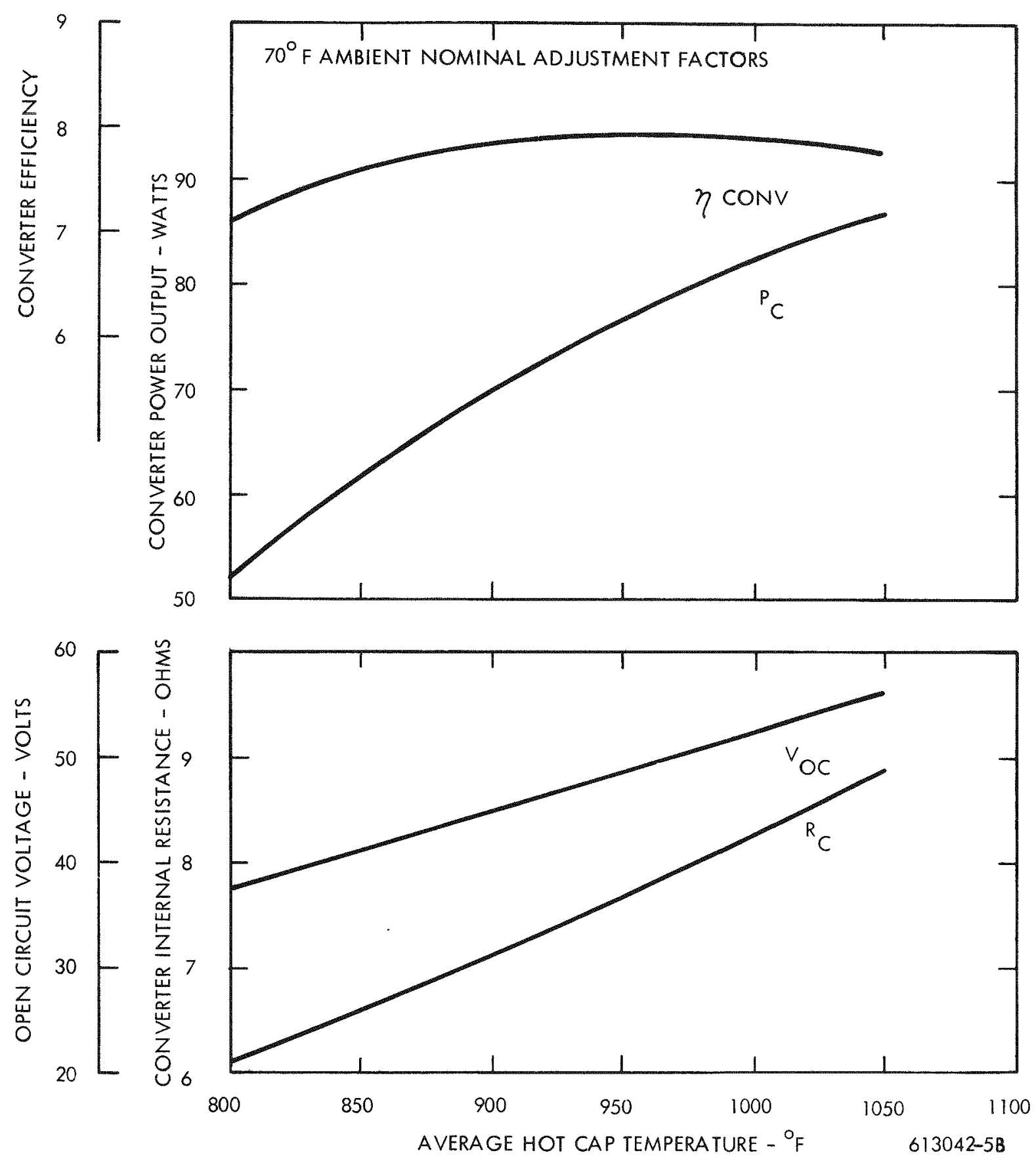

Figure 3-21. PMC-2 Converter Thermoelectric Performance in FPMS 
(2) Astronuclear

calculation.

The converter efficiency peaks at an intermediate point $\left(\sim 950^{\circ} \mathrm{F}\right.$ hot cap temperature) between the design EOL and BOL temperature, which is a result of the $3 \mathrm{M}$ design philosophy in adjusting the lengths of the thermoelectric hot and cold segments to maximize the efficiency at EOL without exceeding desirable temperature limits on cold segment materials and the 24-volt load restriction. A power output of 61 watts is achieved at a hot cap temperature of $843^{\circ} \mathrm{F}$ and a 7.6 percent conversion efficiency. An efficiency of 7.7 percent can be achieved at a temperature of $860^{\circ} \mathrm{F}$ with a corresponding power output of 64 watts. The design EOL case is at $852^{\circ} \mathrm{F}$ with a power output of 62.7 watts at an efficiency of 7.66 percent. The variations in predicted performance for this design condition are within calculational accuracy. For example, at the $852^{\circ} \mathrm{F}$ hot cap temperature under worst case conditions, the converter will produce 61.2 watts at a 7.5 percent efficiency, and under optimistic conditions it will produce 64. 1 watts at an efficiency of 7.85 percent (based on $3 M^{\prime}$ 's adjustment factors).

The resulting performance estimates as presented in Figures $3-21$ and $3-22$ provide a basis for analyzing the performance of the FPMS by mating this data with heat source performance data on a fixed heat input basis.

Subtask 390 - Capsule Design \& Development

During this reporting period, liaison activities with ORNL were continued. Two capsule hydrostatic tests were completed by ORNL. Tables 3-9 and 3-10 summarize the strain gage data obtained from these tests. Visual examination of the capsules shows no obvious effects from testing. Pre-test and post-test scribe line data were received from ORNL and reviewed. The post-test ultrasonic inspection of the capsules was also completed. These dat a verify the fact that both capsules successfully passed the tests.

WANL comments on the preliminary capsule specification were received and are being reviewed. 

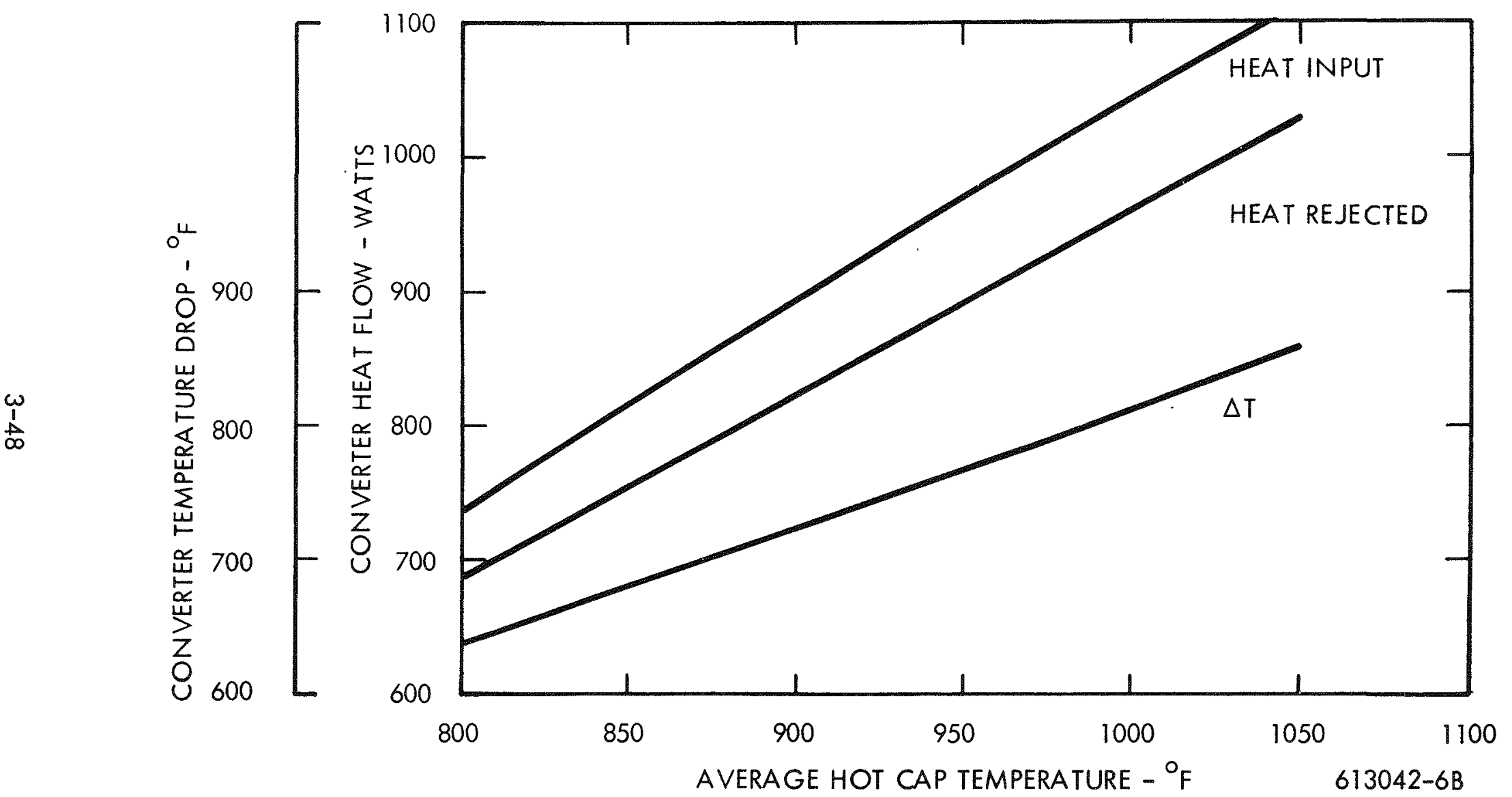

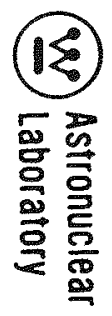

Figure 3-22. PMC-2 Converter Thermal Performance in FPMS 
TABLE 3-9

STRAIN GAGE DATA FOR SNAP-23A CAPSULE 23-4

\section{Pressure, psig}

0

1000

2000

3000

4000

5000

6000

7000

8000

9000

9200

10000

0

0

1000

5000

7000

9000

0

Strain, $\mu$ in./in.

Gage No. 1

0

$-0.001827$

$-0.002413$

$-0.002932$

$-0.003327$

$-0.003522$

$-0.003888$

$-0.004267$

$-0.005200$

$-0.007517$

$-0.007583$

$-0.007632$

$-0.004227$

0

$-0.000639$

$-0.002173$

$-0.002911$

$-0.003295$

$-0.000097$
Gage No. 2

0

$-0.000526$

$-0.000627$

$-0.000796$

$-0.000909$

$-0.000961$

$-0.000976$

$-0.000939$

$-0.000919$

$-0.000860$

$-0.000858$

$-0.000866$

$-0.000606$

0

$-0.000126$

$-0.000160$

$-0.000174$

$-0.000208$

$-0.000120$
Gage No. 3

0

$-0.001187$

$-0.001739$

$-0.002502$

$-0.002762$

$-0.003033$

$-0.003366$

$-0.003567$

$-0.004334$

$-0.004616$

$-0.004626$

$-0.005058$

$-0.001159$

0

$-0.000741$

$-0.002259$

$-0.003075$

$-0.003679$

$-0.000144$ 


\section{(2) Astronuclear}

TABLE 3-10

STRAIN GAGE DATA FOR SNAP-23A CAPSULE 23-6

Pressure,

psig

0

1000

2000

3000

4000

5000

6000

7000

8000

9000

9200

0

0

1000

3000

5000

7000

9000

0
Gage No. 1

0

$-0.000993$

$-0.001739$

$-0.001755$

$-0.002336$

$-0.002802$

$-0.003514$

$-0.004733$

$-0.006182$

$-0.008930$

$-0.009430$

$-0.006490$

0

$-0.001050$

$-0.001794$

$-0.002572$

$-0.003307$

$-0.004179$

$-0.000552$ $\frac{\text { Strain, } \mu \text { in./in. }}{\text { Gage No. } 2}$

Gage No. 3

0

$-0.000064$

$+0.000233$

$+0.000184$

$+0.000039$

$-0.000035$

$-0.000274$

$-0.000383$

$-0.000533$

$-0.000681$

$-0.000923$

$+0.000970$

$+0.000500$

0

$-0.000358$

$-0.000733$

$-0.001136$

$-0.001480$

$-0.001796$

$-0.000325$ 


\section{MATERIALS AND COMPONENT TESTING}

Subtask 410 - Materials Engineering and Testing

The activities of the Materials Department during this reporting period were as follows:

1) Materials selections and appropriate specifications and welding procedures were supplied to aid in the design of the shipping container.

2) The environmental limits for a nylon stuffing gland (converter power cable) were investigated and recommendations against the use of nylon were made.

3) A review of the corrosion test progress, including the thermal grease evaluation, was held with the AEC at WANL.

4) A review of the EMS Failure Report was held at RDT. The AEC recommendations submitted are being incorporated into the final report.

5) Methods for specifying minimum materials properties for design purposes were reviewed. It was agreed that the 80 percent minimums as published in the NERVA Materials Manual were sufficient to ensure that $99+$ percent of all possible materials property data points would be greater than the minimums.

6) Procedures were established for closure welding, inspecting, and leak testing the heat source assembly.

7) The designs of the radiator, rain shield insulation, and seal were reviewed in detail.

8) The detailed experimental approach was established for the Fusible Insulation Program.

9) The designs of the various FPMS components were reviewed in detail as the drawings became available.

Spherical Insulation Testing

Min-K-2002. Life testing of Min-K-2002 is continuing. A total time of 194 days (4656 hours) has accumulated on this test up to and including August 31, 1969. There has been no observable degradation in the properties of $\mathrm{Min}-\mathrm{K}-2002$ during this period. 
Min-K-2000. This test was concluded on August 15, 1969. The Min-K-2000 test accumulated 242 days ( 5808 hours) of testing time before shutdown. The test was discontinued primarily because of the lack of degradation or trend toward degradation in thermal characteristics. It is apparent under the conditions of this experiment, in which the source temperature, temperature gradient, insulation thickness, and system atmosphere closely approximated those of the EMS base assembly, that Min-K-2000 is stable for extended periods of time (refer to Subtask 340).

\section{Thermal Grease Testing}

Thermal grease solubility tests were completed at room temperature and at $140^{\circ} \mathrm{F}$. One remaining test is planned at $200^{\circ} \mathrm{F}$.

The experimental procedure for the tests is as follows:

Samples of Inconel 625 and unanodized 6061-T6 aluminum were covered with GE-64 I high thermal conductivity silicone grease by masking the metal surface, spreading the grease, and removing the mask. (A set of coated samples is shown in Figure 4-1.) The masking served two purposes: 1) It enabled the application of a uniform grease layer, and 2) it located the grease on the sample in such a way as to eliminate the possibility of losing grease while handling or positioning the sample in the aqueous media. Each sample was then placed in a beaker in the appropriate aqueous solution. The beakers for the $140^{\circ} \mathrm{F}$ test were immersed in a constant temperature oil bath to maintain the required temperature for the duration of the test.

The stirred samples were held in a plexiglass and pyrex jig to prevent movement due to the action of the water. The sample jigs were then secured in a beaker and stirring was accomplished by stirrers driving glass stirring rods. The unstirred samples were placed on $3 / 16$ inch diameter pyrex rods on the bottom of beakers with the greased surface facing upward. For all the experiments the only metallic component in the solution was the metal substrate on which the grease was applied. This eliminated the possibility of any galvanic corrosion or the formation of corrosion products. Sample weight losses were measured by removing the samples from the aqueous solution, drying the specimens with heated air, and then weighing.

\section{Room Temperature Test Results}

Table 4- 1 specifies the exposure of each sample shown in Figure 4-1. The samples were weighted after exposure times of $125,261,336,594,669$, and finally 1119 hours. Fresh 
(W) Astronuclear
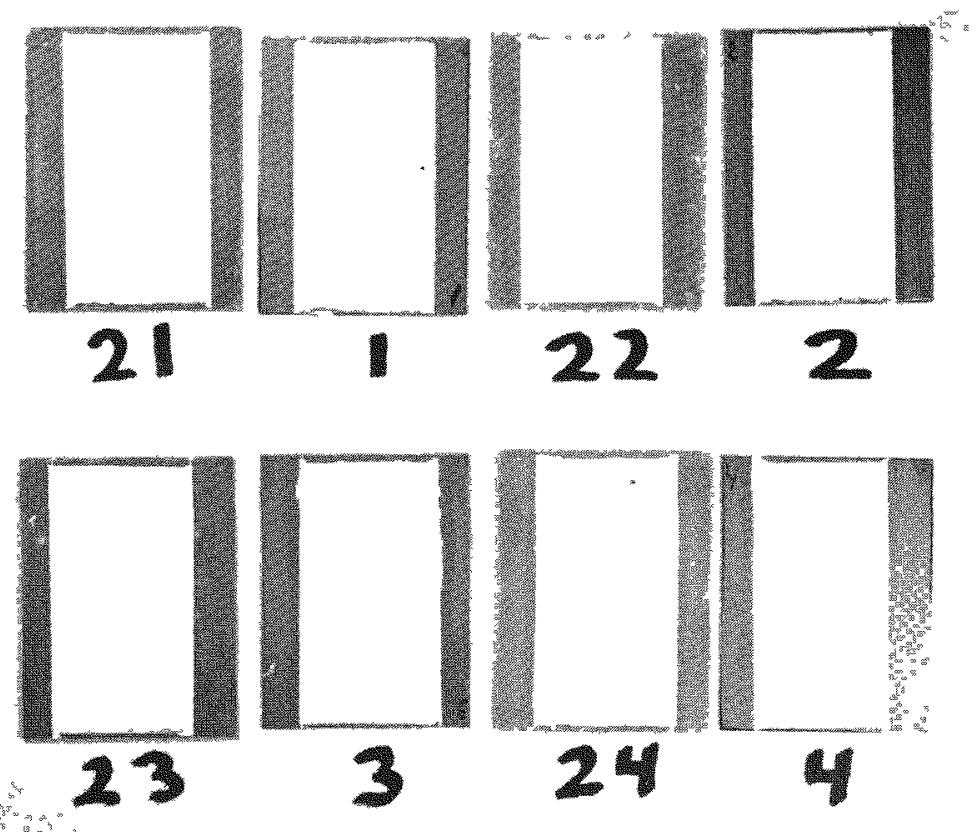

Figure 4-1. Samples of Aluminum 6061 and Inconel 625 Coated With GE 641 Silicone Thermal Conducting Grease After Exposure in Fresh and Syntheric Sea Water for 1119 Hours. Samples 1, 2, 3, and 4 are Inconel 625; Samples 21, 22, 23, and 24 are 6061-T6 Aluminum. 
TABLE 4-1

RESULTS OF ROOM TEMPERATURE THERMAL GREASE SOLUBILITY EVALUATION

\begin{tabular}{ccccccc}
$\begin{array}{c}\text { Sample } \\
\text { Number }\end{array}$ & Material & \multicolumn{2}{c}{$\begin{array}{c}\text { Exposure } \\
\text { Sea Water }\end{array}$} & $\begin{array}{c}\text { Grease } \\
\text { Fresh Water }\end{array}$ & $\begin{array}{c}\text { Weight Loss } \\
\text { Weight Lost }\end{array}$ & $\begin{array}{c}\text { Weight Change } \\
\text { of Metal }\end{array}$ \\
\hline 1 & \multirow{2}{*}{ Inconnel 625} & & Stirred & 0.141 & 0.0020 & -0.0038 \\
2 & & Stirred & & 0.98 & 0.0118 & +0.0014 \\
3 & & & Unstirred & 0.564 & 0.0082 & +0.0012 \\
4 & & Unstirred & & 0.060 & 0.0084 & +0.0010 \\
21 & $6061-T 6 A 1$ & & Stirred & 0.58 & 0.0056 & +0.0001 \\
22 & & Stirred & & 2.65 & 0.0349 & -0.0080 \\
23 & & & Unstirred & 0.496 & 0.0046 & +0.0025 \\
24 & & & & 0.113 & 0.0010 & +0.0015
\end{tabular}


solutions were used after the 336 hour weighing. This did not, however, affect the rate of weight change with time. After the 1119 hour exposure, the weight of grease removed from the sample and the weight of the metal sample were compared to the initial weights of the respective components at the beginning of the test. These weight changes are listed in Table 4-1.

The experiments show that, except for the stirred sea water $/ 6061 /$ sample, the weight loss was less than 1 percent of the total amount of grease present. On both the 6061 aluminum and the Inconel 625 substrates, the greatest weight loss was found in the stirred sea water environment. In addition, the rate of weight loss decreased significantly as a function of time. In most cases 25 to 40 percent of the grease weight loss occurred during the first 125 hours of a 1119 hour exposure. Although the weight loss as a function of time did indicate that the greatest weight loss occurred during the first 125 hours of exposure, the weight changes reported are gross weight changes, i.e., the weight change of the grease and the weight change of the metal.

Some corrosion of the metal was noted and is visible in Figure 4-2 (A and B). Pits are apparent on the aluminum samples, but only slight staining was noted on the Inconel 625 samples. It is readily apparent that the area covered by the grease was profected from corrosion and staining in the aqueous environment.

Several observations during the experiment were made. No attempt has been made, as yet, to explain these observations.

1) Samples 1 and 3 , Inconel 625 in fresh water, exhibited a yellowish coloring on the GE-64l grease.

2) Precipitates in the solutions were observed in both the unstirred fresh water and unstirred synthetic sea water with aluminum substrates.

\section{$140^{\circ} \mathrm{F}$ Test Results}

Table 4-2 indicates the weight changes of the metal substrate and the G-641 grease. The samples were weighed after 140, 281, 460, and finally after 920 hours of exposure. The solutions were replaced after 460 hours of exposure. As in the room temperature tests, the grease was removed after the 920 hours of exposure to determine the weight changes of the 
W Astronuclear

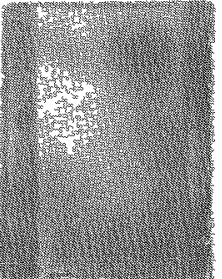

21

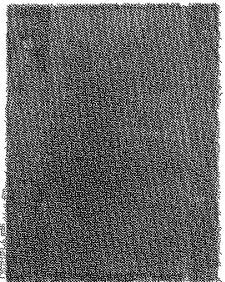

23

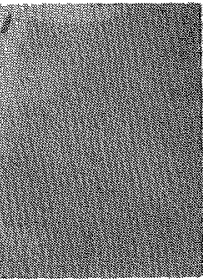

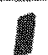

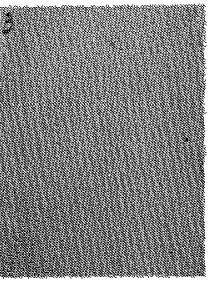

3

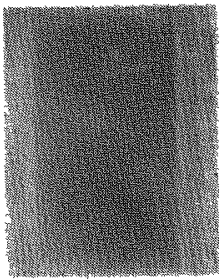

22

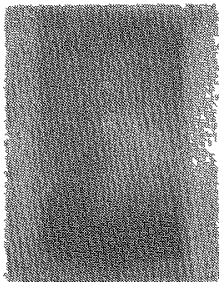

24

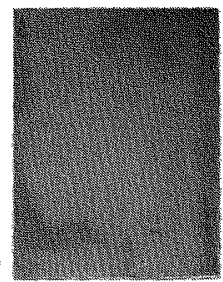

2

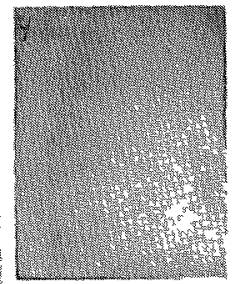

4

A) SURFACE OF METAL SAMPLES WITH GREASE REMOVED

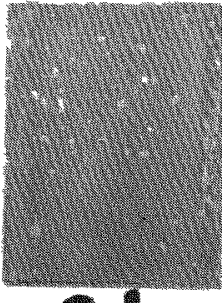

21

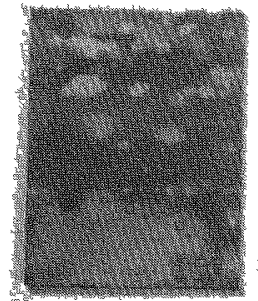

23

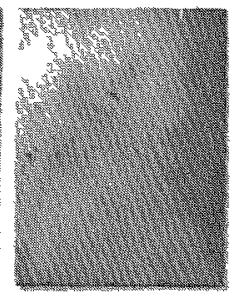

I

22
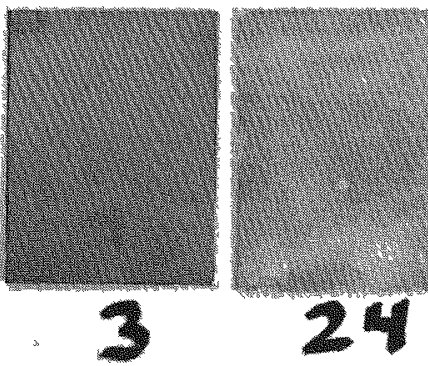

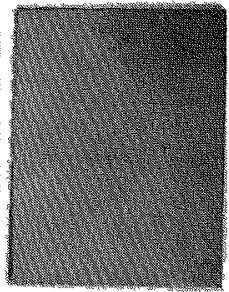

2
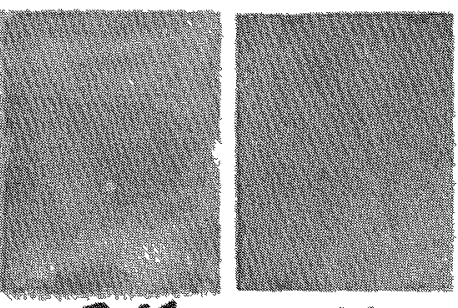

4

B) REAR OF METAL SAMPLES

Figure 4-2. Effect of Exposure on the Surface of the 6061 Aluminum (Samples 21 Through 24) and the Inconel 625 (Samples 1 through 4) as a Result of the 1119 Hour Exposure to Room Temperature Fresh and Synthetic Sea Water. 
TABLE 4-2

RESULTS OF $140^{\circ} \mathrm{F}$ THERMAL GREASE SOLUBILITY EVALUATION

\begin{tabular}{|c|c|c|c|c|c|c|}
\hline $\begin{array}{l}\text { Sample } \\
\text { Number }\end{array}$ & Material & $\begin{array}{r}\text { Expo } \\
\text { Sea Water } \\
\end{array}$ & $\begin{array}{l}\text { sure } \\
\text { Fresh Water }\end{array}$ & $\begin{array}{c}\% \text { Grease } \\
\text { Weight Change } \\
\end{array}$ & $\begin{array}{l}\text { Grease } \\
\text { Weight } \\
\text { Change } \\
\text { (grams) } \\
\end{array}$ & $\begin{array}{c}\text { Weight Change } \\
\text { of Metal } \\
\text { (grams) } \\
\end{array}$ \\
\hline 5 & Inconel & & Unstirred & -2.20 & -.0218 & -.0005 \\
\hline 6 & 625 & Unstirred & & -1.97 & -.0207 & -.0005 \\
\hline 7 & & & Stirred & +0.71 & +.0068 & -.0009 \\
\hline 8 & & Stirred & & -2.72 & -.0212 & -.0004 \\
\hline 25 & $6061-$ T6 & & Unstirred & -0.27 & -.0036 & -.0102 \\
\hline 26 & Aluminium & Unstirred & & +0.71 & +.0073 & -.0105 \\
\hline 27 & & & Stirred & No change & No change & -.0048 \\
\hline 28 & & Unstirred & & +5.46 & +.0521 & -.0083 \\
\hline
\end{tabular}


metal substrate. Unlike the room temperature tests where all but two of the metal pieces gained weight, all of the metal samples lost weight at $140^{\circ} \mathrm{F}$. The weight losses for the aluminum were much greater than those for the Inconel 625.

The grease tested on the Inconel surface appeared to lose about 2 percent of its weight except for sample 7 which appeared to gain weight. All of this weight gain occurred between the 446 hour weighing and the final weighing. Prior to this the sample had lost weight at each preceding weighing as did the other three Inconel samples. The grease surface on sample 7 also exhibited a much harder crust than that on the other samples.

The grease on the aluminum sample showed a very anomalous behavior since there seems to be no correlation between the exposure variables and measured grease weight loss. It appears that the aluminum/grease/heated water system produces some kind of interaction other than the simple solubility of the grease. Although the grease weight changes were erratic, the aluminum itself lost weight as the result of its exposure. For purposes of comparing the solubility of the grease as a function of temperature, direct comparison of the room temperature and $140^{\circ} \mathrm{F}$ tests on the Inconel surface indicates that increasing the temperature results in about a 1.5 to 2.0 percent increase in grease solubility. Direct comparison of the grease on the aluminum surface is difficult because of the complication of interactions with the aluminum.

All of the grease surfaces appeared dry after removal at 920 hours, although the grease just under the surface was tacky and more viscous than the fresh grease. As in the room temperature tests, yellowing of the grease on the Inconel surfaces was noted. Figure 4-3 shows the greased surface of the metal substrate with the grease removed.

Figure 4-4 shows how the grease "bleeds" after several hundred hours when placed on a clean metal substrate. Evidently, the silicone oil vehicle is being drawn from the mixture as a result of surface diffusion force on the metal surface. It should be noted that the exposure in the experimental setup, exposure of the entire greased surface, is much more severe than that which would be encountered in actual service where only the edge of the interface between the aluminum and Inconel would be exposed. 

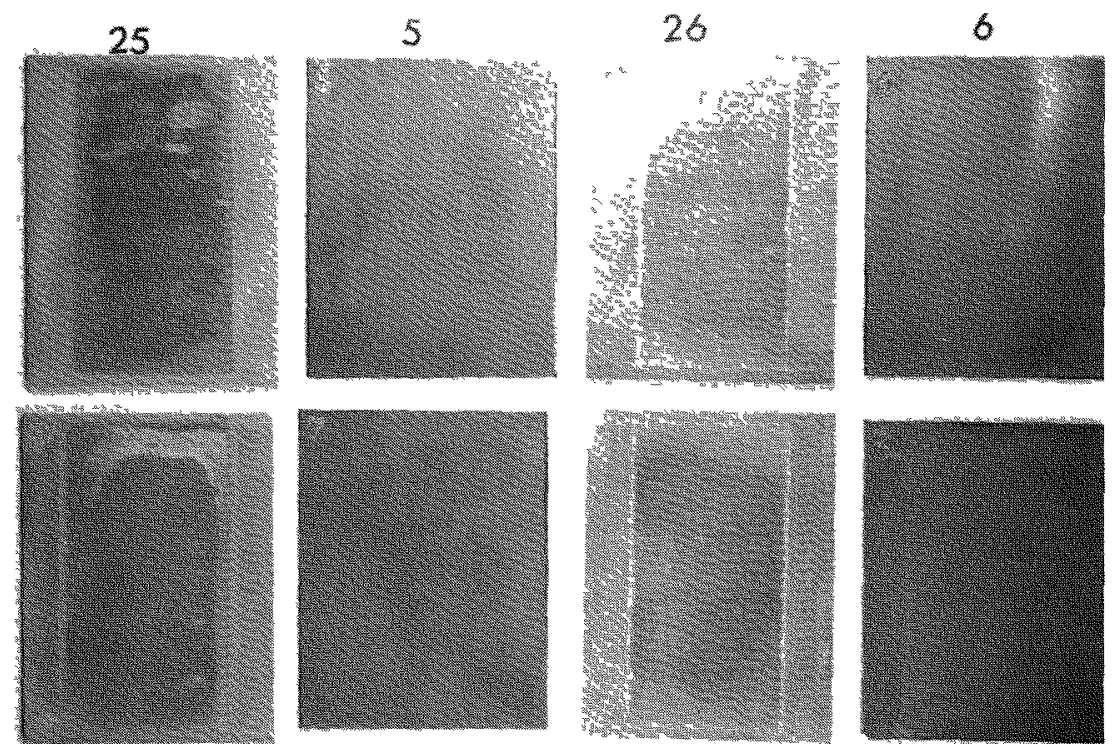

27

28

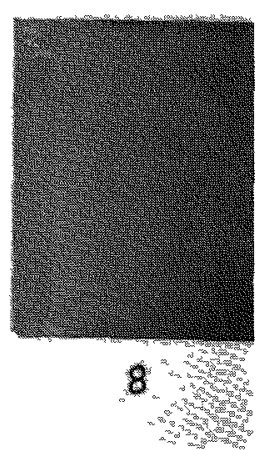

Figure 4-3. Metal Samples With Grease Removed Showing Effect of 920 Hour Exposure at $140^{\circ} \mathrm{F}$. Aluminum Samples (25 through 28). Inconel 625 Samples (5 through 8).

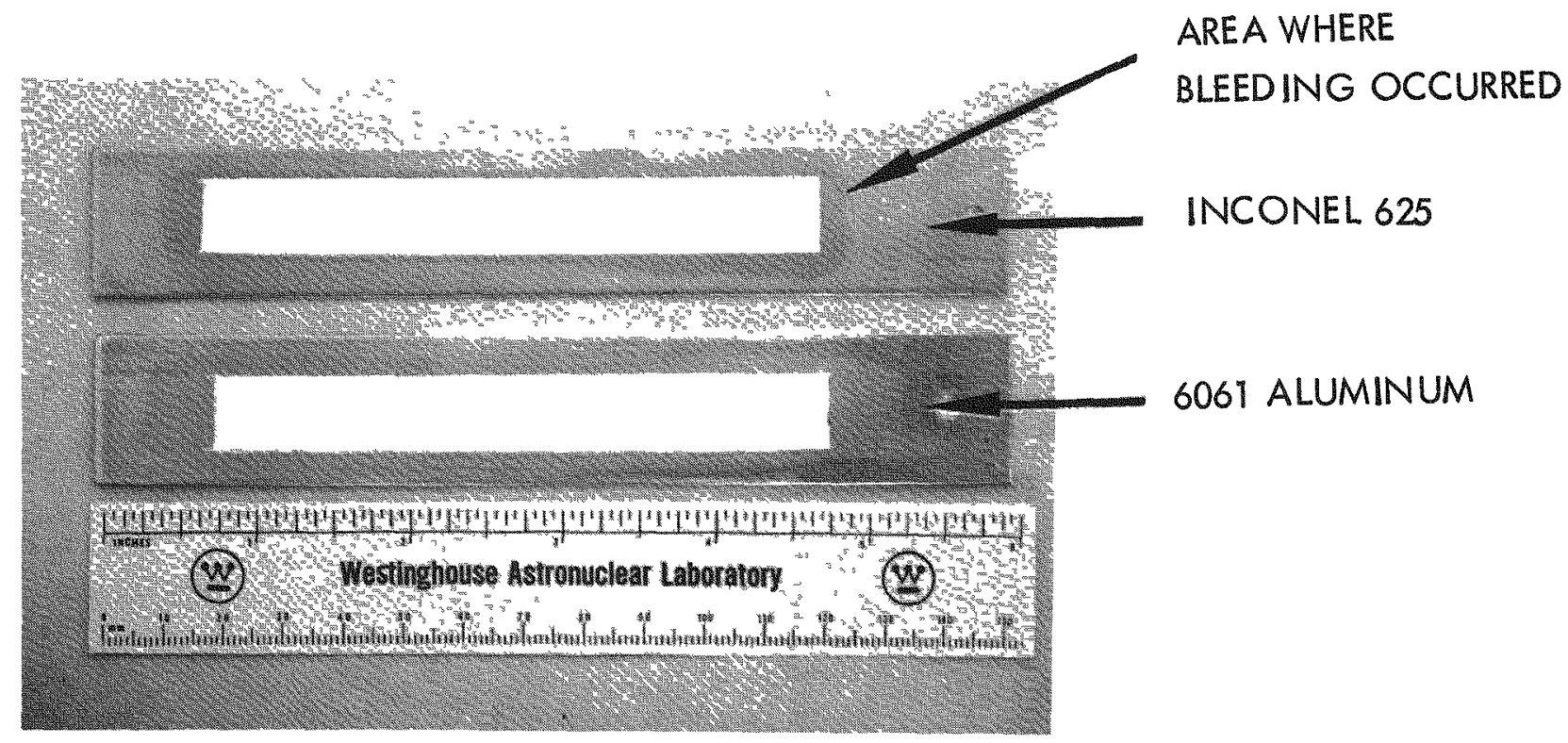

Figure 4-4. "Bleeding" of Thermal Grease When Applied to an Inconel 625 and 6061 Aluminum Surface. 


\section{U-8Mo Impact Test Results}

Tensile test results indicated that the tensile ductility of U-8Mo in the $\gamma^{\prime}+a$ condition in the temperature range of 500 to $900^{\circ} \mathrm{F}$ is very low. * These results also indicate that the material is very brittle and would not be able to withstand any significant impact stresses without fracturing. Because of the stringent safety requirements of radioisotope power systems, and the associated precautions which must be taken to ensure safe transportation, it is.necessary to know if the U-8Mo shield can withstand impact stresses in this temperature range without failure.

In order to evaluate the behavior of U-8Mo under high strain rate loading, notched and unnotched charpy impact tests were made over the temperature range of 500 to $900^{\circ} \mathrm{F}$. A series of test specimens were machined from as-cast U-8Mo rods, $3 / 4$ inch in diameter and 12 inches long. Five notched specimens and five unnotched specimens were machined to the dimensions described in ASTM Standard Methods for "Notched Bar Impact Testing of Metallic Material, "Designation E23-66, for a Type A charpy (simple-beam) impact test specimen. The impact test specimens were cleaned with eythl alcohol after machining and individually encapsulated in $V y c o r$ tubes filled with $1 / 3$ atmosphere of pure argon. These encapsulated specimens were then heat treated by holding them for 96 hours at $900^{\circ} \mathrm{F}$ to ensure transformation to the $\gamma^{\prime}+$ a condition.

The impact test temperatures were attained by heating the test piece for 10 to 20 seconds in an infrared radiant heating chamber to a temperature somewhat above the test temperature and then soaking for 30 seconds at this temperature. At this time the specimens were transferred to the charpy testing apparatus and the striker was released as the specimen temperature reached the desired test temperature. Table 4-3 presents the results of the impact tests in tabular form. A plot of energy absorbed versus temperature is presented in Figure 4-5. Analysis of the results of the impact tests indicate the following:

1) U-8Mo is notch sensitive.

2) Above $600^{\circ} \mathrm{F}$ the material in the $\gamma^{\prime}+\alpha$ condition can be considered to be fairly ductile.

*WANL-3800-9, SNAP-23A Quarterly Progress Report, December 1967 
(W) Astronuclear

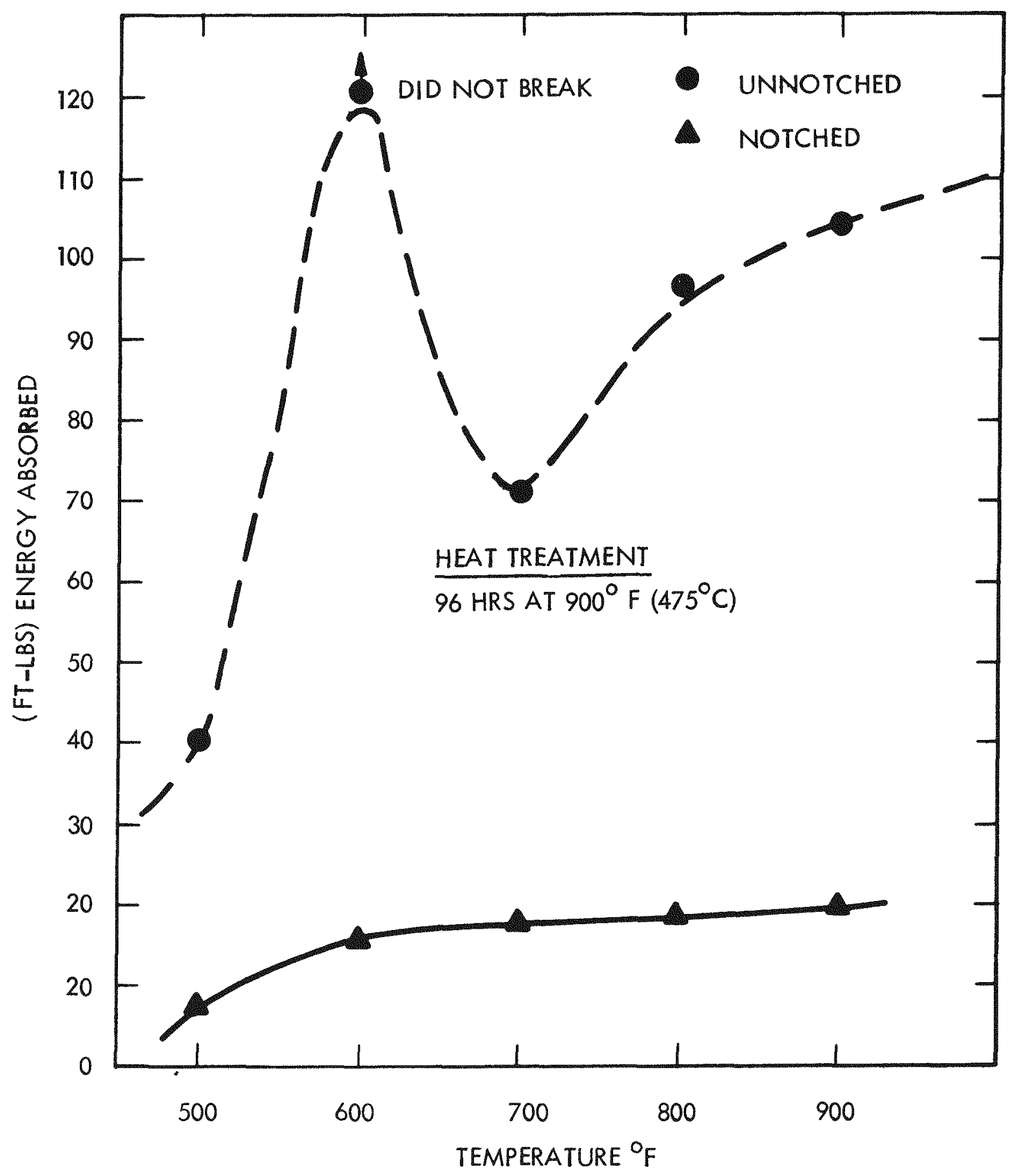

$613040-2 B$

Figure 4-5. Charay-Impact Test Results on U-8Mo. 
Astronuclear
Laboratory

TABLE 4-3

IMPACT TEST RESULTS FOR U-8Mo

\begin{tabular}{ccc} 
Temperature & & \multicolumn{2}{c}{ Energy Absorbed (Ft-Lbs) } & \\
${\left.^{\circ} \mathrm{F}\right)} }$ & Notched & Unnotched \\
\hline 500 & 7.5 & 40.0 \\
600 & 16.0 & $120.0^{*}$ \\
700 & 18.0 & 71.0 \\
800 & 18.5 & 96.5 \\
900 & 19.8 & 104.0 \\
\hline
\end{tabular}

*Sample did not fracture.

3) The U-8Mo in the $\gamma^{\prime}+\alpha$ condition is not as brittle as indicated by the tensile tests previously reported.

4) Although impact test results are not directly comparable to tensile test results, it appears that the brittle behavior is strain-rate sensitive.

Fusible Insulation Testing

The portion of the fusible insulation evaluation program conducted during this reporting period demonstrated that the insulation sinters quickly at elevated temperatures, a feature necessary for the successful application of a fusible insulation system. The rate of sintering at lower temperatures is also being evaluated. The mockup assembly layout drawing has been reviewed and the detail drawings necessary for fabrication are being prepared.

The sintering rate of the borosilicate E-type microfiber insulation is being evaluated in accordance with the following experimental procedure. Containers for the insulation were fabricated from 304 stainless steel sheet and spot welded together. These containers have a volume of 32.4 cubic inches and are nominally $3 \times 1.75 \times 6$ inches in size. Sufficient insulation (0.131 pound) to obtain a packed density of 7 pounds/cubic foot was cut from a 40-pound bale of insulation received from Johns-Manville. Figure 4-6 shows the stainless 
(W. Astronuclear

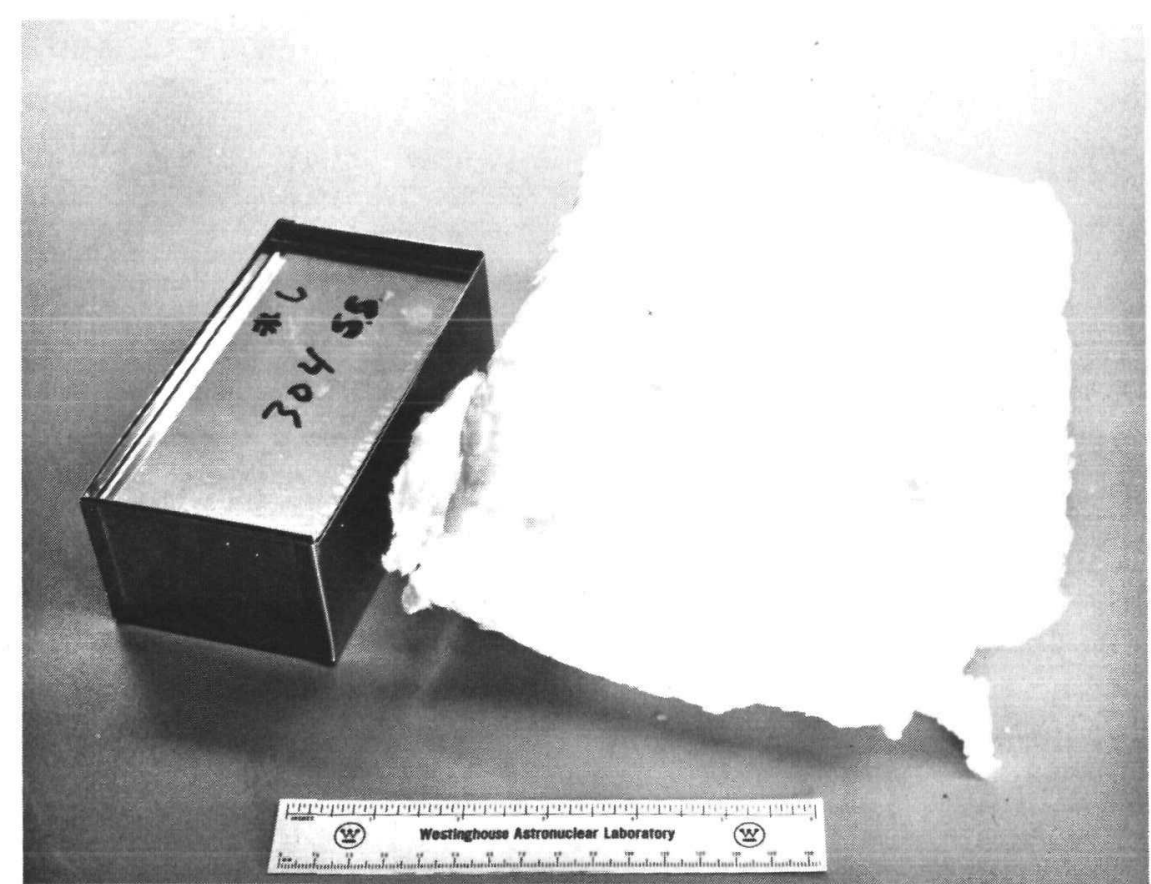

Figure 4-6. Original Size of As-Received Insulation Required to Attain an Insulation Density of $7 \mathrm{lb} / \mathrm{ft}^{3}$ Within the Volume of the Stainless Steel Box. 


\section{Q Astronuclear}

steel container and the bulk of as-received insulation required to obtain the desired density. The insulation was then carefully compacted in the containers and the lids were crimped on the containers so that they would not be opened by force due to the initial resiliency of the fresh packed insulation.

The filled boxes were then placed in furnaces for the times and at the temperatures indicated in Table 4-4. The volume listed is the volume of the insulation measured after the indicated exposure. The densities calculated from the initial weight of insulation are also presented. Figure 4-7 is a plot of the volume versus time at temperatures of 1200, 1250, 1350, and $1600^{\circ} \mathrm{F}$. At the temperatures below the melting point of the borosilicate glass, the insulation behavior can be characterized. An initial period of about 1 hour is required for the insulation to reach thermal equilibrium and lose the as-packed resiliency. After this period the shrinkage as a function of temperature begins, the rate and amount of shrinkage being a function of time and temperature.

At a temperature above the melting point the insulation coalesces to a glassy state and attains a density equal to that of borosilicate glass.

Figure 4-8 shows the sample heated for 168 hours at $1200^{\circ} \mathrm{F}$. Note that it pulled away from the walls. The wrinkled surface appearance and the non-uniformity of the sample are probably the result of non-uniform density caused by the necessity of extreme localized pressures exerted on the insulation during packing. These irregularities in density arise because the insulation must be forced into the box, a number of smaller pieces of insulation being necessary to fill the box uniformly. The localized pressures required to force the insulation into the box result in a non-uniform compaction since some fibers are crushed more than others.

Figures $4-9$ and $4-10$ show the results of heating at $1250^{\circ} \mathrm{F}$ for various times. The sample removed after 4 hours had the same appearance as sample 5, Figure 4-11. Figures 4-9 and 4-10 illustrate the progressive shrinkage as a function of time.

Figures 4-11 through 4-14 illustrate the progressive shrinkage of the insulation at $1350^{\circ} \mathrm{F}$ and also show the configuration of the insulation at $1,6,22$, and 85 hours, respectively. The bottom heavy shape probably results from gravitational forces tending to compress the insulation on the bottom of the container. 
(w) Astronuclear

Laboratory

TABLE $4-4$

\section{SINTERING EVALUATION EXPERIMENTAL CONDITIONS AND RESULTS}

\begin{tabular}{|c|c|c|c|c|c|}
\hline $\begin{array}{l}\text { Sample } \\
\text { Number }\end{array}$ & $\begin{array}{l}\text { Temperature } \\
\text { (OF) }\end{array}$ & $\begin{array}{l}\text { Accumulated } \\
\text { Time In } \\
\text { Furnace } \\
\end{array}$ & $\begin{array}{l}\text { Density } \\
\left(\mathrm{lbs} / \mathrm{ft}^{3}\right) \\
\end{array}$ & $\begin{array}{r}\text { Volume } \\
\text { (in.) }\end{array}$ & Comments \\
\hline 5 & $1350^{\circ}$ & $1 \mathrm{hr}$ & 7 & 32.4 & $\begin{array}{l}\text { Lost resiliency } \\
\text { but completely } \\
\text { filled box }\end{array}$ \\
\hline 5 & $1350^{\circ}$ & $6 \mathrm{hr}$ & 14.0 & 16.2 & \\
\hline 5 & $1350^{\circ}$ & $22 \mathrm{hr}$ & 26.9 & 8.4 & \\
\hline 5 & $1350^{\circ}$ & $85 \mathrm{hr}$ & 37.1 & 6.1 & \\
\hline 3 & $1600^{\circ}$ & $0.5 \mathrm{hr}$ & 185.5 & 1.22 & $\begin{array}{l}\text { Completely } \\
\text { Fused }\end{array}$ \\
\hline 7 & $1250^{\circ}$ & 4 & 7 & 32.4 & $\begin{array}{l}\text { Lost resiliency } \\
\text { but completely } \\
\text { filled box }\end{array}$ \\
\hline 7 & $1250^{\circ}$ & 67 & 7.38 & 30.7 & \\
\hline 7 & $1250^{\circ}$ & 235 & 7.70 & 29.4 & \\
\hline 1 & $1200^{\circ}$ & 168 & 7.43 & 30.5 & \\
\hline
\end{tabular}




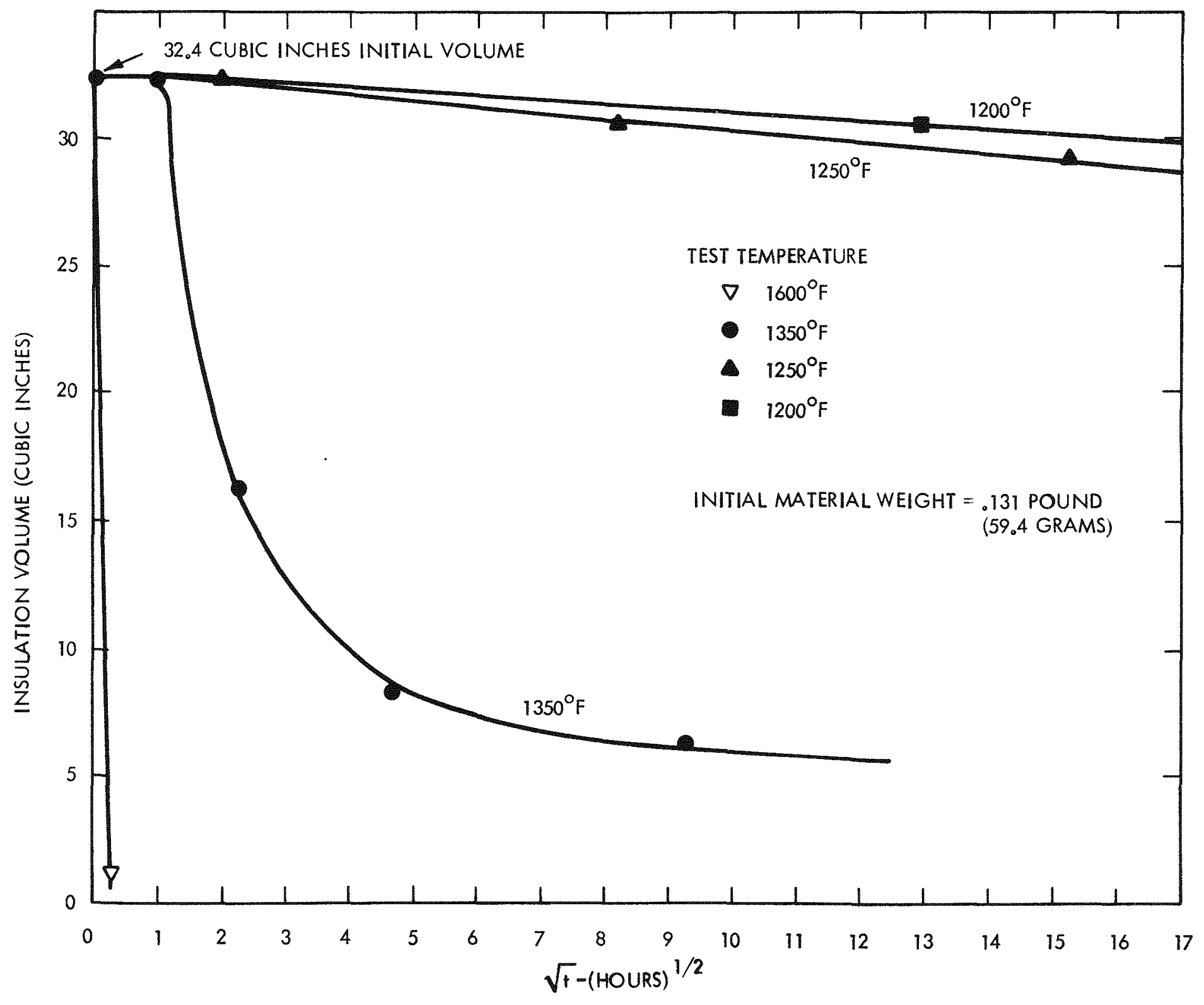

Figure 4-7. Effect of Time and Temperature on the Volume of a Constant Weight of E-Fiber Borosilicate Insulation. 

(W. Astronuclear
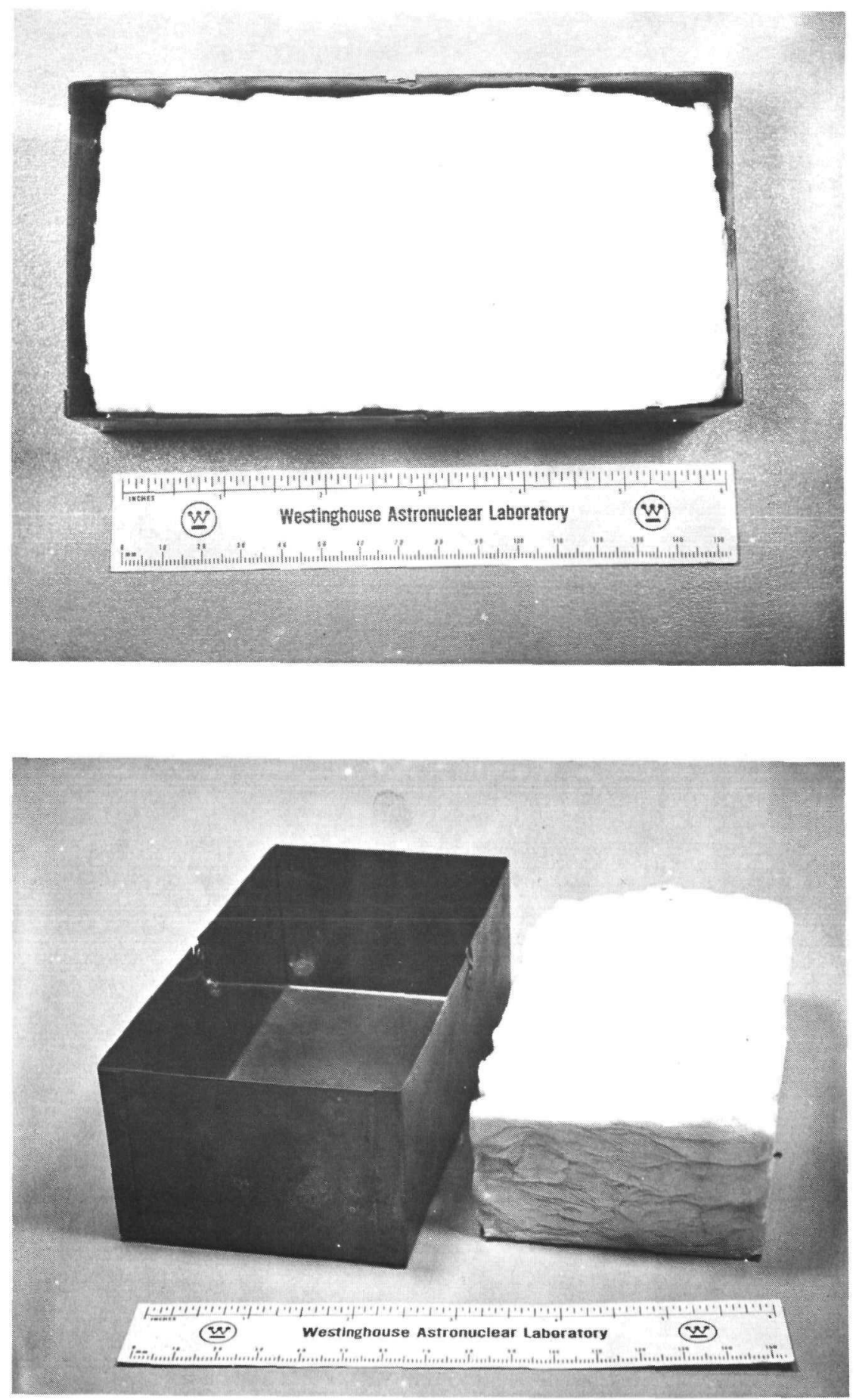

Figure 4-8. Sample No. 1, $1200^{\circ} \mathrm{F}$ for 168 Hours. 


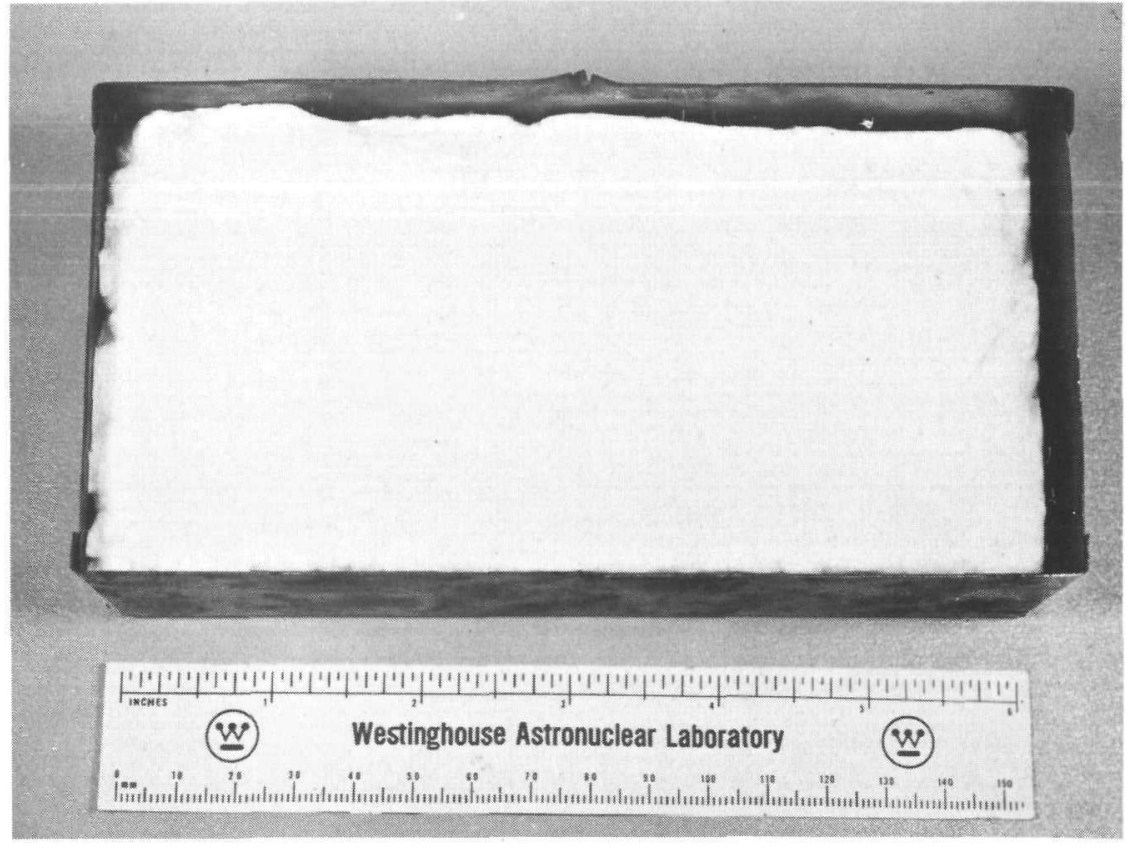

Figure 4-9. Sample No。7, 67 Hours at $1250^{\circ} \mathrm{F}$ 
W Astronuclear Laboratory
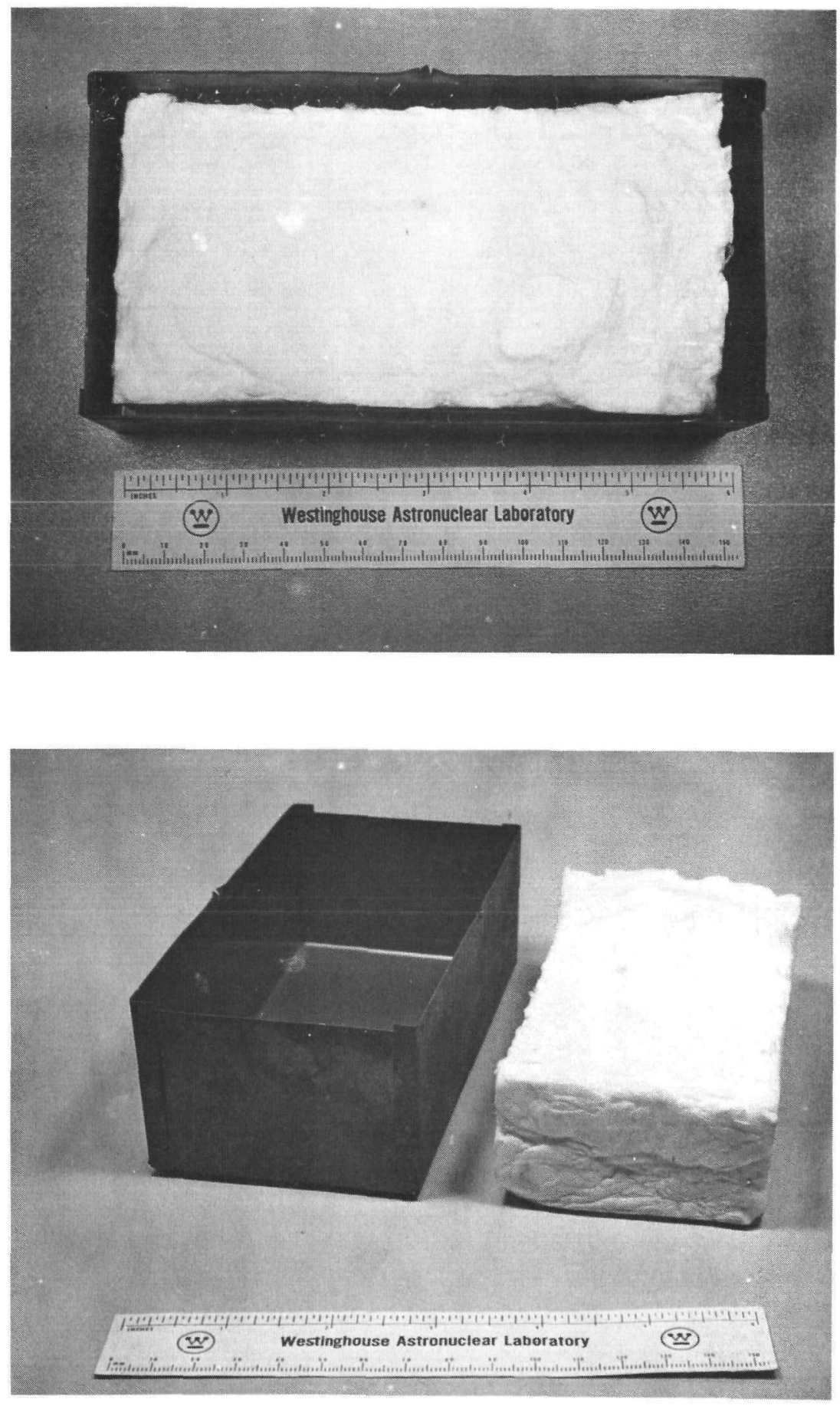

Figure 4-10. Sample No。7, 235 Hours at $1250^{\circ} \mathrm{F}$ 
W. Astronuclear

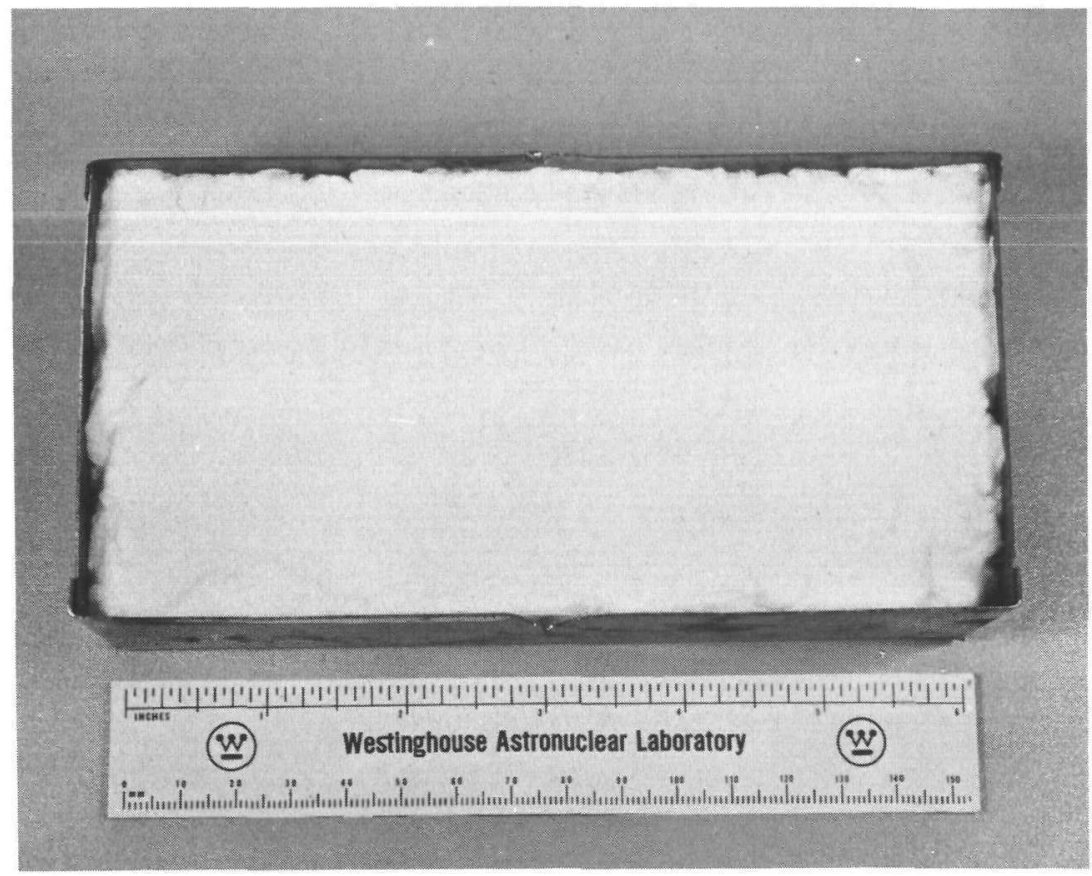

Figure 4-11. Sample No. 5, 1 Hour at $1350^{\circ} \mathrm{F}$ 

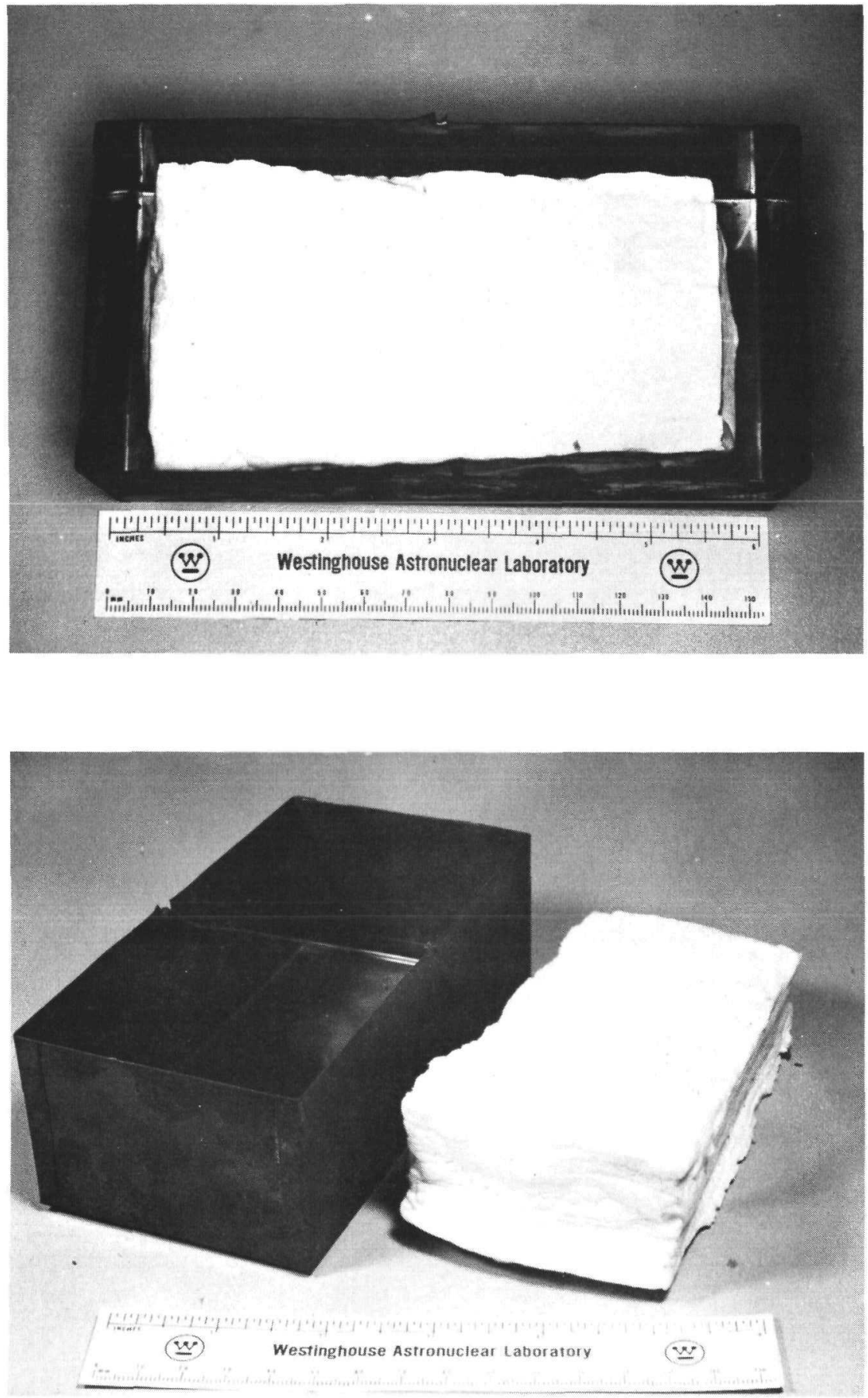

Figure 4- 12. Sample No. 5, $1350^{\circ} \mathrm{F}$ for 6 Hours 
(2) Astronuclear
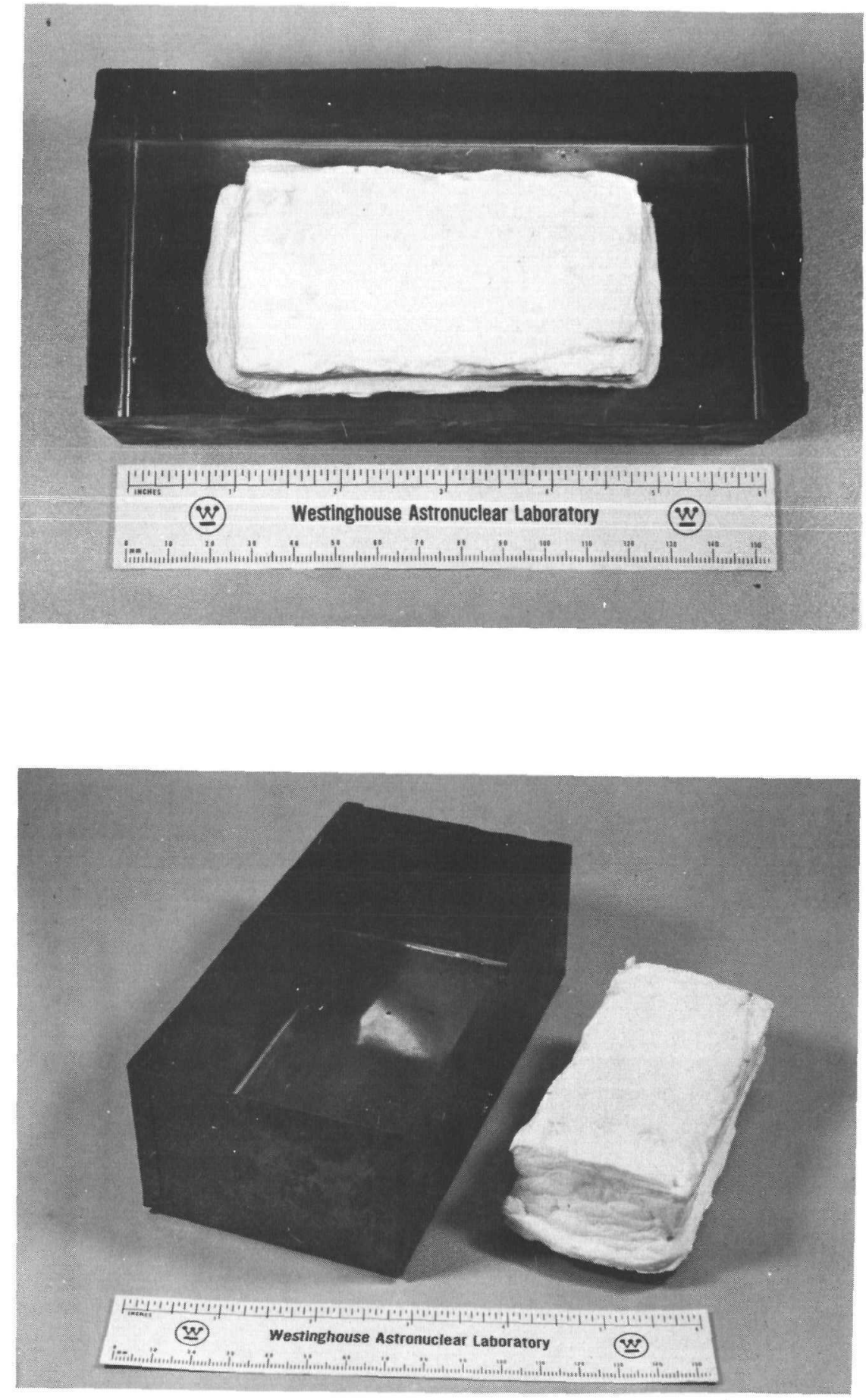

Figure 4-13. Sample No. $5,1350^{\circ} \mathrm{F}$ for 22 Hours 
W. Astronuclear
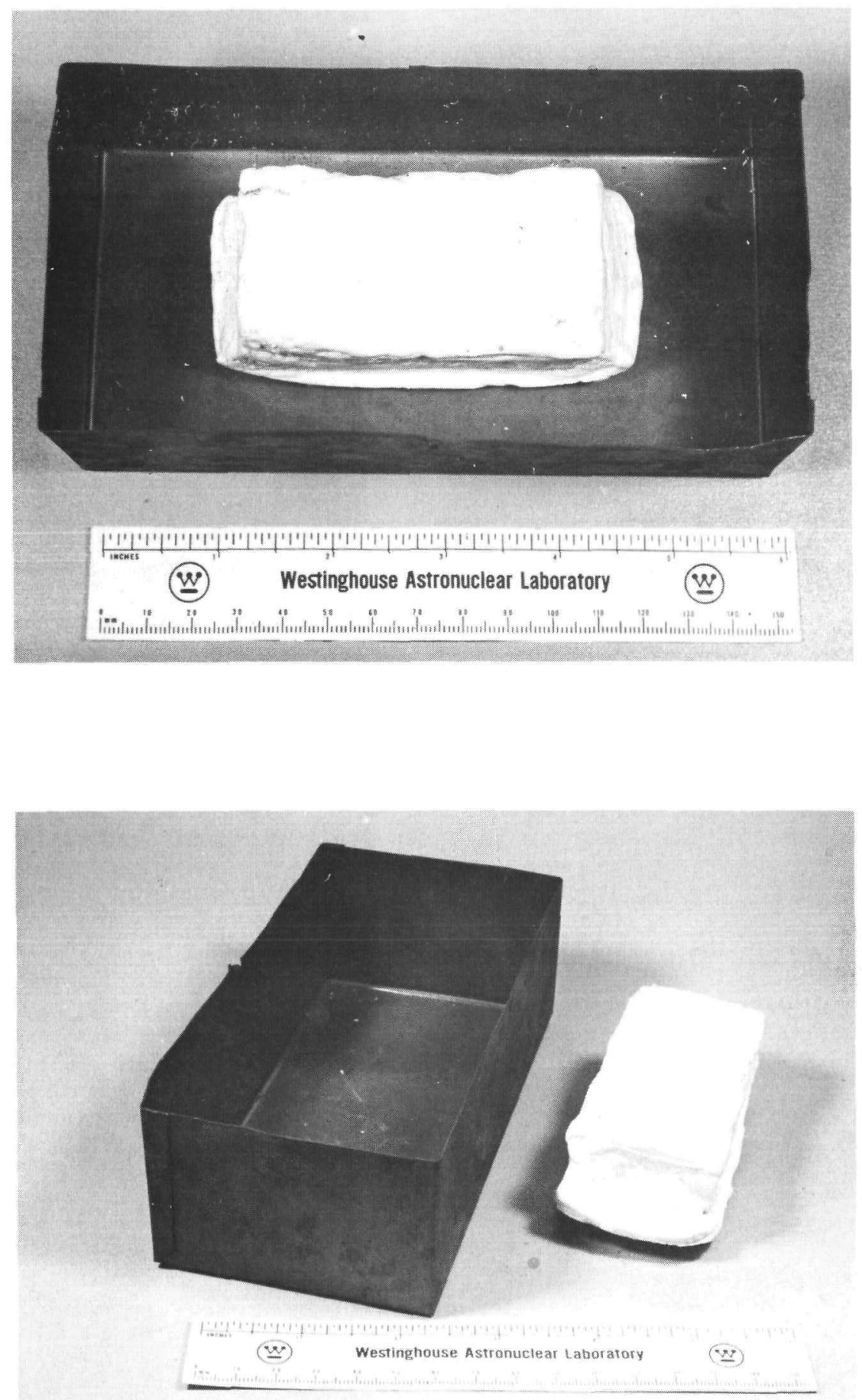

Figure 4-14。 Sample No。 5, 85 Hours at $1350^{\circ} \mathrm{F}$ 
Figure 4-15 shows the results of heating the sample for 30 minutes in a $1600^{\circ} \mathrm{F}$ furnace. Fused insulation adhered to the surfaces of the container because of the initial rapid heating of the container surface which melted the insulation in contact with it. As time increased, the bulk of the insulation began to coalesce and form the melted shape shown in the photograph, leaving the initial melted insulation adhering to the wall.

\section{Galvanic Corrosion Evaluation - Electrical Conductivity of Moist Salt Cake}

This series of tests was conducted to duplicate a marine environmental condition whereby continuous exposure to salt spray coupled with alternate evaporation of the moisture would leave a bulk deposit of moist salt bridging the gap between the aluminum radiator and the Inconel 625 outer case of the converter.

The salt cake was first formed between an unanodized Aluminum 6061-T6 strip and a strip of Inconel 625 by heating the metal with an air gun and filling the gap with a saturated solution of synthetic sea water. The heat caused the moisture to evaporate, leaving the salt residual bridging the gap between the Inconel 625 and the aluminum. The gap between the Inconel 625 and the aluminum was maintained by a glass microscope slide epoxied to the metals. Figure $4-16$ is a photograph of the salt cake experimental configuration. This procedure was duplicated and a salt cake was also formed between an anodized and sealed aluminum sample and Inconel 625 to demonstrate the reduction in corrosion rate afforded by the anodized aluminum.

Moisture was added to the salt cake by two methods: 1) drop by drop with an eye dropper, and 2) by exposing the heated sample to $150^{\circ} \mathrm{F}-200^{\circ} \mathrm{F}$ water vapor. The results are shown in Table 4-5.

The currents and voltages are steady-state values obtained after periods of about 1 hour. The current is an indicator of the rate of corrosion of the couple. The unanodized aluminum sample exhibited much larger corrosion current than the anodized and sealed sample, as anticipated. Visual examination of the surface of the plain aluminum indicated that corrosion of the bare aluminum occurred. Figure 4-17 shows the corroded surface exposed to the moist salt cake. Visual examination of the anodized sample revealed no holes or breaches in the 


\section{(W) Astronuclear}
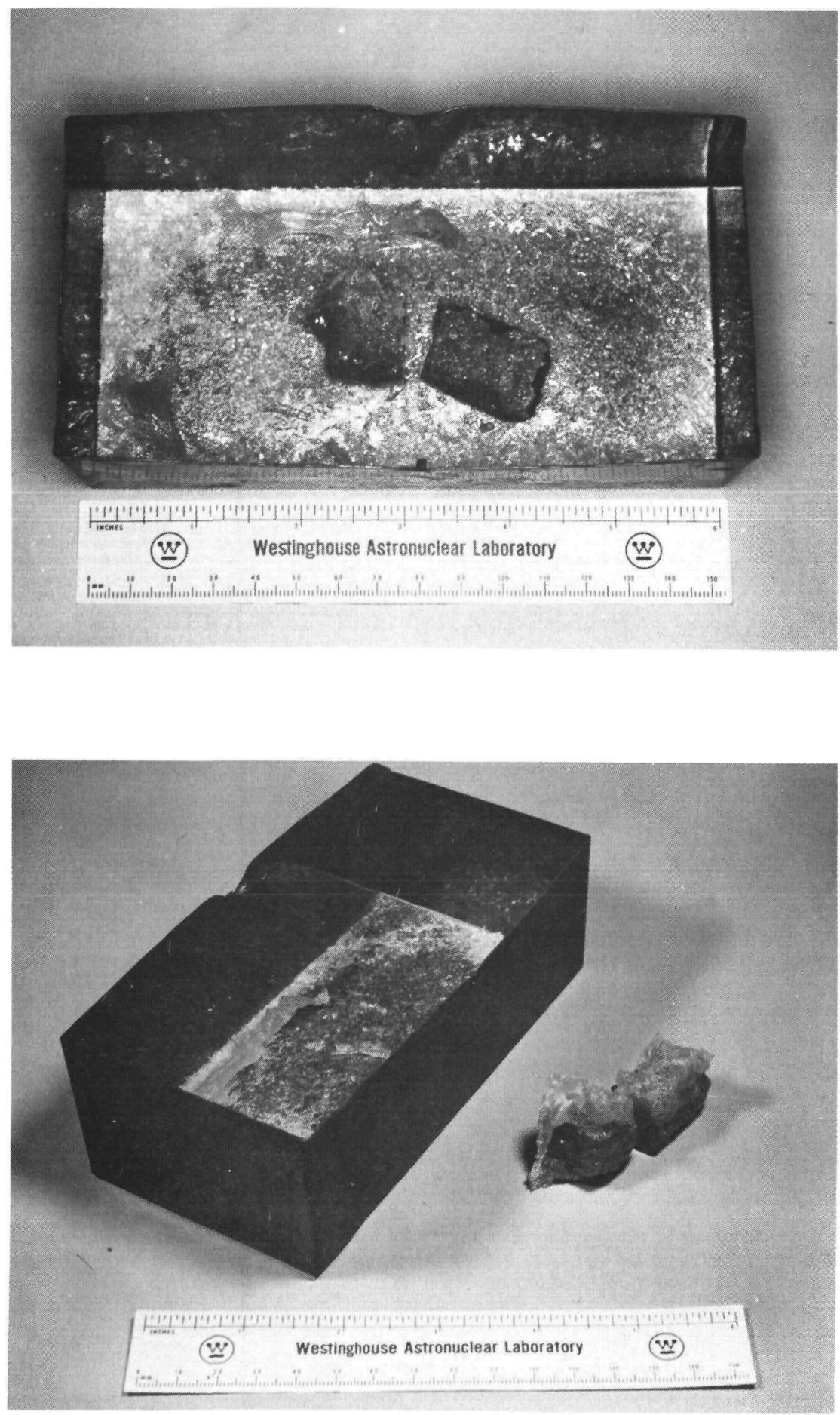

Figure 4-15. Sample No。3, 30 Minutes at $1600^{\circ} \mathrm{F}$ 
(2) Astronuclear

SALT CAKE

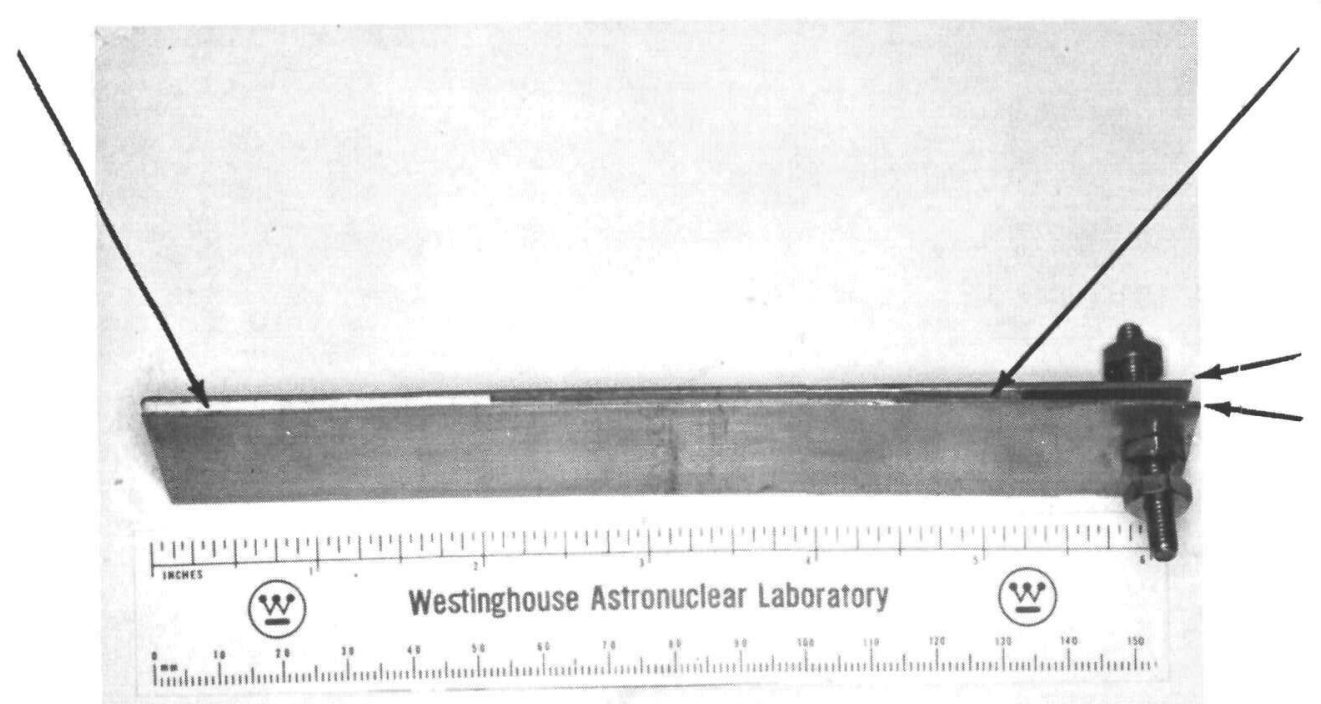

GLASS SLIDE

INCONEL 625

ALUMINUM $6061-76$

Figure 4-16. Configuration of Moist Salt Cake Test

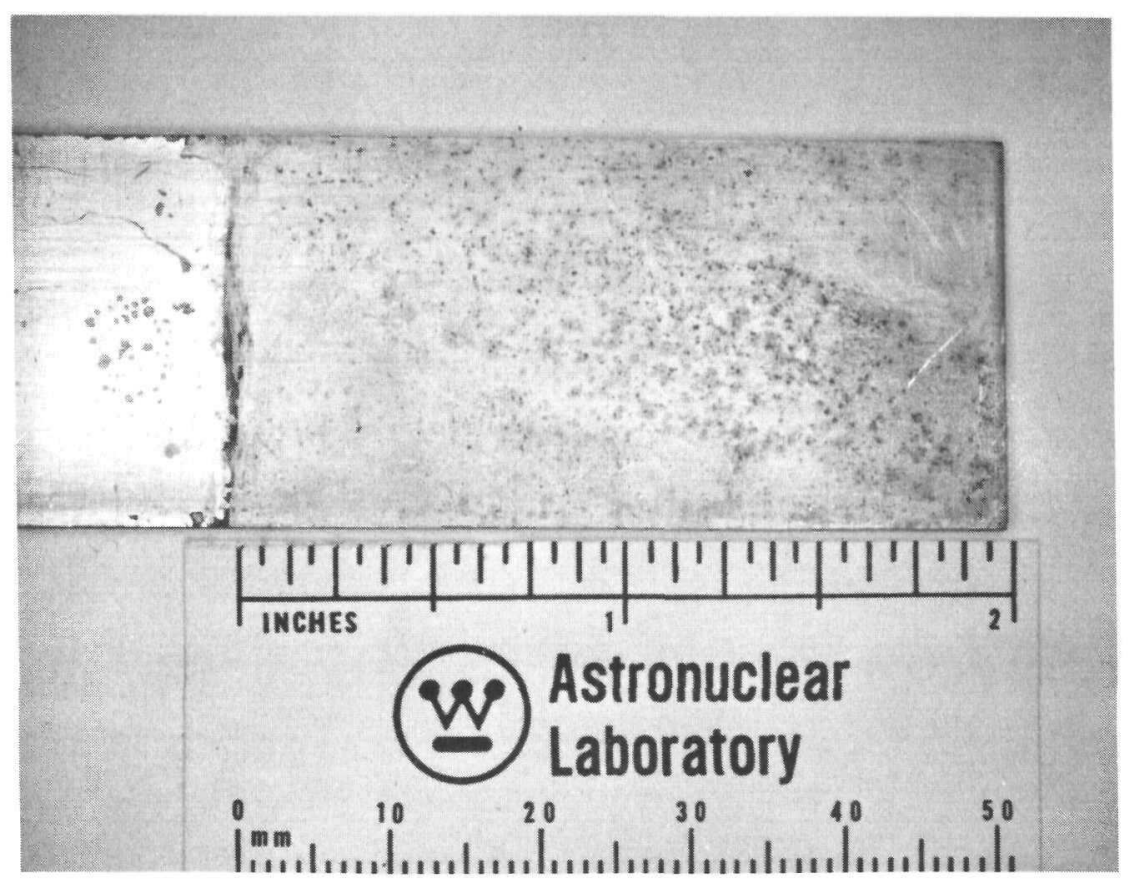

Figure 4-17. Surface of 6061-T6 Aluminum Exposed to Moist Salt Cake for Approximately 2 Hours at $150^{\circ} \mathrm{F}$ (Unanodized). 
TABLE 4-5

SALT CAKE CORROSION TEST RESULTS AT $150^{\circ} \mathrm{F}$

\begin{tabular}{|c|c|c|c|}
\hline Couple & Wt. $\mathrm{H}_{2} \mathrm{O}$ Added & Voltage* & Current* \\
\hline $\begin{array}{c}\text { Inconel Aluminum } \\
625 \quad 6061-16\end{array}$ & 0.0377 gram & 0.31 volt & $0.16 \mathrm{ma}$ \\
\hline Unanodized & $0.0313 \mathrm{gram}$ & 0.16 volt & $0.12 \mathrm{ma}$ \\
\hline Inconel Aluminum & $03680 \mathrm{aram}$ & 020 volt & $001 \mathrm{ma}$ \\
\hline
\end{tabular}

*Measurements were made using a Simpson 260 meter.

anodized coating. However, examination of the sample under a 60 power microscope showed areas of discoloration and dark spots on the edge of the sample. A dye penetrant test was made on the sample. The spots observed on the edges are visible in Figure 4-18. These areas are responsible for the 0.01 ma of corrosion current observed in the tests.

These tests indicated the following:

1) A moist salt cake is an effective electrolyte and can cause corrosion in a galvanically coupled system.

2) Anodization and sealing of the aluminum greatly inhibits corrosion current flow in the moist salt cake electrolyte and therefore greatly reduces the amount and extent of the aluminum galvanic corrosion.

3) Imperfections may still exist in the anodized coatings; nevertheless the corrosion rate is considered decreased. 
Q Astronuclear

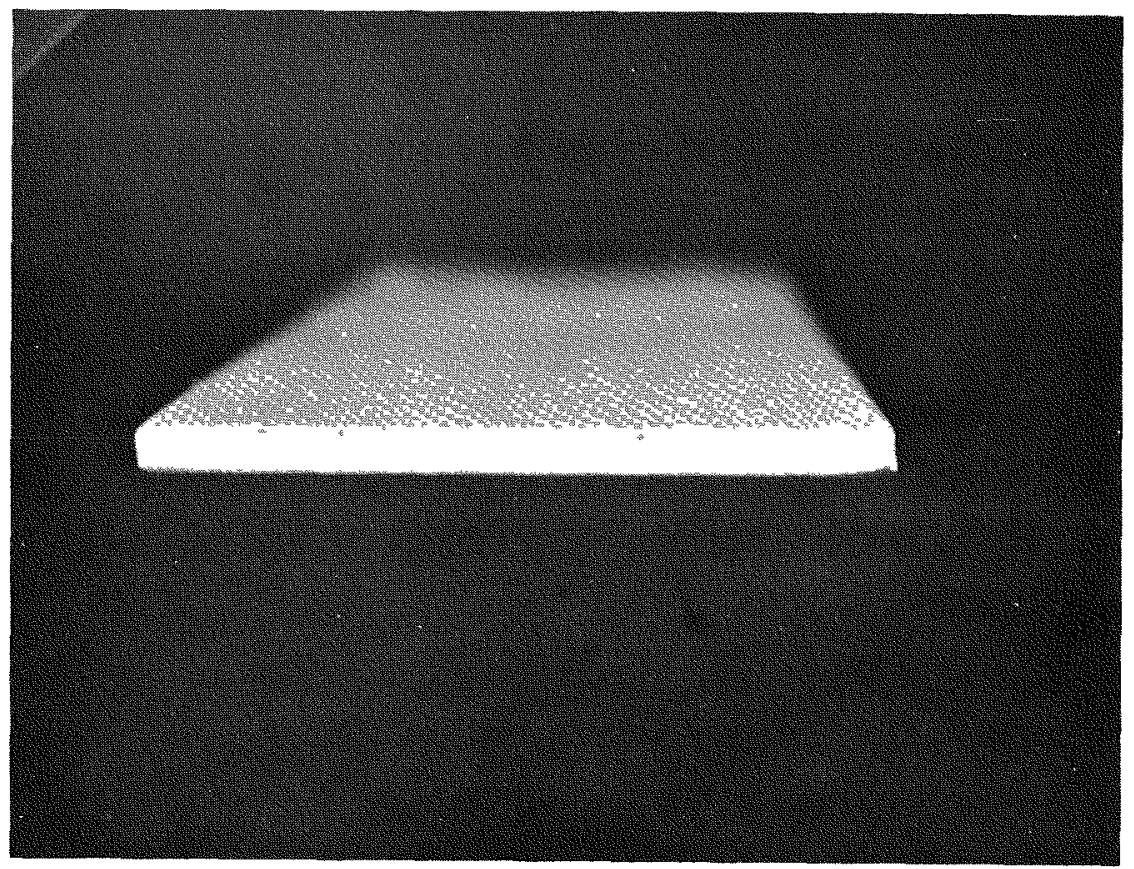

Figure 4-18. Voids in Anodized Coating of Salt Cake Test Specimen as Revealed by Dye Penetrant Tests. 
Galvanie Corrosion Evaluation - Aqueous Solution Test Results. A galvanic corrosion evaluation apparatus was built to test the effectiveness of various surface treatments, anodic and cathodic protective coatings, and temperature on the relative corrosion rates of galvanically coupled SNAP-23A materials.

The experimental apparatus consists of an electrolyte bath of synthetic sea water contained in a large plastic tank. A common electrolyte was used to minimize experimental variables and make direct comparison of the results possible. Figure 4-19 is a photograph of the system showing the electrode support and shorting mechanism. Figure 4-20 shows a schematic of the electrical measuring system employed for this test. The current was measured using the zeroresistance milliohmmeter method.

The electrolyte bath was in turn contained in a constant controlled temperature oil bath. Corrosion voltages and currents were measured by opening the shorting switches and switching the electrodes of interest into the measuring circuit. The shorting switches were closed to allow galvanic corrosion to proceed between the desired galvanic couples.

Table 4-6 lists the various combinations of couples evaluated thus far. Couples 1 through 8 were placed in the electrolyte to a depth of 4 inches, and this immersed length remained constant. The couples were then allowed to corrode galvanically in situ for periods of 24 and 150 hours. Couples 1 through 4 were designed to evaluate the effect of elevated temperature on the relative corrosion rates of aluminum in the conditions designated in Table 4-6. Couples 5 through 8 were evaluated to determine what effect edge treatment prior to anodization had on the relative corrosion rates of the aluminum electrodes. Couples 9 through 11 were short-time tests designed to evaluate the effects of immersion depth, edge preparation, and temperature on the corrosion rate.

The relative corrosion currents for couples 1 through 4 and 5 through 8 are reported in Table 4-7. In all cases the bare unanodized aluminum exhibited the highest average corrosion currents. The current measurements fluctuated as a function of time with in the range indicated. This can be explained by the formation of aluminum corrosion products on the aluminum electrode, causing changes in the effective area exposed to the electrolyte. These products would form and grow and then spall off, causing fluctuations in the corrosion current. 


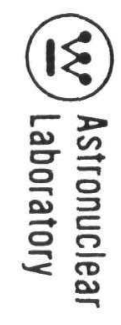

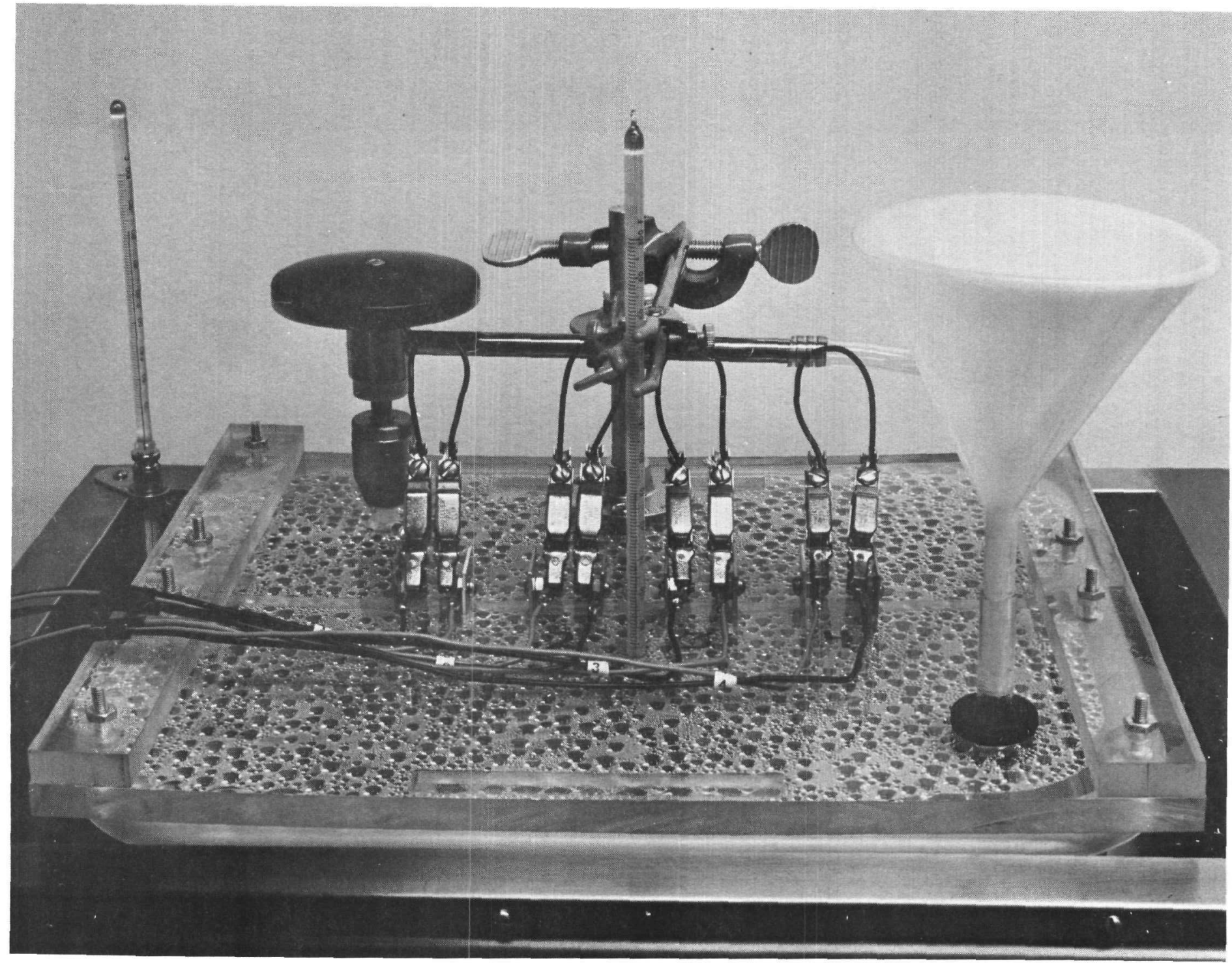

Figure 4-19. Galvanic Corrosion Apparatus. 


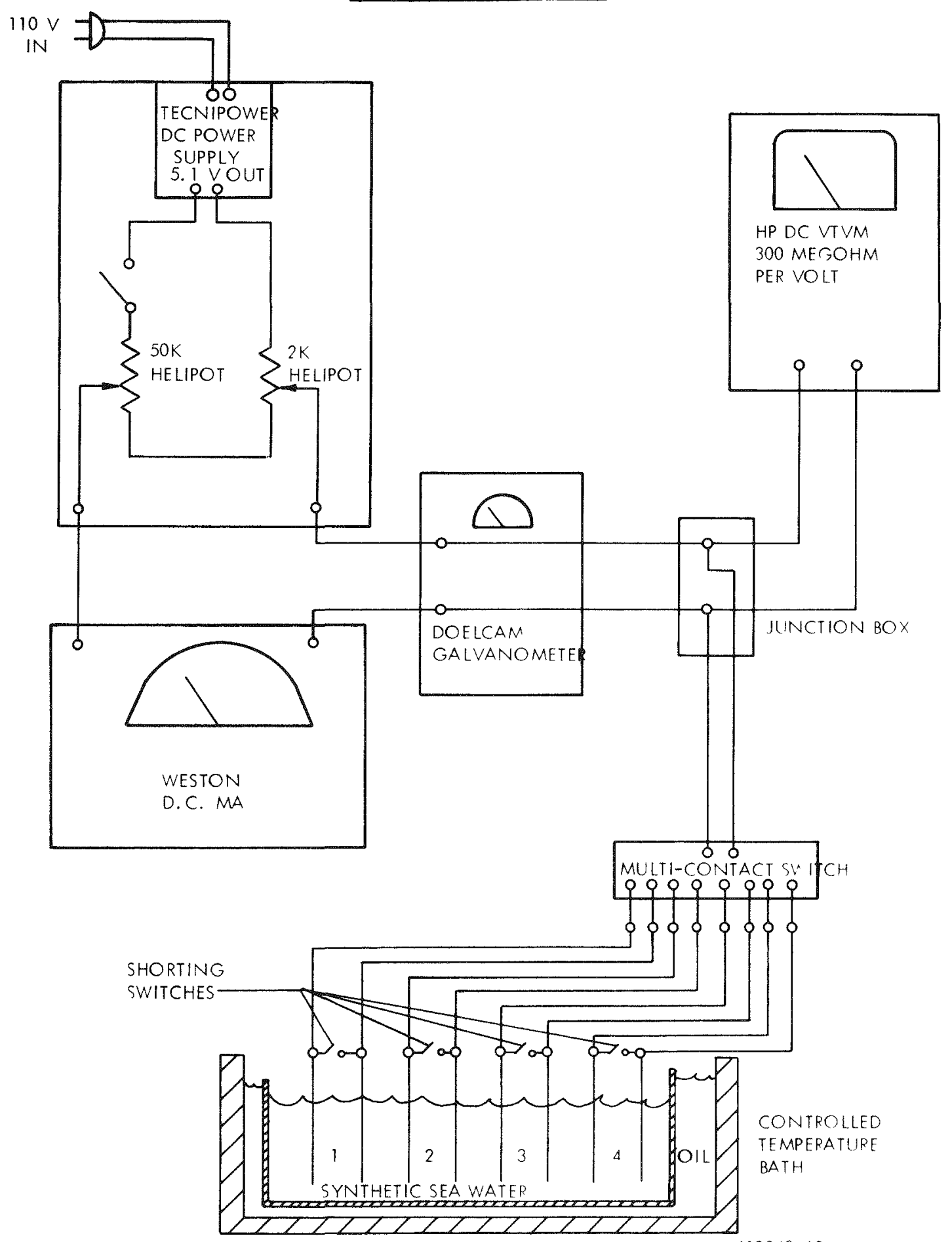

$613040-68$

Figure 4-20. Electrochemical Corrosion Rate Measurements of Galvanically Coupled SNAP-23 Materials in Synthetic Sea Water at Elevated Temperatures. 


\title{
TABLE 4-6
}

\section{GALVANIC COUPLES EVALUATED DURING THE ELECTROCHEMICAL CORROSION TEST PROGRAM}

\author{
Couples \\ Bath Temp. $=160^{\circ} \mathrm{F}$
}

1. Inconel 625-6061-T6 Al Unanodized

2. Inconel 625-6061-T6 Al Anodized and Unsealed

3. Inconel 625-6061-T6 Al Anodized and Sealed

4. Inconel 625 - 1100 Al Unanodized

5. Inconel 625-6061-T6 Unanodized, Sheared and Deburred

6. Inconel 625-6061-T6 Anodized, Sealed, Sheared and Deburred

7. Inconel 625-6061-T6 Anodized, Sealed, Square Edge

8. Inconel 625-6061-T6 Anodized, Sealed, Rounded Edge

Bath Temp. - Room Temp. and $200^{\circ} \mathrm{F}$

9. Inconel 625 - 6061-T6 Al Anodized and Sealed - Edge Sheared and Deburred

10. Inconel 625-6061-T6 Al Anodized and Sealed - Edge Sheared and Deburred, Edge Polished

11. Inconel 625-6061-T6 Al Anodized and Sealed - Edge Sheared, Deburred, Edge Rounded and Polished. 
TABLE 4-7

RESULTS OF ELECTROCHEMICAL CORROSION PROGRAM (CONSTANT SUBMERSED AREA)

\begin{tabular}{ccccc}
\hline Couple & $\begin{array}{c}\text { Temperature } \\
(\text { OF) }\end{array}$ & $\begin{array}{c}\text { Corrosion Time } \\
(\mathrm{hrs})\end{array}$ & $\begin{array}{c}\text { Current Range } \\
(\mathrm{ma})\end{array}$ & $\begin{array}{c}\text { Current Aver- } \\
\text { age (ma) }\end{array}$ \\
\hline 1 & 160 & 24 & $0.092-0.230$ & 0.125 \\
2 & 160 & 24 & $0.074-0.180$ & 0.108 \\
3 & 160 & 24 & $0.050-0.140$ & 0.094 \\
4 & 160 & 24 & $0.092-0.209$ & 0.136 \\
5 & 160 & 150 & $0.126-0.552$ & 0.171 \\
6 & 160 & 150 & $0.105-0.160$ & 0.124 \\
7 & 160 & 150 & $0.084-0.174$ & 0.115 \\
8 & 160 & 150 & $0.097-0.159$ & 0.117 \\
\hline
\end{tabular}


Figures 4-21 and 4-22 show the results of the corrosion on the aluminum electrode surfaces. The unanodized samples from couples 1 and 4 exhibited a larger average corrosion current but appear to contain fewer pit-type marks than the anodized samples. This is due to the general surface corrosion of the unanodized material. The anodized surfaces exhibited pits which are the result of imperfections in the anodized coating. The sample was adequately protected except in the area of the imperfections, and the corrosion reaction caused pits to form in these areas. The radiator fin material, 1100 Aluminum, did not exhibit as many localized pits as did the 6061-T6, which indicates that the corrosion reaction was evenly distributed over the surface. Corrosion currents measured with the 1100-625 couple were the highest of the group, indicating that corrosion did occur even though pitting was not evident.

Figures 4-23 and 4-24 illustrate the effect of partial surface protection as provided by a commercially anodized sample compared with a bare metal sample exposed for 150 hours. The protected surface has fewer but larger corrosion pits than does the unprotected surface. On both sets of tests, the general integrity of the anodized surface can be illustrated by noting that it is not possible to determine the depth of immersion on the anodized samples because of the protective nature of the coatings.

A reduction in corrosion current was achieved by finishing the edges of the sheared and deburred samples. The edge finishing removed the ragged, deformed material from edge surfaces that resulted from the shearing process. This condition is equivalent to that expected in the SNAP-23A radiator.

Table 4-8 shows the effect of immersed electrode area on the relative corrosion rate at room temperature and at $200^{\circ} \mathrm{F}$. These results are plotted in Figures 4-25 and 4-26. These graphs indicate that as the Inconel 625 immersion area increases with respect to the aluminum area, the corrosion rate increases. However, when the Inconel $625 \mathrm{immersed}$ area is held constant and the depth of aluminum immersion is varied, the corrosion rate remains essentially constant. These results indicate that the rate controlling factor in the case of the variable 625 constant aluminum immersion area is the area of Inconel 625 available to the electrolyte solution. The rate controlling factor in the case of the constant Inconel 625 area and variable aluminum area is imperfections in the anodic coating rather than immersed area. This indicates 
(W) Astronuclear

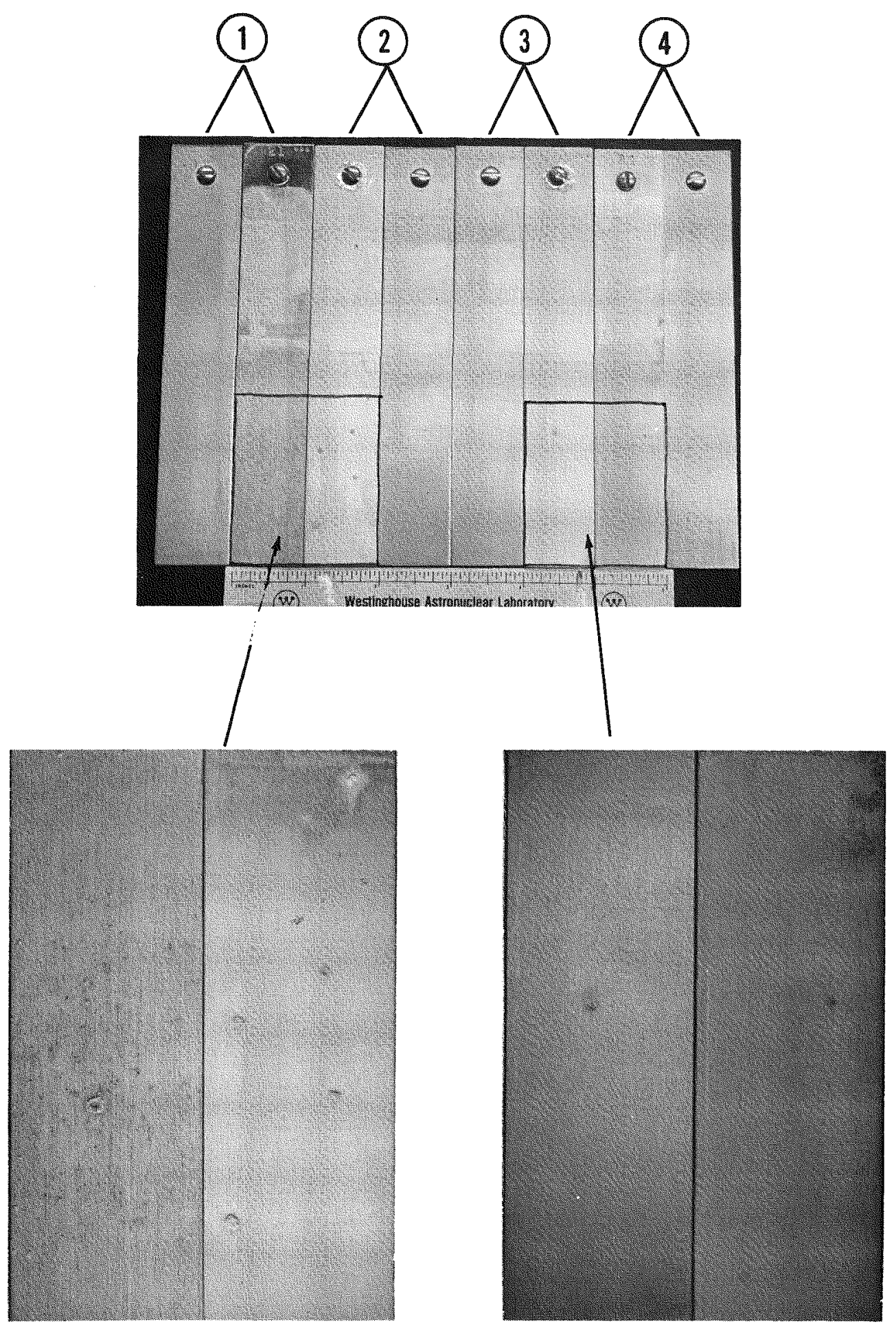

Figure 4-21. Side One of Galvanic Corrosion Couples 1 Through 4 Showing the Effect of Corrosion on the Aluminum Electrode. 
(W) Astronuclear

Laboratory
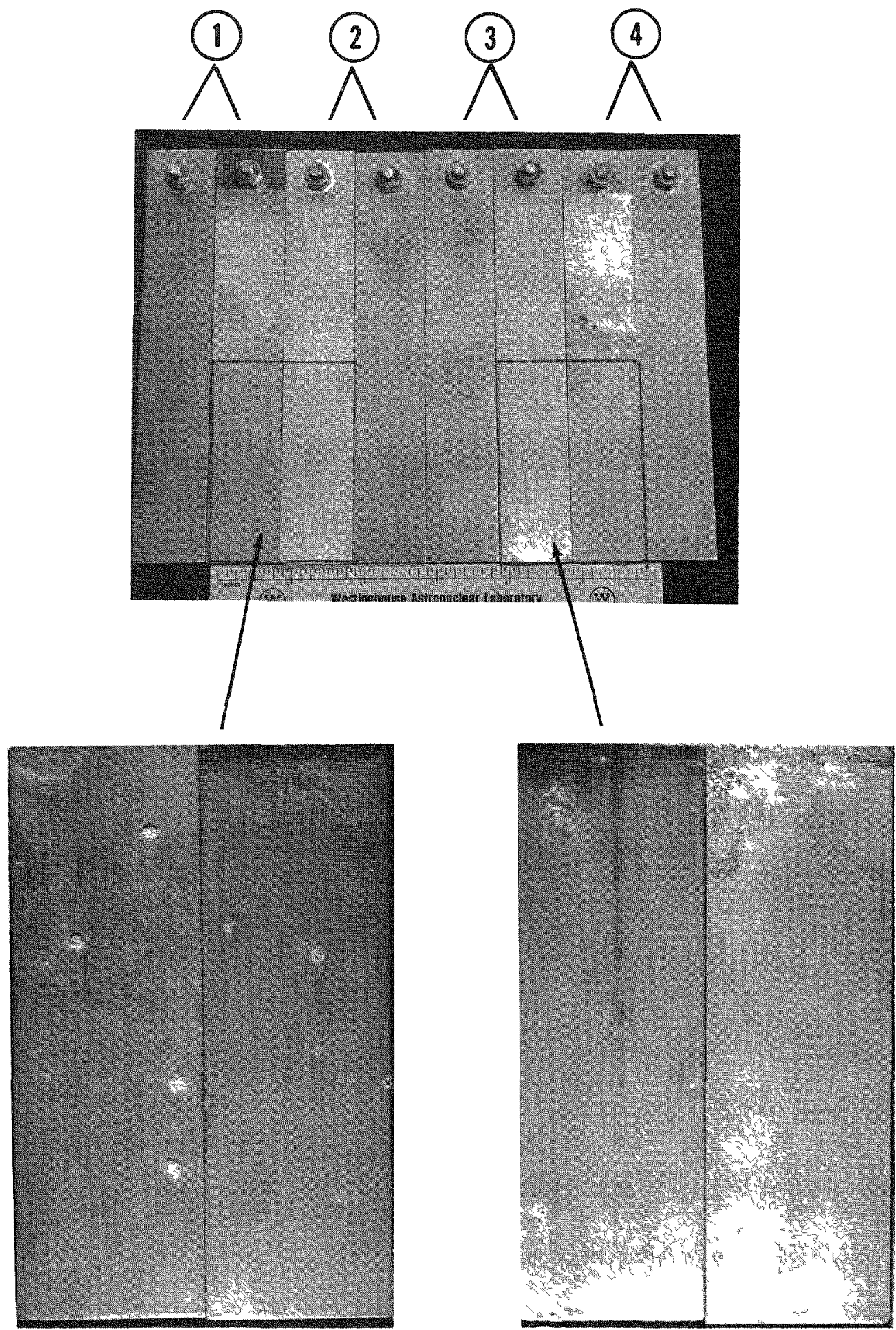

Figure 4-22. Side Two of Galvanic Corrosion Couples 1 Through 4 Showing the Effect of Corrosion on the Aluminum Electrode. 
(W) Asironuclear
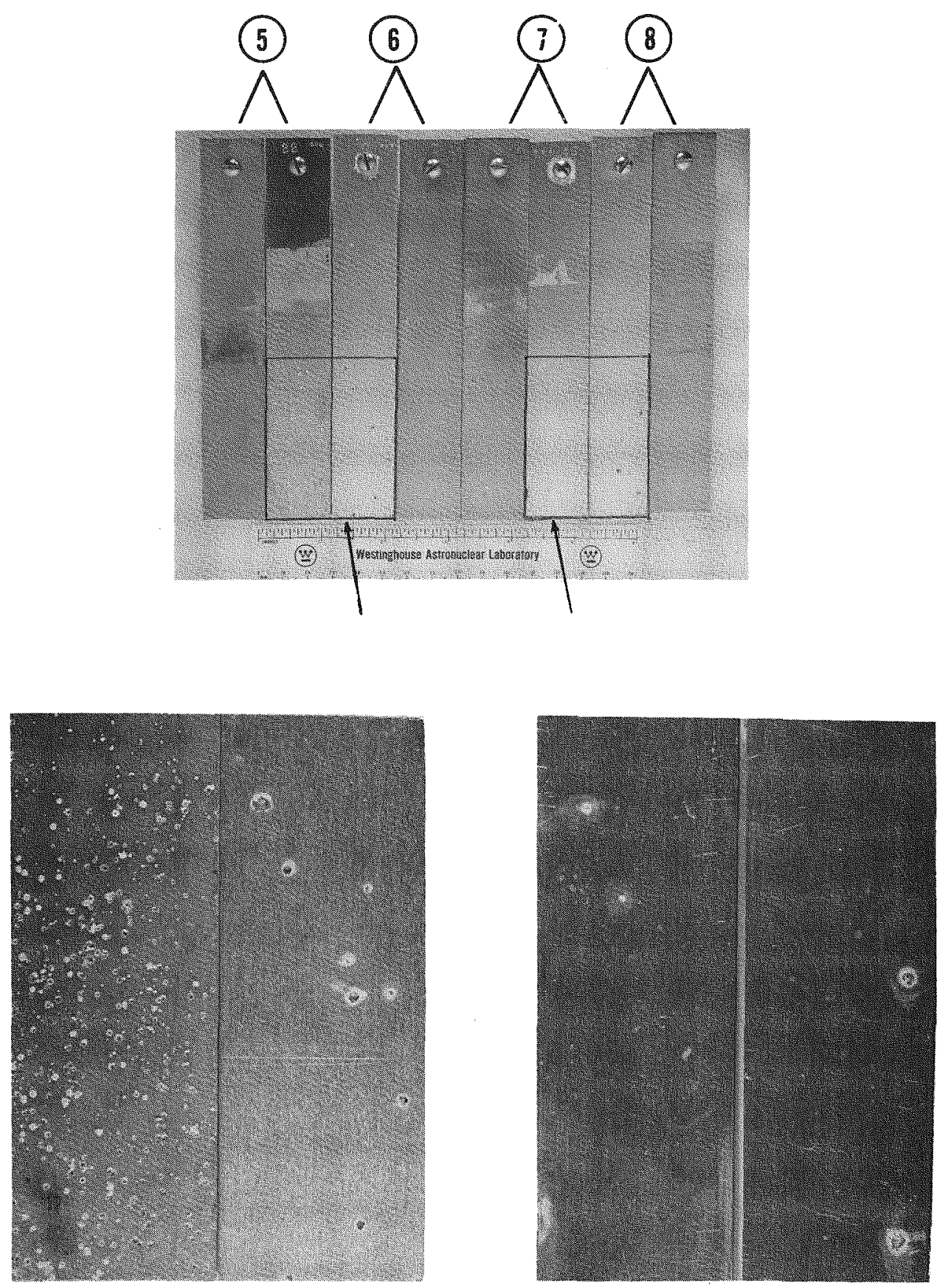

Figure 4-23. Side One of Galvanic Corrosion Couples 5 Through 8 Showing the Effect of Corrosion on the Aluminum Electrode. 
(20) Astronuclear

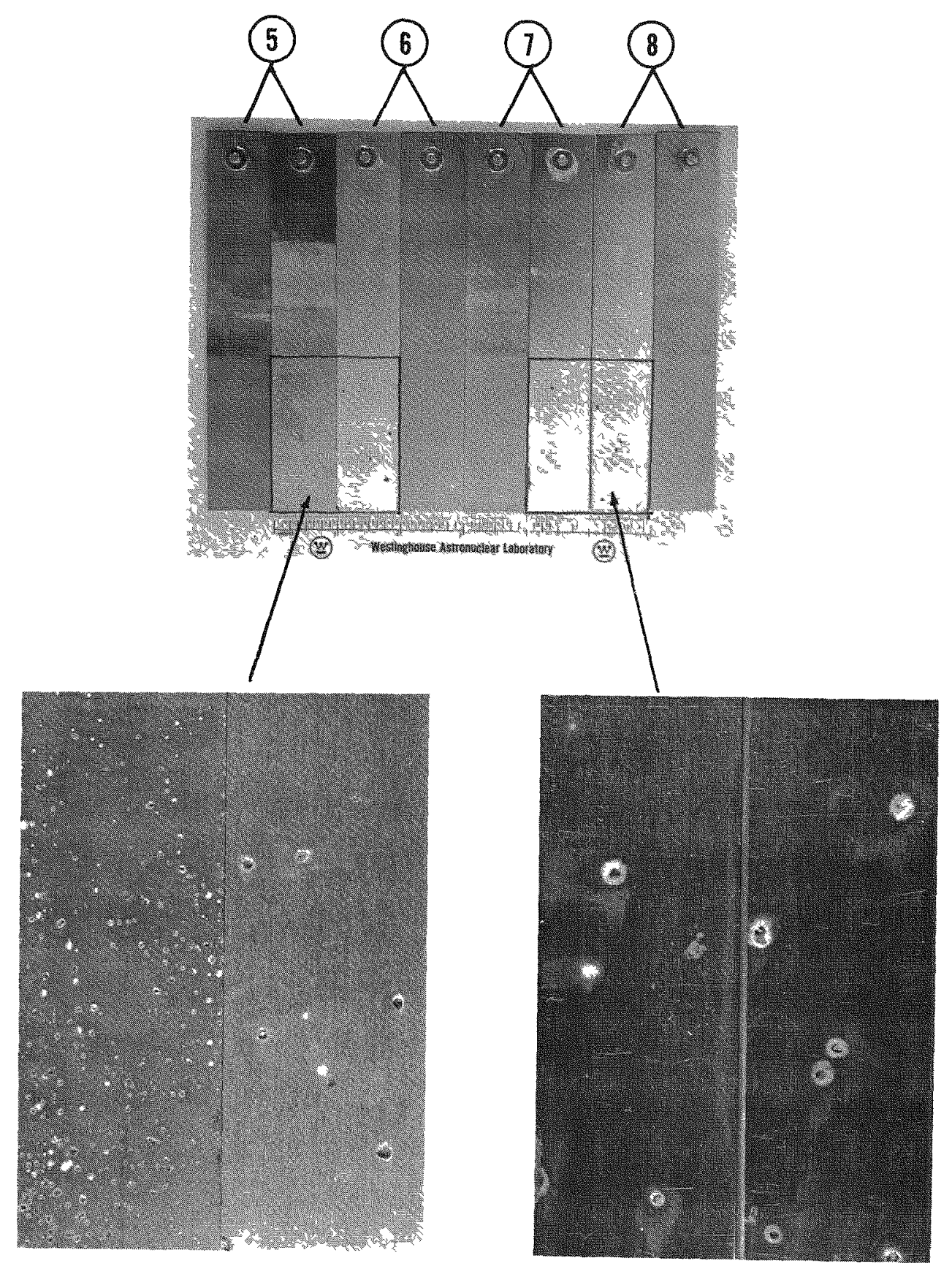

Figure 4-24. Side Two of Galvanic Corrosion Couples 5 Through 8 Showing the Effect of Corrosion on the Aluminum Electrode. 
TABLE 4-8

RESULTS OF ELECTROCHEMICAL CORROSION PROGRAM

(VARIABLE SUBMERSED AREA)

\begin{tabular}{|c|c|c|c|c|c|c|}
\hline \multirow{2}{*}{ Couple No。 } & \multicolumn{2}{|c|}{ Submersed Area (sq. in.) } & \multicolumn{2}{|c|}{ Voltage (volts) } & \multicolumn{2}{|c|}{ Current $(m a)$} \\
\hline & Inconel 625 & Al & Room Tempo & $2000 \mathrm{~F}$ & Room Temp. & $2000 \mathrm{~F}$ \\
\hline \multirow[t]{7}{*}{9} & 8 & 2 & 0.50 & 0.59 & 0.12 & 0.29 \\
\hline & 8 & 4 & 0.37 & 0.35 & 0.13 & 0.23 \\
\hline & 8 & 6 & 0.37 & 0.30 & 0.13 & 0.23 \\
\hline & 8 & 8 & 0.35 & 0.30 & 0.14 & 0.21 \\
\hline & 6 & 8 & 0.35 & 0.35 & 0.13 & 0.18 \\
\hline & 4 & 8 & 0.32 & 0.35 & 0.12 & 0.16 \\
\hline & 2 & 8 & 0.30 & 0.35 & 0.11 & 0.10 \\
\hline \multirow[t]{7}{*}{10} & 8 & 2 & 0.50 & 0.25 & 0.18 & 0.22 \\
\hline & 8 & 4 & 0.32 & 0.25 & 0.15 & 0.21 \\
\hline & 8 & 6 & 0.30 & 0.25 & 0.16 & 0.21 \\
\hline & 8 & 8 & 0.30 & 0.27 & 0.16 & 0.21 \\
\hline & 6 & 8 & 0.30 & 0.27 & 0.15 & 0.18 \\
\hline & 4 & 8 & 0.32 & 0.25 & 0.14 & 0.15 \\
\hline & 2 & 8 & 0.27 & 0.23 & 0.10 & 0.11 \\
\hline \multirow[t]{7}{*}{11} & 8 & 2 & 0.30 & 0.30 & 0.04 & 0.17 \\
\hline & 8 & 4 & 0.32 & 0.23 & 0.05 & 0.16 \\
\hline & 8 & 6 & 0.30 & 0.23 & 0.06 & 0.16 \\
\hline & 8 & 8 & 0.30 & 0.24 & 0.06 & 0.15 \\
\hline & 6 & 8 & 0.37 & 0.26 & 0.08 & 0.13 \\
\hline & 4 & 8 & 0.29 & 0.23 & 0.08 & 0.12 \\
\hline & 2 & 8 & 0.27 & 0.23 & 0.08 & 0.10 \\
\hline
\end{tabular}


(W) Astronuclear

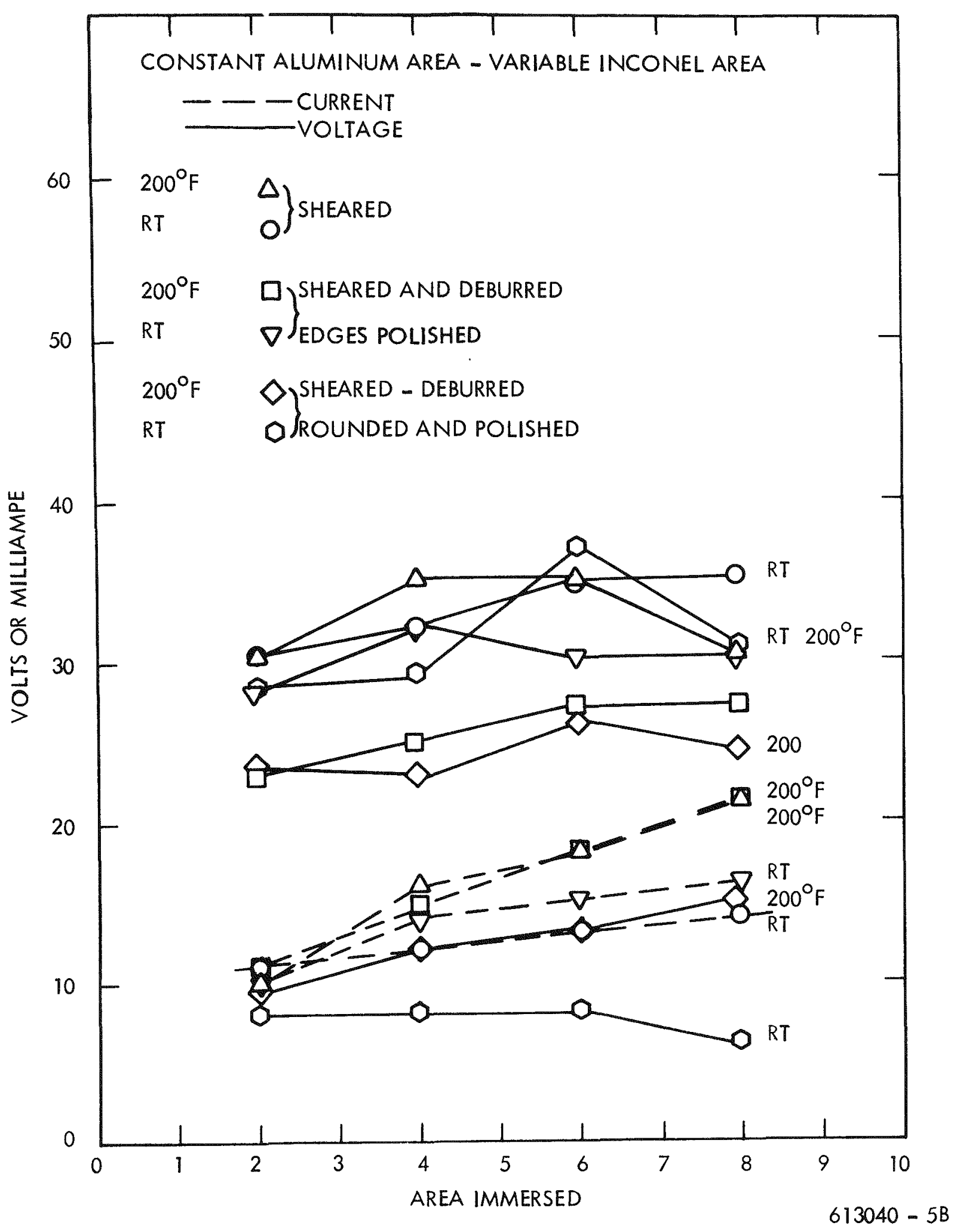

Figure 4-25. Effect of Edge Treatment on Corrosion Current. 


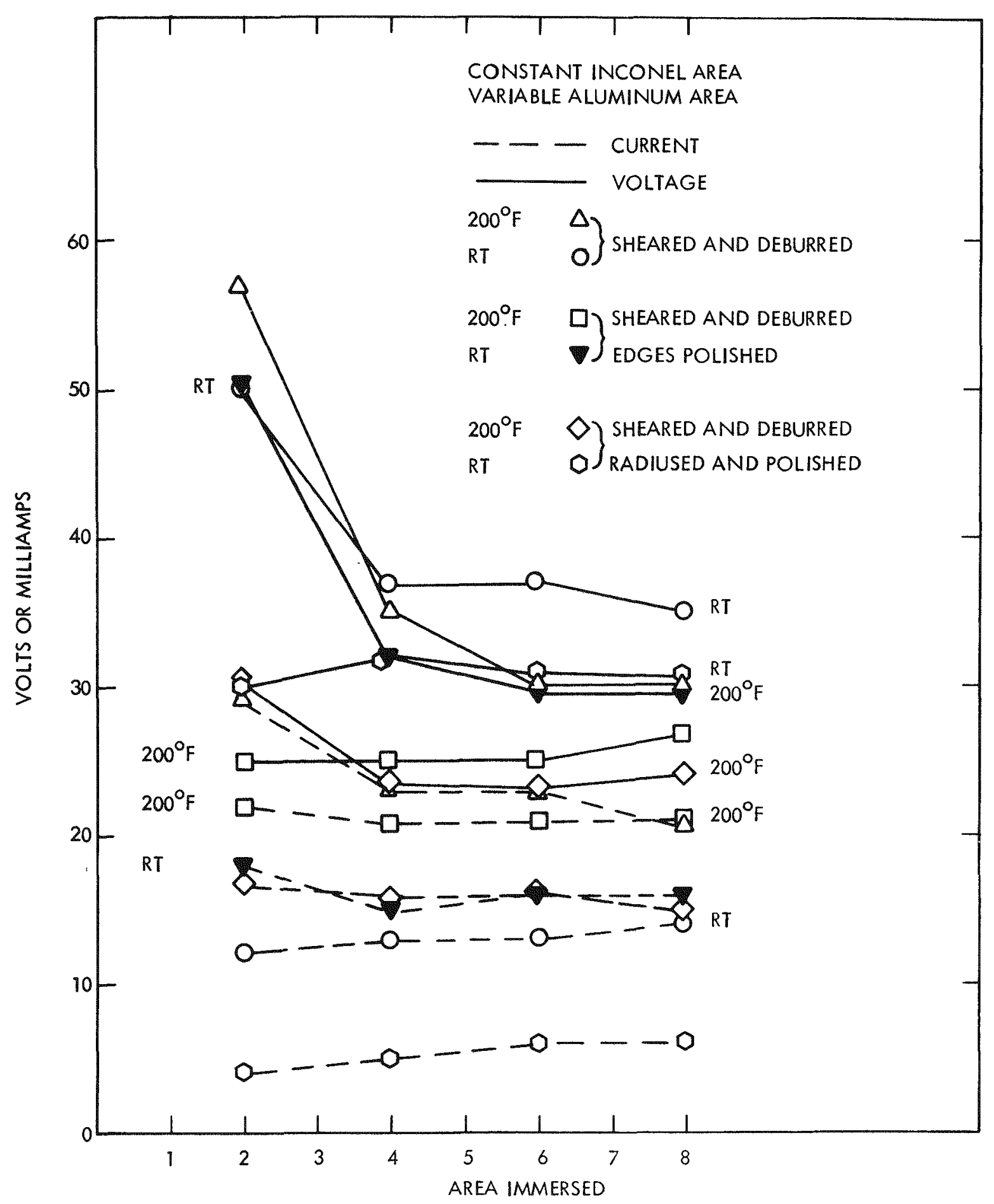

$613040-4 B$

Figure 4-26. Effect of Edge Treatment on Corrosion Current. 
that, along with anodic protection on the aluminum, the Inconel 625 cathode should be coated to minimize the area available for participation in the electrochemical reaction.

Also, the corrosion resistance increased as the edge treatment became more precise. This result is in agreement with the results obtained in the long-term tests with couples 5 through 8.

The conclusion to be drawn from these corrosion tests are as follows:

1) A moist salt cake is a very good electrolyte and this kind of galvanic corrosion mechanism must be prevented.

2) Anodization and sealing decrease the average corrosion rate. However, localized pits are formed due to imperfections in the coating. These pits are deeper than those formed on an unprotected surface.

3) Coating the cathode (Inconel 625) with some inert compound would give increased corrosion protection.

4) The corrosion rate is much greater at elevated temperatures.

\section{Long-Term Compatibility Test Results}

The long-term compatibility tests have now been completed with a total exposure time of 10,000 hours at temperatures of $1000^{\circ} \mathrm{F}, 1200^{\circ} \mathrm{F}$, and $1400^{\circ} \mathrm{F}$. The preparation and assembly procedures for the compatibility samples were reported previously in WANL-PR-(SS)-007.*

Although it was decided early in the program that titanium would not be a suitable diffusion barrier between copper and Hastelloy $C$, the long term compatibility tests were continued to evaluate the diffusion zone at the uranium alloy - copper interface and the copper - Inconel 718 interface.

WANL-PR-(SS)-007* gives a straight line relationship between the diffusion zone thickness and the square root of time at $1400^{\circ} \mathrm{F}$ and $1200^{\circ} \mathrm{F}$. This relationship gives a diffusion thickness at 5000 and 10,000 hours of 29.7 mils and 42 mils, respectively. The zone thickness at $1200^{\circ} \mathrm{F}$ was estimated to be 12.7 mils at 10,000 hours.

The measurements on the compatibility samples indicate that the zone thickness is smaller than that estimated, based on the early data. Table 4-9 indicates the measured values as compared with the calculated values.

* SNAP-23A Quarterly Progress Report, August 1967 
TABLE 4-9

COMPARISON OF CALCULATED AND ACTUAL

DIFFUSION ZONE THICKNESS BETWEEN

COPPER AND THE URANIUM-MOLY ALLOY

\begin{tabular}{|c|c|c|c|}
\hline $\begin{array}{c}\text { Time } \\
\text { (Hrs.) }\end{array}$ & $\begin{array}{c}\text { Temp. } \\
\left({ }^{\circ} \mathrm{F}\right)\end{array}$ & $\begin{array}{c}\text { Zone (Measured) } \\
\text { Thickness (mils) }\end{array}$ & Calculation * (mils) \\
\hline 5012 & 1400 & 19.3 & 29.7 \\
10,000 & 1400 & $15.3^{*}$ & 42.0 \\
10,000 & 1200 & $23.0^{*(*}$ & 12.7 \\
\hline
\end{tabular}

*This value appears low

** Expected thickness based on extrapolation of all previous data.

The values measured are lower than would be expected based on the extraploation of the previous data.

The thickness of the diffusion measured for 10,000 hours at $1400^{\circ} \mathrm{F}$ is lower than the value measured for the 5012 hour test. Examination of the entire interface area showed that the diffusion zone was not uniform in thickness. Apparently, the interface was not in good initial contact or the interface was separated upon cooling when the furnace failed after about 5000 hours of exposure. Based on extrapolating the existing data, this zone should be about 23 mils thick at 10,000 hours. Figure 4-27 shows the Cu-U-10Mo interfaces and reaction zones.

The other objective of these tests was to demonstrate the compatibility between copper/Inconel 718, U-10Mo/tungsten, U-10Mo/tantalum, Hastelloy C/tungsten, and Hastelloy $\mathrm{C}$ /tantalum. All of these samples demonstrated comparibility in the 10,000 hour compatibility test program.

Figure 4-28 shows the Inconel 718/copper interface. There is no interdiffusion zone present although the interfaces show diffusion bonding.

\footnotetext{
WANL-PR-(SS)-007, SNAP-23A Quarterly Progress Report, August 1967
} 

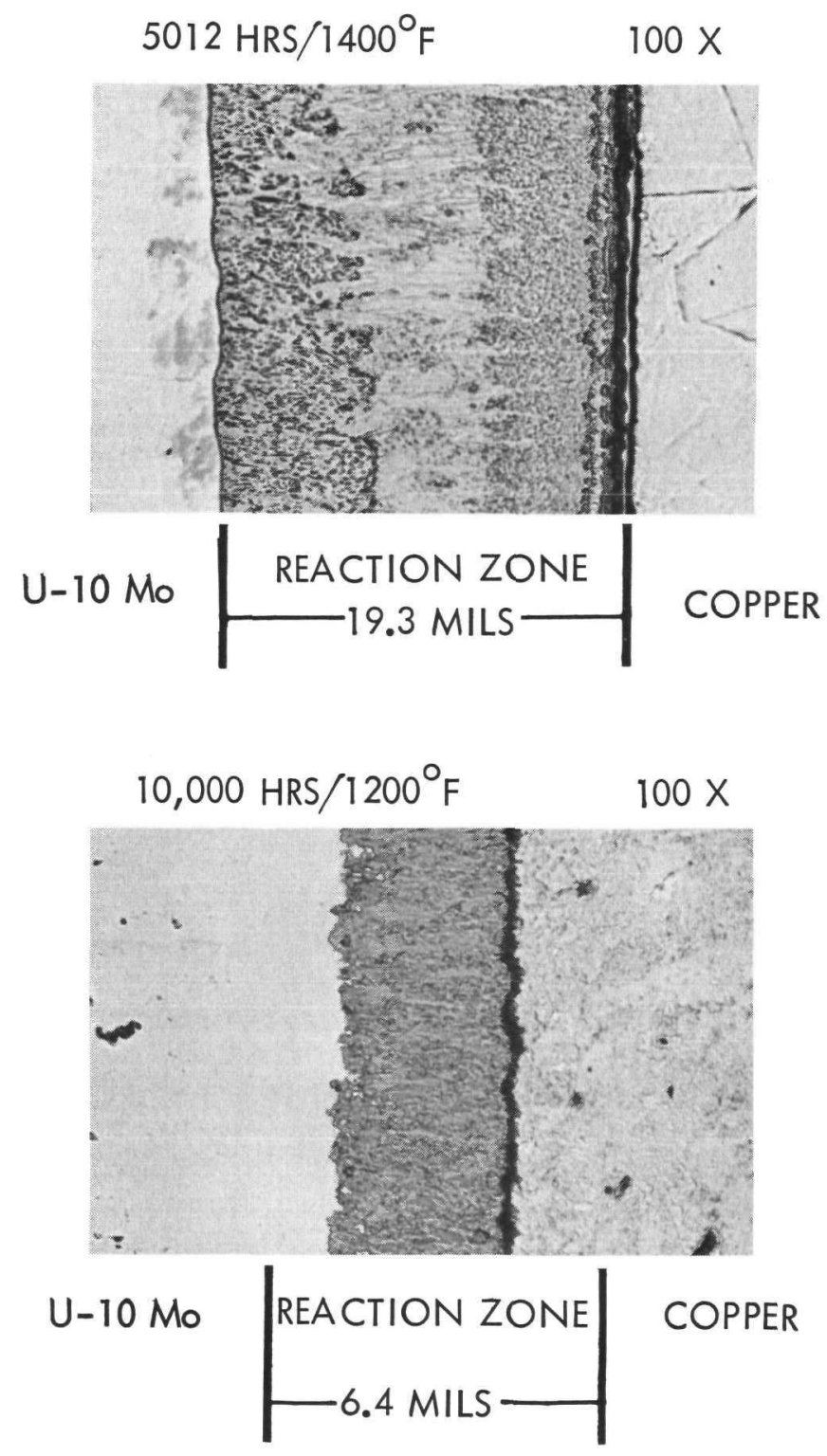

Figure 4-27. U-Mo/Copper Interface Showing Reaction Zone at $1400^{\circ} \mathrm{F}$ and $1200^{\circ} \mathrm{F}$. 


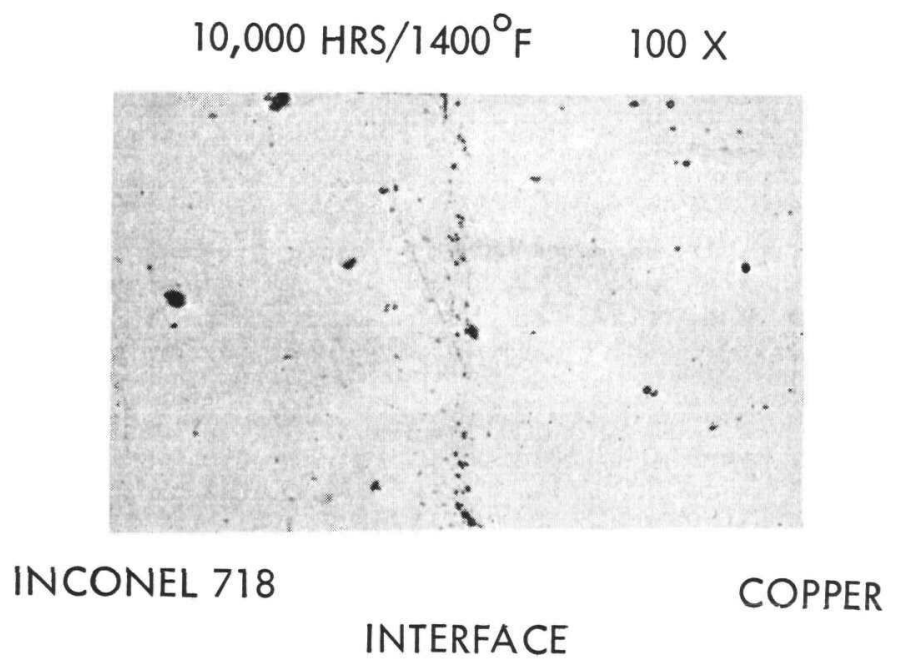

Figure 4-28. Lack of Reaction Zone Between Copper and Inconel 718. A Diffusion Bond Has Been Formed. 


\section{Waboratory}

The effectiveness of tantalum and tungsten as a diffusion barrier between Hastelloy $\mathrm{C}$ and $\mathrm{U}-10 \mathrm{Mo}$ is illustrated in Figure 4-29. No reaction zones were formed and no diffusion bonding occurred after 10,000 hours at $1400^{\circ} \mathrm{F}$.

These tests ensure that the selection of tantalum as a diffusion barrier was sound and no interaction between the fuel capsule and U-8Mo shield should occur. 
(We Astronuclear
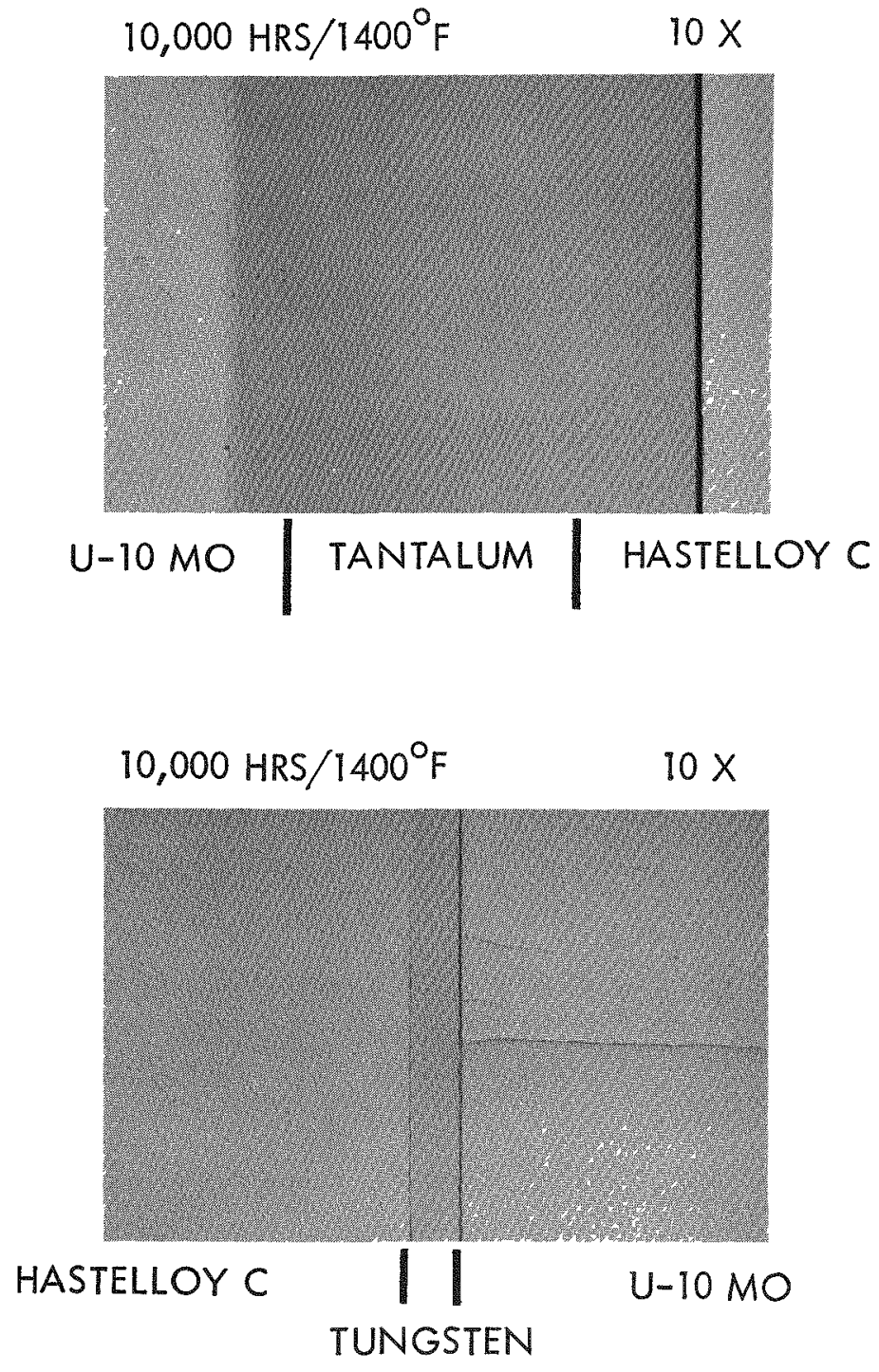

Figure 4-29. Lack of Reaction Showing the Effectiveness of Tantalum and Tungsten as a Diffusion Barrier Between U-10Mo and Hastelloy C. 


\section{SYSTEM DEVELOPMENT}

Subtask 510 - System Testing

EMS life testing continued through this report period. At the end of August, 1969, the EMS unit accumulated 8260 hours of operation, of which 6060 hours have been on life test.

During the past report period, the control system was modified to permit testing at variable load conditions as per Revision 1 of Life Test Procedure EMSN-3C. Variable load testing was initiated on July 23, 1969. Converter voltage and current were recorded for the following conditions: loss of load, load at three times the normal load, load at one-third the normal load, and converter short circuit. The second part of the variable load test was conducted by permitting the system to reach equilibrium at three load conditions, short circuit, load at one-third the normal load, and load at three times the normal load. Data points were taken at each condition after equilibrium was achieved. The variable load test was completed on July 31 and "life testing" was resumed with the normal load resistance. The next variable load test will be conducted at the end of October 1969.

Three power failures occurred during the past quarter. The loss of the 220 VAC power was due to thunderstorms. The system returned to normal operation after the power was restored and switches were reset. In each case, heater input power was gradually increased until the specified limit of 1440 watts was reached.

On August 15, 1969, a monitoring meter exceeded a 1 ma limit. Upon investigation, it was determined that a radio frequency signal, generated by an adjacent testing area, was being picked up by the leakage to ground meter, causing system shutdown. The EMS and other meters were not affected by the radio frequency signal. Corrective action by increasing the leakage to ground limit will avoid future system shutdowns. 


\subsection{SAFETY ANALYSIS}

Subtask 610 - Safety Analysis

Fire Analysis

A thermal analysis was performed to support the SNAP-23A thermoelectric converter module fire test at $3 M$. The results of this analysis are presented in Figures 6-1 and 6-2. These curves will form a part of the $3 \mathrm{M}$ module fire test plan. The radiator emissivity during the fire was assumed to be 0.8 . The $1850^{\circ} \mathrm{F}$ fire thermal model results indicate that all of the radiator melts. The post $1850^{\circ} \mathrm{F}$ fire converter hot frame and cold frame temperatures presented reflect the absence of the radiator. The $1475^{\circ} \mathrm{F}$ fire does not supply sufficient energy to completely melt the aluminum radiator. The analytical model predicts that about $1 / 5$ of the radiator remains. Figure 6-2 reflects the relatively low converter temperatures achieved with a partial radiator. The curves for both $1475^{\circ} \mathrm{F}$ and $1850^{\circ} \mathrm{F}$ fires were continued to the time where calculated converter temperatures reached their approximate minimum values. Continuation of the curves further in time would show a gradual increase in temperature due to heat production within the system. The ultimate steady-state temperature would depend on the effective thermal impedance of the converter following the fire.

\section{Air Transport Investigation}

An investigation of aircraft transport of the SNAP-23A generator has been undertaken. The study has the primary objective of providing some ground rules for the design of the system shipping container. Preliminary events and probabilities were established for likely air carrier accidents. A review of available documents led to the preliminary aircraft accident network shown in Figure 6-3.

The data in Figure 6-3 were based on a series of documents published by the Civil Aeronautics Board for the period 1960 through 1962. The document subjects are:

- U.S. Air Carrier Accidents, Statistical Review and Resume of Accidents

- General Aviation Accidents, A Statistical Review

It is planned to update the aircraft accident probabilities based upon more recent data for the period 1964 through 1968. The data are now published by the National Transportation Safety Board. For the 3-year period reported in Figure 6-3, there were no extensive 


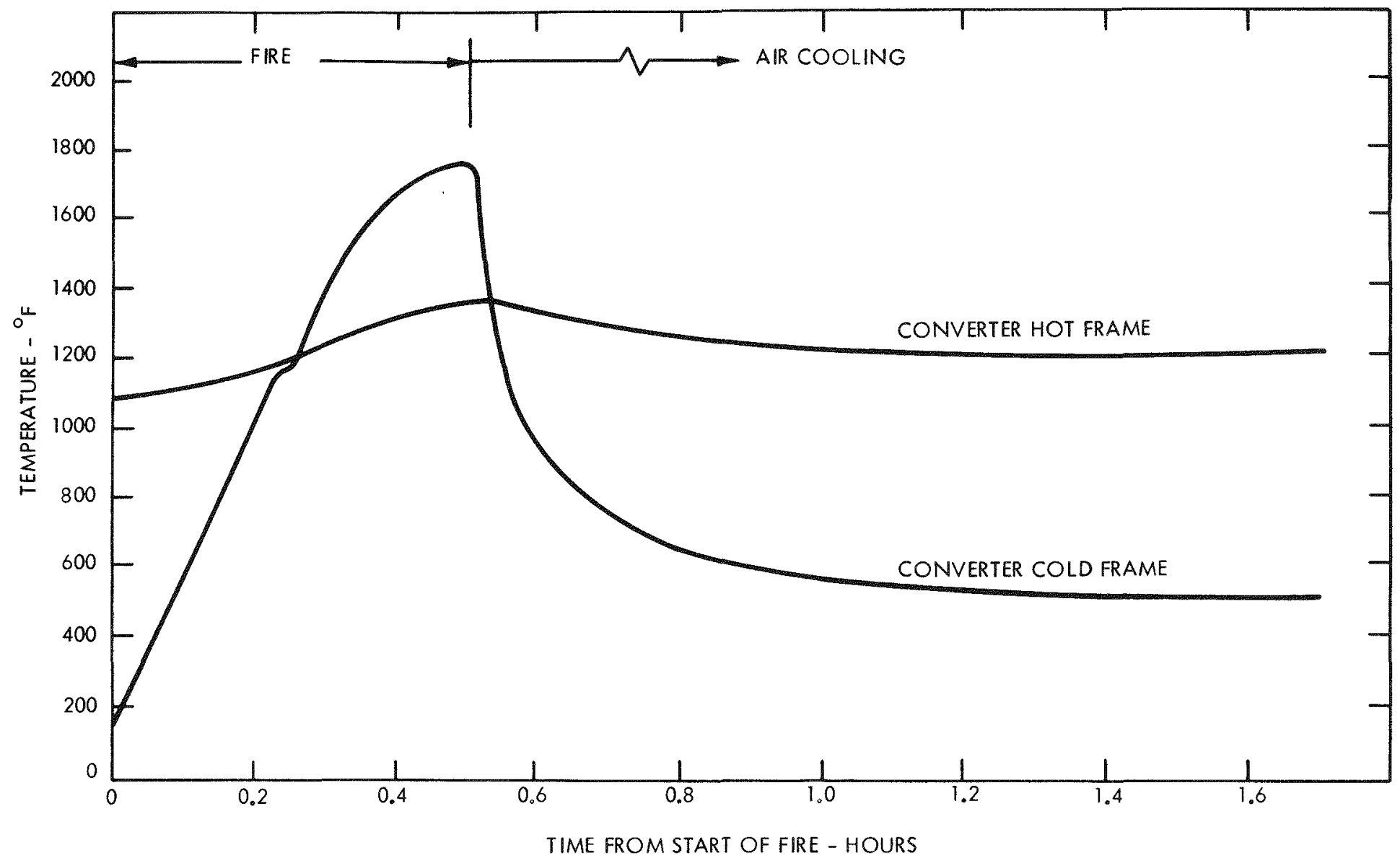

Figure 6-1. Calculated Response of SNAP-23A Converter Components During $1850^{\circ}$ Half-Hour Fire. 


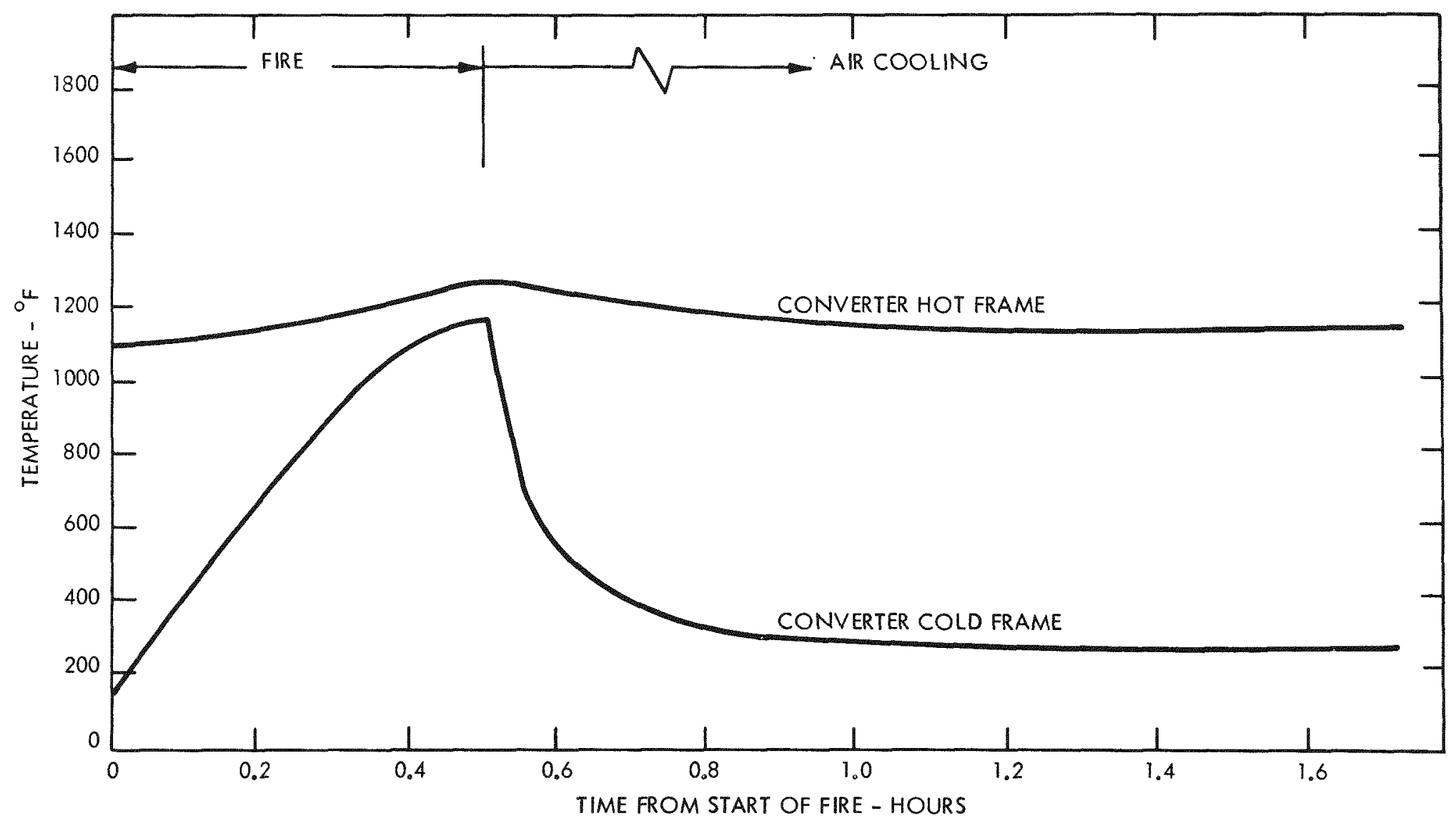

Figure 6-2. Calculated Response of SNAP-23A Converter Components During $1475^{\circ} \mathrm{F}$ Half-Hour Fire. 


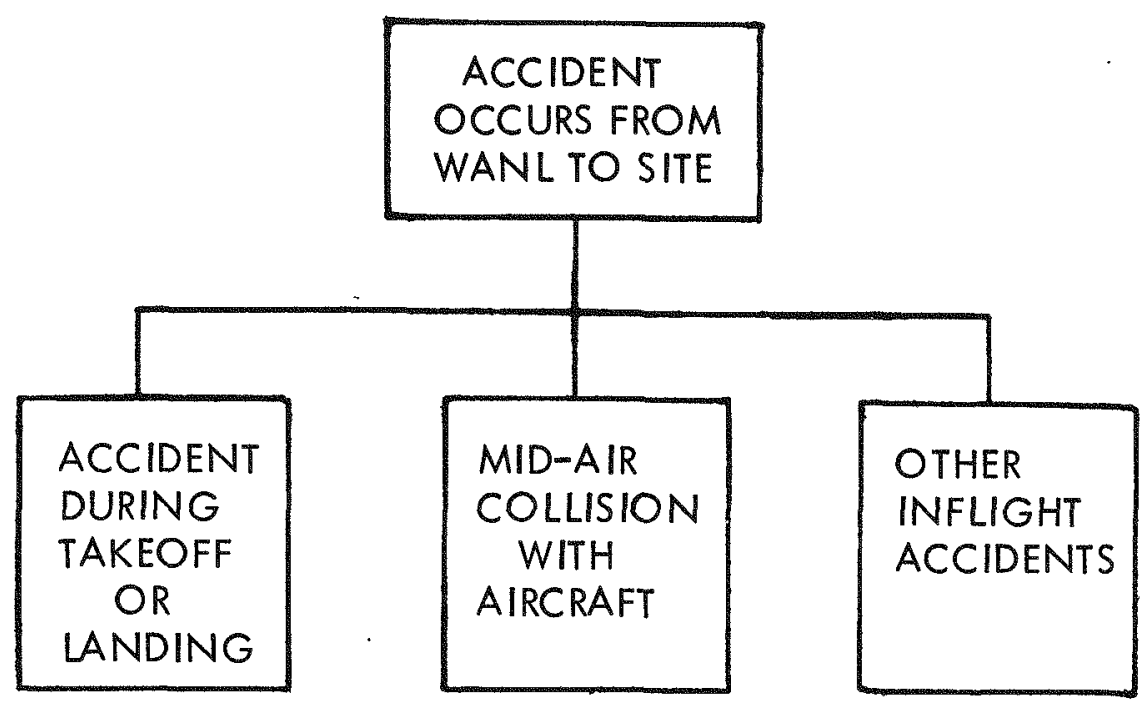

FREQUENCY

FACTOR FOR

NONSCHEDULED

CARGO FLIGHTS

0.714

0.071

0.214

ACCIDENTS

PER MILE

$3.3 \times 10^{-8}$

$0.33 \times 10^{-8}$

$0.99 \times 10^{-8}$

NOTES:

1. THESE DATA ARE PRELIMINARY AND WILL BE REVISED AS ADDITIONAL DATA BECOME AVAILABLE.

2. TOTAL ACCIDENTS PER MILE FOR NONSCHEDULED REVENUE SERVICE, ALL CARGO CARRIERS $=4.6 \times 10^{-8}$. THE FIGURE COMPARES TO $3.5 \times$ $10^{-6}$ ACCIDENTS/MILE FOR TRUCKS.

3. AIRCRAFT ACCIDENT PROBABILITIES ARE AS FOLLOWS:

FOR WANL TO SITE 1000 MILES AWAY, $P=4.6 \times 10^{-5}$

FOR WANL TO SITE 12,000 MILES AWAY, $P=0.55 \times 10^{-3}$

(THE 12,000 MILE NUMBER DOES NOT INCLUDE STOPS)

4. DEPLOYMENT OF SYSTEM AT OR NEAR SITE MAY BE BY HELICOPTER. FOR THE PERIOD 1960-1962, NO ACCIDENTS WERE RECORDED FOR NONSCHEDULED REVENUE SERVICE OF DOMESTIC HELIOCOPTER CARRIERS.

Figure 6-3. SNAP-23A Aircraft Accident Network 
statistics on the special category of nonscheduled revenue cargo carriers. However, the frequencies of occurence of the accidents for these special aircraft corresponded approximately to that tabulated in these documents for all aircraft.

In general each category of aircraft accident can lead to one or more of the environments of impact, fire, earth burial, water burial, and thermal shock. Release of the system from an airplane (as from a mid-air impact or explosion) was analyzed with respect to the ensuing impact velocity. The system alone will achieve a terminal impact velocity at sea level of about 540 to $610 \mathrm{ft} / \mathrm{sec}$. Damage at these velocities cannot be predicted, but severe deformations and failure of the radiation shield or even the fuel capsule are possible. A shipping container and pallet can be used to reduce impact velocity since it can be assured that the system will stay inside the shipping cask even though the airplane breaks up. Figure 6-4 shows the tradeoff in terminal velocity and area requirements associated with various container weights. As velocity and impact energy decrease, the probability of assuring fuel capsule integrity becomes very great. At sufficiently low velocities, damage to the radiation shield may also be minimized.

Another approach which may be used to lower the terminal velocity of a free falling system and shipping container is to use a cubic container. The cube is a high drag configuration. Figure 6-5 shows typical terminal velocities which may be achieved for one assumed cubical cask configuration. This particular container configuration consists of aluminum 1-beam and channel structural elements. As illustrated in Figure 6-5, an aluminum container 5 feet on a side can be made relatively low in weight and will achieve an impact velocity under $250 \mathrm{ft} / \mathrm{sec}$.

Safety analyses on the SNAP-23A have progressed to a point where it is now desirable to quantitatively consider the capability of the system to withstand high velocity impacts. To date it has been shown that the heat source alone, at temperature, will meet the requirements for AEC hypothetical accidents, and the heat source in its shipping container is safe for truck transport from ORNL to WANL. An analysis has been initiated to describe the impact parameters such that fuel containment can be assured for the spectrum of accidents to which the generator may be subjected. Because the probabilities of a variety of aircraft accidents are finite, the premise used is that the accident can occur, but proper design of the shipping container coupled 
(W) Astronuclear

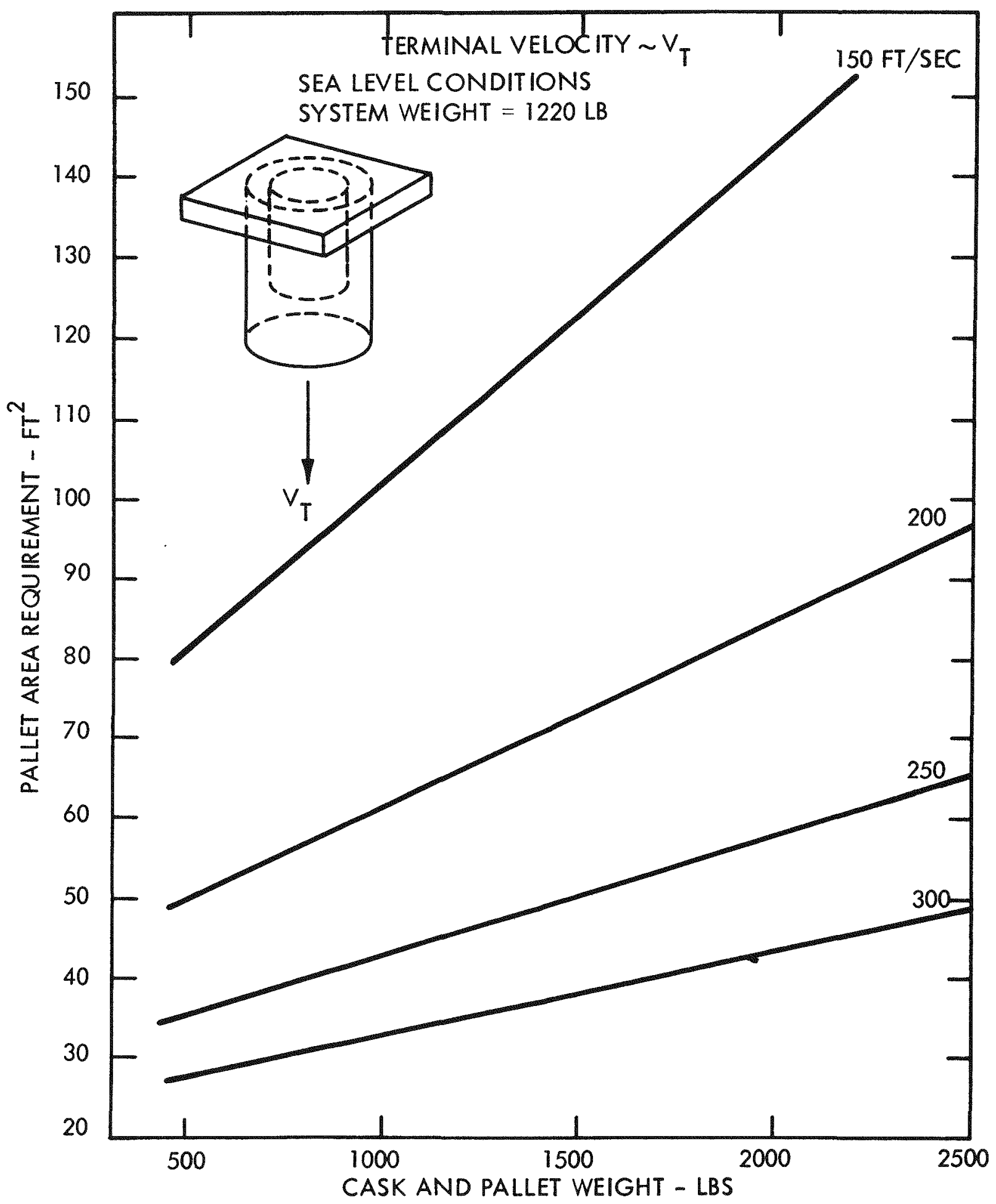

Figure 6-4. Requirements for Various Impact Velocities 


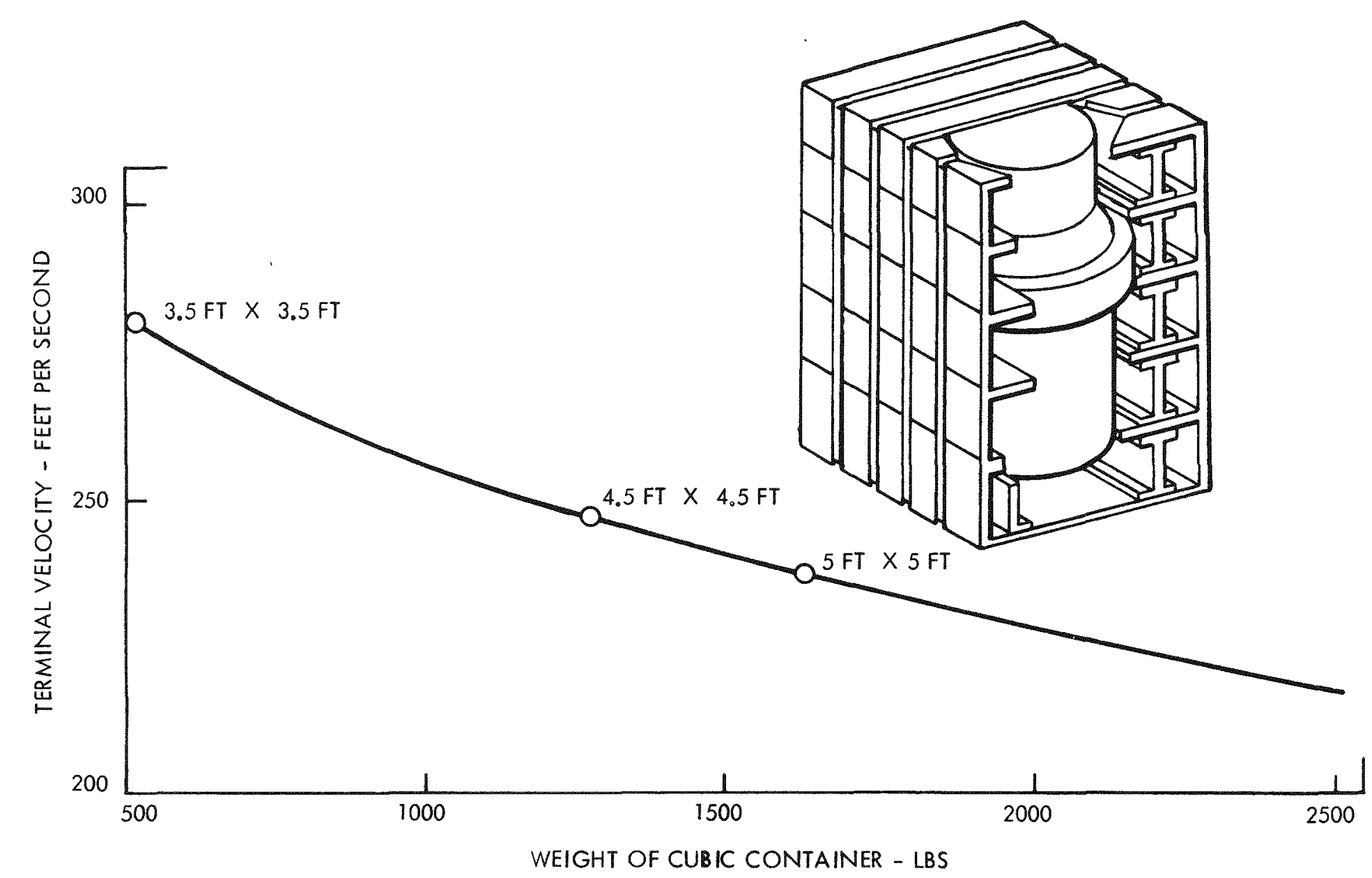

Figure 6-5. Terminal Velocity of SNAP-23A System in an Aluminum Cubic Container. 
with a rugged capsule design will assure fuel containment. Impacts will be analyzed by an impedance technique which properly considers the successive layers around the fuel capsule.

The SNAP-23A is a continuous system and can be assumed to be approximated by a lumped mass system comprised of the following elements: heat source biological shield generator structure, containment structure, aircraft fuselage structure (for the aircraft accident case) and the nonrigid impact medium (soil or water). The impact impedances of each element will be derived. There exist test data correlated to computer simulation results considering the response of aircraft fuselage structures to impact. These data will be employed in an attempt to derive an impedance for the aircraft structure during impact. Then for a spectrum of impact velocities ranging from the 30 foot drop ( 44 feet per second) up to those corresponding to various accident modes (i.e., fake-off and landing crashes, crashes resulting in impact at terminal velocity, etc.) the integrity of the generator, heat source, and fuel capsule can be estimated. Using this approach, the impact resistance of the SNAP-23A system and the required shipping cask impact impedance will be established as a function of terminal velocity.

\section{Ground Level Airborne Fuel Release}

A ground level release of the fuel inventory of the SNAP-23A fuel capsule is severe enough. A heat transfer analysis of the SNAP-23A system indicated that a transportation or operational fire and/or explosion would not cause a capsule breach. Extremely high temperatures within the fuel capsule (causing meltdown of the walls) cannot be achieved during a standard fire. Also, since the fuel capsule is surrounded by massive rigid components, it is not credible that an explosive atmosphere would breach the capsule. Only in a long duration, high temperature environment is it possible to breach the capsule and cause fuel vaporization. This type of environment is very unlikely since it represents the conditions found only in a nuclear explosion. In order to present a complete nuclear safety study of the SNAP-23A system, an airborne fuel release study is being performed. This is being done without specifying a particular type of destructive event that would generate a high temperature environment and cause a capsule breach. It is also assumed that only a small percentage of the fuel inventory is vaporized upon release. 
Items being considered include fuel activity concentrations as a function of downwind distance, wind velocity, and meteorological conditions. Fuel inhalation studies urilize the ICRP and NRDL lung deposition models. These studies are currently in progress

Subtask 630 - Preliminary Safety Analysis Report

A revised Preliminary Safety Analysis Report outline has been prepared which is a result of meetings and discussion between WANL and Hittman Associates.

Subtask 640 - Safety Review

FPMS Licensing

Comments on the document containing the engineering analyses for the heat source assembly shipping container were incorporated into the final report, including those suggested by AEC-RDT at a review meeting held in Germantown on June 9, 1969. The document "Engineering Analysis of Shipping Container for SNAP-23A Heat Source, "WANL-3800-34, was issued, and the application for amendment of the WANL license to ship the FPMS heat source assembly in the proposed shipping container was submitted on July 28, 1969, to the AEC Division of Materials Licensing, Irradiated Fuels Branch. A request for additional information on the lifting and tiedown systems was subsequently received from the Division of Materials Licensing and a supplement to the original submittal is being prepared.

The document "Safety Evaluation of SNAP-23A/FPMS Test Program, " WANL-380038 , was completed and formally approved by the WANL Radiation Safety Committee; it is currently in the final publication phase and will be issued for external distribution in the next reporting period. FPMS testing will be accomplished in the same area used for the Electrical Mockup System (EMS) but will be provided with additional monitoring and access control features as required by $A E C$ regulations for radioactive sources. The application for an amendment to the WANL license for possession of the SNAP-23A/FPMS heat source will be submitted to the AEC Division of Materials Licensing, Isotope Branch, in early September.

On the basis of the status of these two licensing activities, it is anticipated that safety approvals to ship the heat source assembly from ORNL and to test the FPMS in WANL facilities will be received at times that are quite compatible with the current FPMS schedule. 
(W) Astronuclear

Converter Fire Test

This program was initiated at $3 M$ Company in mid-July, at which time design of the converter test modules, the dummy (calibration) module, and the test stand was started. A test plan was submitted to WANL, where it received a detailed review, appropriate comments were forwarded to the $3 \mathrm{M}$ Company. Temperature profiles of the converter hot and cold frames predicted by Hittman Associates for $1475^{\circ} \mathrm{F}$ and $1850^{\circ} \mathrm{F}$ fires were forwarded to $3 \mathrm{M}$ for inclusion in the test plan. On the basis of these predictions it was recommended to AEC/RDT that the $1475^{\circ} \mathrm{F}$ transient be used for the first test.

\section{Miscellaneous}

Discussions with AEC/RDT and HAI on upgrading the PSAR, issued in April 1968, resulted in an agreement to issue a Revised Preliminary Analysis Report rather than to publish a PSAR supplement. A detailed outline and technical scope have been defined for this PSAR revision, and preparation of this document has been initiated by HAl with an anticipated completion date of December 31, 1969.

Reviews and appropriate revisions were made to the Preliminary System Design Description and the Integrated Test Plan on the basis of AEC comments. 